Rafael José Rorato

\title{
ALTERNATIVAS DE TRANSPORTE RODO-MARÍTIMO NA DISTRIBUIÇÃO DE CARGAS FRIGORÍFICAS NO BRASIL
}

Dissertação apresentada à Escola de Engenharia de São Carlos da Universidade de São Paulo, como parte dos requisitos para a obtenção do Título de Mestre em Engenharia Civil - Área de Transportes.

Orientador: Prof. Titular João Alexandre Widmer

São Carlos

2003 
Ficha catalográfica preparada pela Seção de Tratamento da Informação do Serviço de Biblioteca - EESC/USP

R787a Rorato, Rafael José

$$
\text { Alternativas de transporte rodo-marítimo na }
$$
distribuição de cargas frigoríficas no Brasil / Rafael José Rorato. -- São Carlos, 2003.

Dissertação (Mestrado) -- Escola de Engenharia de São Carlos-Universidade de São Paulo, 2003.

Área : Transportes.

Orientador: Prof. Tit. João Alexandre Widmer.

1. Intermodalidade. 2. CVC. 3. Combinações de veículos de carga. 4. Bitrem. 5. Cabotagem. 6. SIG-t. 7. Modelo de custos. 8. Economia no transporte.

I. Título. 
FOLHA DE JULGAMENTO

Candidato: Engenheiro RAFAEL JOSÉ RORATO

Dissertaçào defendida e julgada em 22-08-2003 perante a Comissão Julgadora
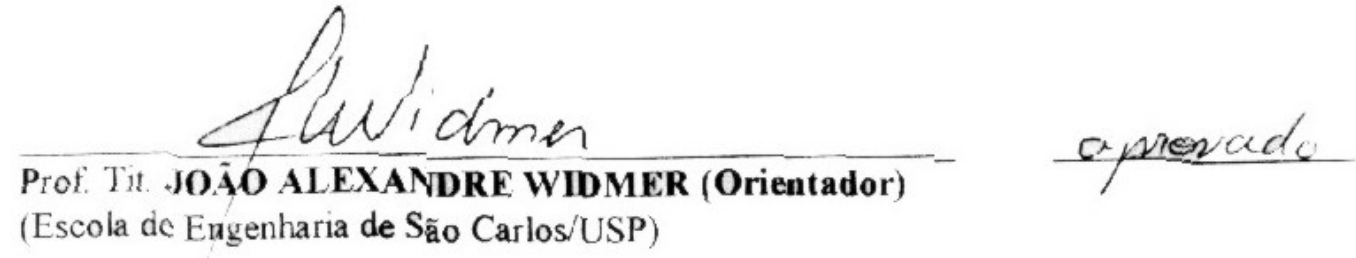

(Escola de Engenharia de São Carlos/USP)
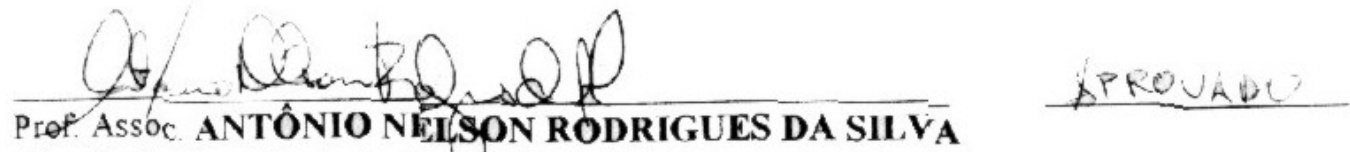

(Escola de Engenharia de São Carlos/USP)

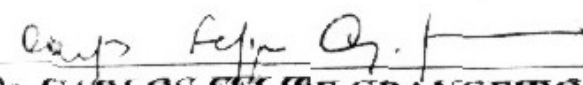

APRAVADO

Prof Dr CARLOS FELIFE GRANGEIRO LOURETRO

(Universidade Federal do CearáLTFC)

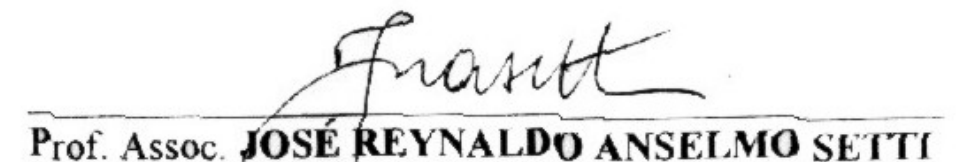

Coordenador do Programa de Pós-Graduação em Engenharia de Transportes

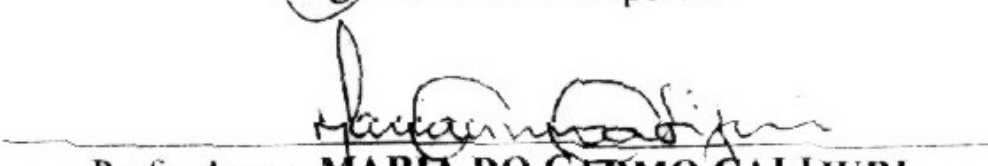

Profa. Assoc. MARIA do CATMO dALIJURI

Presidente da Comissão de Pós-Graduação da EESC 
Dedico este trabalho a todas as representações da Divindade e aos meus pais, Neiva e Irineu, a minha irmã Scheila e a Dona Rosa, pelo amor, pela educação e pelos valores ensinados nesta vida. 


\section{AGRADECIMENTOS}

Ao Prof. João Alexandre Widmer, pela orientação e ensinamentos concedidos durante a execução deste trabalho.

Ao Conselho Nacional de Desenvolvimento Científico e Tecnológico (CNPq) pela bolsa de estudo concedida para a realização do mestrado.

A minha família que sempre me incentivou na realização deste trabalho.

As pessoas que ajudaram direta ou indiretamente na obtenção dos dados para esta pesquisa: Luiz Gonzaga e Celso Paslene (DATAMAR); Comandante Santana (SINDARMA); Paulo Augusto Camello (ALIANÇA/HSAC); Eng. Paulo Gomes (RECRUSUL); Prof. Hilton (FATEC-JAÚ); Prof. Rui Botter (EPUSP); Prof. Almir M. Valente (UFSC); Prof Felex e Prof Eiji (EESC); Cézar Roberto Menegat; Ângelo Cecchet (DICAVE - VOLVO); e Neudi Scandolara (COOPERCARGA)

Aos meus grandes amigos, Edson de Oliveira, Erik A. Jenichem, Célio Daroncho, Marcelo B. da Silva e Luiz Carlos Simões Junior, Laura M. Pinotti que participaram da evolução desta etapa de minha vida.

A Cynthia Perpétua Lotti pela amizade, orientação e atenção dedicada no auxílio nas dificuldades.

Um agradecimento totalmente especial a minha amiga Adriane Fontana pela amizade, compreensão e apoio nos momentos mais difíceis que passaram no período desta pesquisa e nos momentos que hei de passar.

A minha menina Marta, um agradecimento carinhoso pela serenidade na revisão da formatação e da ortografia; pela objetividade e determinação na busca da maturidade profissional; e pelo calor do sentimento que pude encontrar nos abraços e nas trocas de olhares.

Aos amigos e colegas de departamento Rafael Moraes, Rômulo Xerez, Sandra Oda, Renato Tiago, aos internacionais Carolina, Charlie e Pastor, Mauro Kenji, Cláudia (crazy!) Andréa Schopf, Dona Marilda, Wilson Motizuki, Ana Paula Larocca, Genival, Gisele, Mário Garrido e Cida Cris, Magali Romão, Dinato, a dupla dinâmica Ari e João, Coutinho, Márcia Lika, João Marcelo, Hélio Marcos, Joel, Josi, Cláudio "Dibuá" (no bom francês!!), Rogério, Ugo Diniz, Manuel, Cira e Karênina. 
Ao colega Renato Silva e ao Prof. Antônio Nélson no apoio para sanar as dúvidas referentes ao TransCAD.

Aos funcionários do Departamento de Transportes: Heloísa, Dona Magali, Bete, Toco, Nelsão (Guartelá!), Gigante, Vicente, Paulinho, Lílian e Sueli.

A Pauli, pelo carinho, amizade, compreensão nas ausências requeridas na realização desta pesquisa e pelos momentos em que tivemos, sem esquecer os "pedais" pela cidade de São Paulo.

Aos amigos da extinta república R69: Ivan, Murilo, Caio, Luizinho, Ricardo (bigode), Nestor, aos internacionais Marika e Mário, e em especial ao grande ser humano e 'mamãe' da república, Braw! (vulgo Cláudio Toledo) por toda a amizade, companheirismo, ao apoio logístico e etílico concedido no final deste trabalho.

Ao Dagnor Roberto Schneider e Adenir Basso, da Coopercarga, pela possibilidade da aplicação da teoria acadêmica na prática diária do planejamento em transportes, pelas informações e pelo tempo concedido à pesquisa científica.

Aos grandes companheiros do pedal de São Carlos: Motta (bração!), Cowboy, Carlos, “Kojak”, Celso e Tânia, Tio Suquita, Paulão, Batista, Carlão, Mané e Sueli pela grande parceria nas belas trilhas da região.

Agradeço ao companheirismo e amizade das seguintes pessoas: Gláucia, Keka, Denise e Fernando, Guto, Virginia, Pazu, Kássia e as meninas, Glorinha, Déia, Carina, Sidão, Lú, Paulinho e Amauri, Célio e Wilian (Tchê!). 
Raciocine imparcialmente e nada aceite sem entender. Se não compreende alguma coisa, não a rejeite imediatamente. Procure estudar profundamente o assunto. Não se conforme com a pior das escravidões, que é a mental. Nascemos para sermos livres e só o seremos quando raciocinarmos livremente.

Henrique José de Souza

Spes Messis In Semine

(A esperança da colheita reside na semente) 


\section{SUMÁRIO}

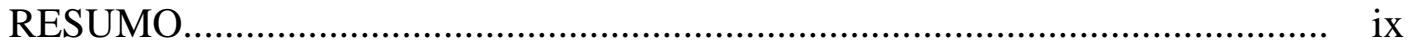

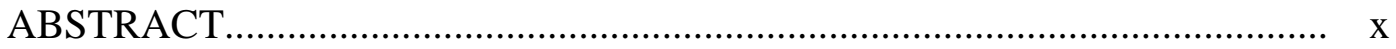

1. INTRODUÇÃ

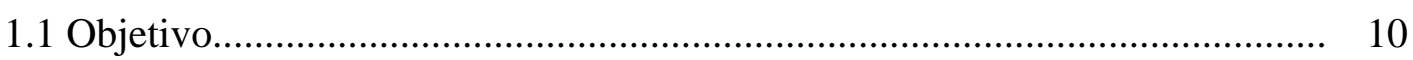

1.1.1 Objetivos principais.................................................................. 10

1.1.2 Objetivo específico............................................................................ 11

1.2 Estrutura da dissertação................................................................ 11

2. ASPECTOS DAS TECNOLOGIAS DE TRANSPORTE.............................. 13

2.1 Competitividade entre tecnologias e modos de transporte............................ 20

2.1.2 Tecnologia rodoviária no Brasil: estudos envolvendo CVCs.................... 20

2.1.3 Tecnologia marítima no Brasil: a cabotagem............................................. 22

2.2 Modelos de redes de transportes................................................................. 24

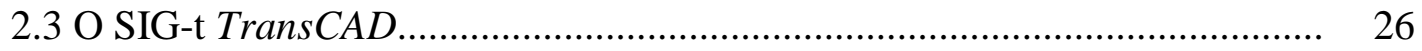

3. MODELAGEM DO PROBLEMA DE TRANSPORTE.............................. 29

3.1 Base de dados para SIG-t TransCAD ................................................... 29

3.2 Composição de custos do transporte rodoviário........................................... 36

3.2.1 Dimensionamento da frota rodoviária................................................... 36

3.2.2 Custos operacionais rodoviários.......................................................... 37

3.2.3 Custos de pedágios............................................................................ 43

3.3 Composição de custos do transporte marítimo............................................. 43

3.3.1 Dimensionamento de frota de contêineres................................................ 44

3.3.2 Custos operacionais da embarcação...................................................... 45

3.3.3 Custos operacionais dos contêineres..................................................... 49 
3.3.4 Custos operacionais portuários........................................................ 51

3.4 Formulação do modelo no SIG-T.......................................................... 52

3.4.1 Custos pontuais: pedágios, transbordos e escalas................................... 52

3.4.2 Custos de arcos: arcos rodoviários e hidroviários.................................... 53

3.4.3 Análise de rede.................................................................................. 56

3.5 Aspectos restritivos do modelo proposto................................................ 57

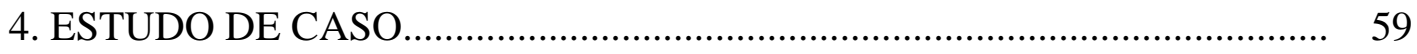

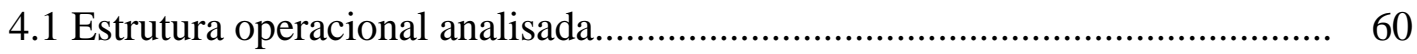

4.2 Cenário 1: Rodoviário 2S3 ................................................................... 61

4.3 Cenário 2: Rodo-hidroviário 3S3B3 ............................................................ 65

4.4 Cenário 3: Rodoviário 3S3B3 ................................................................... 73

4.5 Dimensionamento e custo operacional dos cenários...................................... 74

5. ANÁLISE DOS RESULTADOS ............................................................ 95

5.1 Competitividade econômica dos cenários................................................... 95

5.2 Análise de sensibilidade........................................................................... 101

6. CONCLUSÕES E RECOMENDAÇÕES............................................... 109

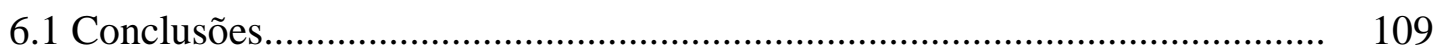

6.2 Recomendações............................................................................ 110

REFERÊNCIAS BIBLIOGRÁFICAS...................................................... 112 


\section{RESUMO}

RORATO, R. J. (2003). Alternativas de transporte rodo-marítimo na distribuição de cargas frigoríficas no Brasil. São Carlos, 2003. 213p. Dissertação (Mestrado) - Escola de Engenharia de São Carlos, Universidade de São Paulo.

Esta pesquisa investiga alternativas de transporte de cargas frigoríficas entre fábricas e centros de distribuição, avaliando as possíveis vantagens econômicas que resultariam do transporte intermodal rodo-hidroviário de contêineres ISO e do uso da CVC (Combinação de Veículo Carga) do tipo 3S3B3 - cavalo mecânico de três eixos mais dois semi-reboques de três eixos unidos por uma conexão do tipo B com PBTC de 74t, em relação ao cenário atual de transporte rodoviário porta-a-porta com a CVC do tipo 2S3 - cavalo mecânico de dois eixos com um semi-reboque de três eixos de 41,5t de PBTC. Com o auxílio de um Sistema de Informações Geográficas (TransCAD) dimensiona-se a frota e elabora-se um modelo de custos de transporte na rede de rotas para diversos cenários alternativos. As tarifas de pedágios das principais concessionárias de rodovias brasileiras e as tarifas portuárias dos portos considerados no modelo serviram como fonte de informações para a criação de mapas temáticos, rotas de caminho mínimo e a obtenção do custo por tonelada transportada. Conclui-se, através da análise dos resultados obtidos, que existem potenciais ganhos econômicos da alternativa de transporte intermodal rodo-marítimo, associado a CVC 3S3B3 - bitrem com implemento porta-contêineres, no acesso aos portos e no trajeto do porto ao centro de distribuição em relação à tecnologia de transporte utilizada atualmente, de transporte rodoviário porta-a-porta com a CVC $2 \mathrm{~S} 3$ - semi-reboque com implemento rodoviário baú frigorífico e capacidade de carga de 26 paletes padrão PBR. Conclui-se também que a tecnologia do tipo 3S3B3 com baú frigorífico e capacidade de carga de 40 paletes oferece aos transportadores uma alternativa que, na grande maioria das rotas estudadas, é mais competitiva que a integração modal rodo-hidroviária.

Palavras-chave: intermodalidade, CVC, combinações de veículos de carga, cabotagem, SIG-T, modelo de custos, economia de transportes. 


\section{ABSTRACT}

RORATO, R. J. (2003). Road-waterway transportation alternatives in the distribution of reefer cargo in Brazil. São Carlos, 2003. 213p. Dissertação (Mestrado) - Escola de Engenharia de São Carlos, Universidade de São Paulo.

This research investigates transportation alternatives between industries and distribution centers by evaluating the possible advantages of the road-waterway intermodal transport of ISO containers and the use of a LCV-Long Combination Vehicle of the 3S3B3 type a tractor plus two semi-trailers linked by a B-train connection and $74 \mathrm{t}$ of GVW, in relation to the present roadway house-to-house operating scenario using a five axles semi-trailer of the $2 \mathrm{~S} 3$ type and 41,5t of GVW. Using a Geographic Information System (TransCAD) the fleet size and the operating costs of the transportation network are calculated. For different alternative scenarios tolls charged by the brasilian private road administration partnership and current port rates are used in the model, and served as the basis to elaborate the thematic maps, minimum cost routes and costs per transported ton. From the analysis of the results it is concluded that the intermodal road-waterway alternative, associated to the transport of containers to the ports and from the ports to the distribution centers using the 3S3B3 with two container flatbeds, offers potencial economic gains in relation to the present technology using the house-to-house road transport with the $2 \mathrm{~S} 3$ and a reefer trailer for $26 \mathrm{PBR}$ pallets. It is also concluded that the 3S3B3 technology with 2 reefer units and capacity of 40 PBR pallets offers an alternative to the transportation industry that outperforms the road-waterway intermodal integration on most studied routes.

Keywords: intermodal, LCV, long combination vehicles, cabotage, GIS-T, cost models, transportation economy 


\section{LISTA DE ILUSTRAÇÕES}

Figura 1.1: Relação entre distância, tecnologia de transporte, demanda por produto e quantidade demandada.......................................................................... 3

Figura 1.2: Custo da cadeia de industrialização avícola................................... 4

Figura 1.3: Exemplo de movimentos dos contêineres na cabotagem................... 8

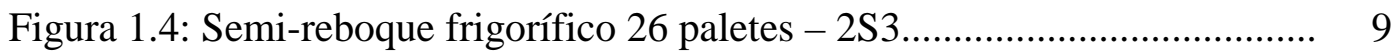

Figura 1.5: Bitrem porta-contêineres e bitrem frigorífico 40 paletes -3 S3B3... 9

Figura 1.6: Porta contêiner M/V Copacabana I................................................. 10

Figura 2.1: Geometria dos veículos rodoviários................................................. 14

Figura 2.2: Combinações de veículos de carga norte americanos: unitários e semi-reboques........................................................................................ 16

Figura 2.3: Combinações de veículos de carga norte americanos: veículos longos combinados.............................................................................. 16

Figura 2.4: Comprimento entre perpendiculares............................................ 17

Figura 2.5: Comprimento de roda a roda....................................................... 17

Figura 2.6: Geometria de embarcações marítimas........................................... 18

Figura 2.7: Tipos de navios mercantes........................................................... 19

Figura 2.8: Configurações de veículos de carga encontradas no Brasil............. 21

Figura 2.9: Evolução do transporte de contêineres por cabotagem.................... 23

Figura 3.1: Camada Rodovias........................................................................ $\quad 30$

Figura 3.2: Mapa temático de acessibilidade - teste de conectividade da rede.. $\quad 34$

Figura 3.3: Geração de solução ótima de mínimo custo................................... 56

Figura 4.1: Distribuição geográfica da estrutura............................................ 60

Figura 4.2: Fluxograma para viagem rodoviária - porta a porta..................... 62

Figura 4.3: Fluxograma para viagem rodo-hidroviária - intermodal............... 66 
Figura 4.4: Exclusão de instalações logísticas do cenário em função do custo de transporte dos portos aos centros de distribuição.

Figura 4.5: Locação de rotas das fábricas aos portos de origem....................... 68

Figura 4.6: Mapa temático: curvas de isocusto - cenário 1: origem Concórdia 78

Figura 4.7: Custos por tonelada transportada- cenário 1: origem Concórdia... 79

Figura 4.8: Mapa temático: curvas de isocusto - cenário 2: origem Concórdia $\quad 80$

Figura 4.9: Custos por tonelada transportada- cenário 2: origem Concórdia... $\quad 81$

Figura 4.10: Mapa temático: curvas de isocusto - cenário 3: origem

Concórdia.

Figura 4.11: Custos por tonelada transportada- cenário 3: origem Concórdia 83

Figura 4.12: Custos por tonelada transportada: origem Chapecó...................... 84

Figura 4.13: Custos por tonelada transportada: origem Concórdia.................. 85

Figura 4.14: Custos por tonelada transportada: origem Dois Vizinhos............. 86

Figura 4.15: Custos por tonelada transportada: origem Duque de Caxias........ 87

Figura 4.16: Custos por tonelada transportada: origem Francisco Beltrão....... 88

Figura 4.17: Custos por tonelada transportada: origem Paranaguá.................. 89

Figura 4.20: Custos por tonelada transportada: origem Ponta Grossa............. $\quad 90$

Figura 4.21: Custos por tonelada transportada: origem São Paulo.................. 91

Figura 4.22: Custos por tonelada transportada: origem Toledo....................... 92

Figura 4.23: Custos por tonelada transportada: origem Três Passos................ 93

Figura 4.24: Tempo de trânsito: cenários rodoviários e rodo-hidoviário -

Origem Chapecó.................................................................................. 94

Figura 5.1: Análise de sensibilidade - cenário 1: Chapecó - Fortaleza............. 102

Figura 5.2: Análise de sensibilidade - cenário 1: Chapecó - Porto Alegre....... 103

Figura 5.3: Análise de sensibilidade - cenário 3: Chapecó - Fortaleza............. 103

Figura 5.4: Análise de sensibilidade - cenário 3: Chapecó - Porto Alegre....... 104

Figura 5.5: Análise de sensibilidade - cenário 2: Chapecó - Fortaleza............. 105

Figura 5.6: Variação dos custos portuários: Chapecó - Belém.......................... 106

Figura 5.7: Variação dos custos portuários: Três Passos - Manaus.................. 106

Figura 5.8: Variação dos custos portuários: Concórdia - Salvador................... 107

Figura 5.9: Variação dos custos portuários: Ponta Grossa - Recife.................. 107

Figura 5.10: Variação dos custos portuários: Paranaguá - Belo Horizonte...... 108

Figura 5.11: Variação dos custos portuários: Dois Vizinhos - Ipatinga............ 108 


\section{LISTA DE TABELAS E QUADROS}

Tabela 1.1: Consumo de carnes - aves e suínos..................................................... 2

Tabela 1.2: Classificação das maiores empresas do setor agroindustrial............. 2

Tabela 1.3: Fretes rodoviários para semi-reboques frigoríficos 4

Tabela 1.4: Porcentagem do transporte no preço final do frango

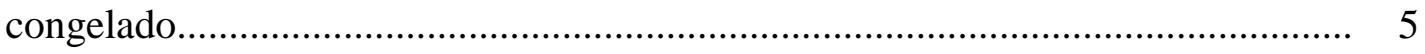

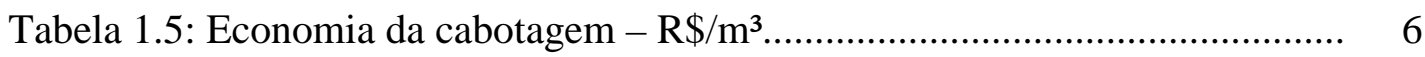

Tabela 1.6: Economia da cabotagem - R \$/t.................................................... 7

Tabela 2.1: Evolução dos pesos e medidas dos veículos de carga........................ 15

Tabela 2.2: Evolução dos navios porta-contêineres............................................. 20

Tabela 2.3: Competitividade no transporte de grãos............................................. 24

Tabela 3.1: Comparação da base rodoviária de dados inicial versus final........... 33

Tabela 3.2: Resumo dos resultados do teste de hipótese..................................... 36

Tabela 3.3: Resumo dos custos portuários dos portos e terminais escolhidos....... 51

Tabela 4.1: Resumo do perfil organizacional.................................................... 60

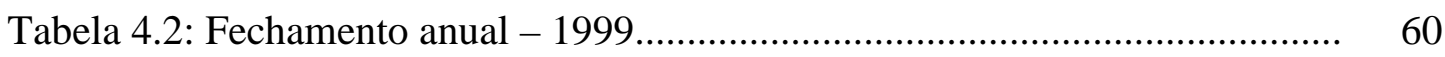

Tabela 4.3: Peso específico por planta fabril..................................................... 61

Tabela 4.4: Semi-reboque frigorífico.............................................................. 63

Tabela 4.5: Cavalo mecânico 4x 2 .................................................................. 63

Tabela 4.6: Dados de entrada da planilha de custo 2S3...................................... 64

Tabela 4.7: Navio porta contêineres................................................................. 71

Tabela 4.8: Bitrem porta contêineres............................................................... 71

Tabela 4.9: Contêineres frigoríficos................................................................ 71

Tabela 4.10: Cavalo mecânico 6x4 .................................................................. 72

Tabela 4.11: Dados de entrada da planilha de custo 3S3B3 / PC1050TEU.......... 72

Tabela 4.12: Bitrem baú frigorífico.................................................................... 73 
Tabela 4.13: Dados de entrada da planilha de custo 3S3B3.

Tabela 4.14: Dimensionamento e custo operacional para os veículos rodoviários.

Tabela 4.15: Resumo dos custos operacionais para o cenário 2. 75

Quadro 4.1: Rotas e escalas analisadas no cenário.

Quadro 5.1: Economia relativa dos cenários 1 e 3 frente à alternativa rodomarítima..

Quadro 5.1: Economia relativa dos cenários 1 e 3 frente à alternativa rodomarítima (continuação).

Quadro 5.2: Economia relativa entre os cenários rodoviários. 


\section{INTRODUÇÃO}

Frutas frescas, vegetais e outros produtos perecíveis estão disponíveis no mercado, em determinados períodos do ano, devido a padrões sazonais de crescimento e pela falta de condições naturais de produção agrícola. Ainda, muitos produtos são ofertados em qualquer período, em diferentes locais do mundo. Remessas rápidas a preços razoáveis colocam esses produtos perecíveis em mercados que não os teriam disponíveis. Bananas da América do Sul são encontradas em Nova Iorque em janeiro; ao longo do ano são servidas lagostas vivas da Nova Inglaterra em restaurantes na cidade de Kansas; e orquídeas do Havaí são abundantes no leste dos Estados Unidos em abril. Um sistema de transporte eficiente e eficaz torna isto possível (BALLOU, 1992).

A econômica de um país é tradicionalmente dividida em três setores: agropecuário, industrial e serviços. No ano de 2001, o PIB brasileiro atingiu o valor de $\mathrm{R} \$ 1,185$ trilhões, sendo o setor agropecuário responsável por R \$ 84,4 bilhões do total (BACEN 2002). Os principais produtos agropecuários brasileiros são a cana-de-açúcar, a laranja, o café, o soja, o milho, a produção de bovinos de corte e leite, e a produção de aves. No ano de 2001, as produções de cana-de-açúcar, laranja e soja totalizaram 346, 17 e 38 milhões de toneladas, respectivamente. As produções brasileiras de bovinos e aves são expressivas. No segundo trimestre de 2002 os totais de carcaças de bovinos e aves somaram, respectivamente, 2 e 3 milhões de toneladas (IBGE, 2002). Com esse volume de produção o Brasil encontra-se não só como o terceiro maior produtor mundial de frango, mas também como o terceiro maior exportador. As exportações de frango, em 1999, totalizaram 771 mil toneladas, sendo o Paraná responsável por 255 mil toneladas desta produção. A exportação catarinense de aves contabilizou cerca de US\$462 milhões em FOB (Free On Board) para o ano de 1996 (BLISKA, 1999). Os cenários do consumo de carne suína e de aves, no Brasil, são apresentados na Tabela 1.1. 
Segundo o ABCS (2001b), 65\% da carne suína industrializada e fiscalizada consumida no Brasil é originária dos estados do Rio Grande do Sul, Santa Catarina e Paraná. As estatísticas para a carne de frango não são diferentes: $53 \%$ do frango industrializado é proveniente da região sul do país (ABEF, 2001). Na Tabela 1.2 são mostradas as indústrias com maior destaque no setor de abate e industrialização de aves e suínos.

Tabela 1.1: Consumo de carnes - aves e suínos

\begin{tabular}{|c|c|c|c|c|c|c|}
\hline \multirow[b]{2}{*}{ Região } & \multirow{2}{*}{$\begin{array}{c}\text { População }{ }^{1} \\
\text { (hab) }\end{array}$} & \multicolumn{2}{|c|}{ Suínos } & \multicolumn{3}{|c|}{ Aves } \\
\hline & & $\begin{array}{c}\text { Per Capita }{ }^{2} \\
\text { (kg/hab) }\end{array}$ & $\begin{array}{c}\text { Total Região } \\
\text { (ton) }\end{array}$ & País & $\begin{array}{c}\text { Per Capita }{ }^{3} \\
\text { (kg/hab) }\end{array}$ & $\begin{array}{l}\text { Total } \\
\text { (ton) }\end{array}$ \\
\hline Norte & 12.893 .561 & 3,50 & $45.127,46$ & B & & \\
\hline Nordeste & 47.693 .253 & 5,50 & $262.312,89$ & $r$ & & \\
\hline Sudeste & 72.297 .351 & 12,00 & $867.568,21$ & a & 29,91 & $5.072 .457,63$ \\
\hline Centro-oeste & 11.616 .745 & 15,40 & $178.897,87$ & S & & \\
\hline Sul & 25.089 .783 & 19,00 & $476.705,88$ & 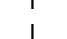 & & \\
\hline Total & 169.590 .693 & & $1.830 .612,32$ & & & \\
\hline
\end{tabular}

Tabela 1.2: Classificação das maiores empresas do setor agroindustrial

\begin{tabular}{lcc}
\hline \multicolumn{1}{c}{ Razão Social } & Localização plantas industriais & Colocação 2000 \\
\hline \hline Sadia S.A. & Sul, Centro-oeste, e Sudeste & $4^{\circ}$ \\
Perdigão Agroindustrial S.A. & Sul, Centro-oeste, e Sudeste & $8^{\circ}$ \\
Seara Alimentos S.A. & Sul & $34^{\circ}$ \\
Avipal S.A. - Avicultura e Agropecuária & Sul & $36^{\circ}$ \\
Frangosul S.A. - Agroavícola Industrial & Sul & $52^{\circ}$ \\
Chapecó Cia. Industrial de Alimentos & Sul & $65^{\circ}$ \\
\hline Fonte: FGV (2000) & &
\end{tabular}

Observa-se que os principais pontos de oferta (produção e industrialização) e demanda (mercado consumidor) de aves e suínos encontram-se geograficamente afastadas. Essa separação gera viagens provenientes da região Sul, destinadas aos principais centros consumidores do país, tais como: São Paulo, Rio de Janeiro, Fortaleza, Recife, Manaus e outros. A distribuição é realizada principalmente pelo modo rodoviário de transporte, sendo percorridos de 400 a 5.000 km por viagem. Nesta concepção, a "boa logística" e, por conseqüência, a eficiência e a eficácia do transporte, desempenham um papel importante na produção, na distribuição e no consumo desses bens. A teoria do consumidor define que o preço no mercado, de um bem importado de outra região, é o preço na região de origem adicionado do custo de transporte. Por sua vez, o custo total do transporte é a soma de uma parcela fixa e de uma outra parcela variável, função da distância percorrida, por exemplo. Através da melhoria na qualidade da infra-estrutura 
de transporte e da inovação tecnológica dos transportes ocorre uma modificação do custo fixo e do custo variável podendo ocasionar assim, uma redução no preço da mercadoria e uma melhor acessibilidade ao bem pelo consumidor, conforme observado na Figura 1.1.

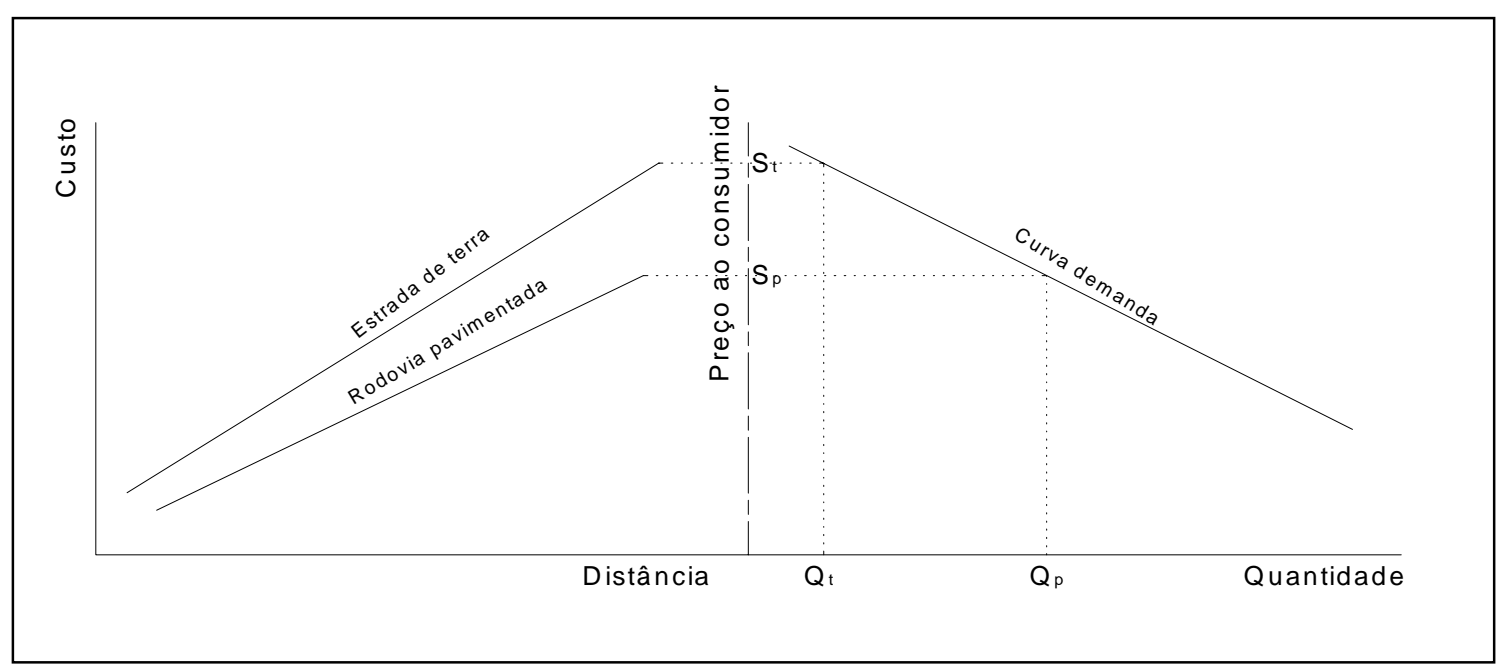

Figura 1.1: Relação entre distância, tecnologia de transporte, demanda por produto e quantidade demandada (KAWAMOTO, 1999)

Através de informações obtidas pelo Centro Nacional de Pesquisa de Suínos e Aves EMBRAPA constatou-se que a produção de aves de corte necessita de estrutura conhecida como aviário que apresentam condições ambientais, sanitárias e tecnológicas para o acondicionamento e a engorda das aves. GIROTTO et al. (2001) classificam os três principais tipos de aviários como: aviários manuais, aviários automatizados e aviários climatizados. A diferença entre elas está na tecnologia empregada e na mão-deobra utilizada para o controle da temperatura, umidade e distribuição de ração. Através de coeficientes técnicos e econômicos, GIROTTO et al. (2001) determinaram que os custos de produção do frango vivo posto na plataforma de abate para os sistemas manual, automático e climatizado acarretaram custos por quilograma produzido de $\mathrm{R} \$ 1,2306, \mathrm{R} \$ 1,2025$ e $\mathrm{R} \$ 1,2262$ respectivamente. Assim o custo médio de produção por quilo de ave é de US\$ 0,5741 (câmbio: US\$1,00 - R \$2,1277, 13/08/2001). Segundo MENEGAT (2001a), o valor médio de uma carga com 27t de frango congelado é de aproximadamente US\$30.550,00 (incluindo custos e lucro da indústria) e os valores de frete para essa carga, segundo STERN (2001), conforme a distribuição geográfica dos 
principais centros de beneficiamento de aves e os centros de consumo brasileiros são observados na Tabela 1.3.

Tabela 1.3: Fretes rodoviários para semi-reboques frigoríficos

\begin{tabular}{|c|c|c|c|c|c|c|c|c|c|c|c|c|}
\hline \multicolumn{13}{|c|}{ Fretes de Semi-Reboques Frigoríficos 26 ou 28 pallets - US $\$$ /ton } \\
\hline $\mathrm{O} / \mathrm{D}$ & SÃO PAULO & RD DE JANERO & V IrÓR $\mathbb{A}$ & SALVADOR & ARACA JÚ & MACEÓ & RECFE & JO ̃̃O PESSOA & NATAL & FORTALEZA & SÃO LU IS & BELÉM \\
\hline Concórdia (SC) & 23,26 & 34,54 & 50,29 & 75,67 & 81,31 & 88,83 & 94,37 & 97,90 & 101,61 & 105,04 & 99,83 & 98,45 \\
\hline Chapecó (SC) & 23,26 & 34,54 & 50,29 & 75,67 & 81,31 & 88,83 & 94,37 & 97,90 & 101,61 & 105,04 & 99,83 & 98,45 \\
\hline Seara (SC) & 24,20 & 35,48 & 51,23 & 76,61 & 82,25 & 89,30 & 95,31 & 98,84 & 102,55 & 105,98 & 100,77 & 99,39 \\
\hline Videira (SC) & 25,14 & 36,42 & 52,17 & 77,55 & 83,19 & 88,83 & 96,25 & 99,78 & 103,49 & 106,92 & 101,71 & 100,33 \\
\hline
\end{tabular}

Fonte: STERN (2001)

Taxa de câmbio: US\$1,00 - R\$2,1277 (13/08/2001)

Para verificar a sensibilidade do custo final da comercialização do frango congelado, em diferentes mercados de consumo no Brasil, adota-se um acréscimo de $10 \%$ no valor final do frango congelado, referente aos impostos e o lucro do comércio varejista. Assim verifica-se que o comportamento do custo final do quilograma de frango produzido em Concórdia, Santa Catarina, nas principais capitais brasileiras apresenta uma variação conforme gráfico da Figura 1.2.

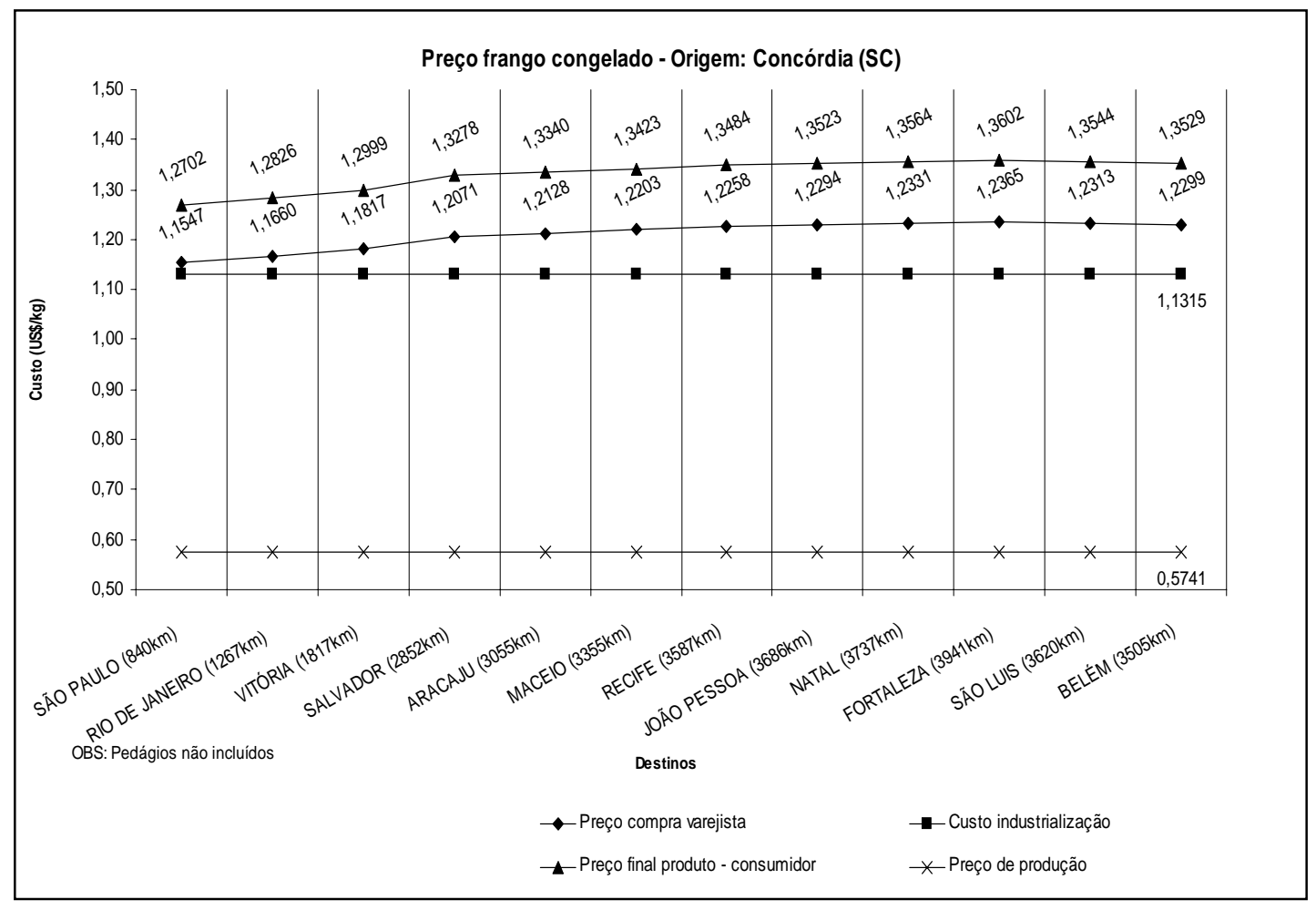

Figura 1.2: Custo da cadeia de industrialização avícola 
O peso médio de um frango inteiro congelado, segundo MENEGAT (2001a), é de aproximadamente $1,90 \mathrm{~kg}$. Assim tem-se um custo de transporte de US\$0,05 para a cidade de São Paulo e um custo máximo aproximado de US\$0,20 para cidades como João Pessoa, Natal, Fortaleza, São Luiz e Belém. Através da análise dessas informações, a Tabela 1.4 mostra qual a participação do transporte no custo do frango congelado produzido no sul do país.

Tabela 1.4: Porcentagem do transporte no preço final do frango congelado

\begin{tabular}{|c|c|c|c|c|c|c|c|c|c|c|c|c|}
\hline $\mathrm{O} / \mathrm{D}$ & $\begin{array}{l}\stackrel{O}{J} \\
\stackrel{\leftarrow}{a} \\
\dot{0} \\
\dot{\infty}\end{array}$ & 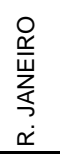 & 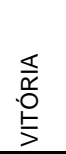 & 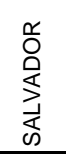 & 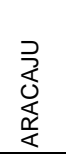 & $\begin{array}{l}\frac{O}{W} \\
\frac{\mathrm{C}}{\Sigma}\end{array}$ & 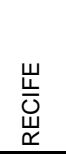 & $\begin{array}{l}\text { ठ } \\
\text { 出 } \\
\text { 员 } \\
; \\
\end{array}$ & $\begin{array}{l}\overrightarrow{\mathbb{E}} \\
\frac{\mathbf{s}}{z}\end{array}$ & 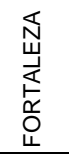 & $\begin{array}{l}\infty \\
\Xi \\
\omega\end{array}$ & 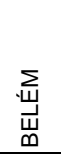 \\
\hline "Concórdia & $\overline{2,0}$ & 3,0 & $\overline{44,3}$ & $\overline{~ 6,3}$ & $\bar{~} 6,7$ & $\overline{77,3}$ & $\overline{77,7}$ & $\overline{8,0}$ & 8,2 & $\overline{88,5}$ & 8,1 & $\overline{8,0}$ \\
\hline Chapecó & 2,0 & 3,0 & 4,3 & 6,3 & 6,7 & 7,3 & 7,7 & 8,0 & 8,2 & 8,5 & 8,1 & 8,0 \\
\hline Seara & 2,1 & 3,0 & 4,3 & 6,3 & 6,8 & 7,3 & 7,8 & 8,0 & 8,3 & 8,6 & 8,2 & 8,1 \\
\hline Videira & 2,2 & 3,1 & 4,4 & 6,4 & 6,8 & 7,3 & 7,8 & 8,1 & 8,4 & 8,6 & 8,2 & 8,1 \\
\hline
\end{tabular}

O processo produtivo da avicultura de corte é sensível a fatores como a variação da cotação dos insumos para ração, tais como o milho e o soja, a disponibilidade do produto no mercado interno e externo, a exposição perante os riscos biológicos e ambientais, os impostos, "a guerra fiscal" (incentivos tributários) entre os Estados e o mercado informal (abatedouros clandestinos sem registro no Ministério da Agricultura). Todos esses fatores, somados aos custos de transporte e armazenagem, podem acarretar um péssimo desenvolvimento comercial do produto em mercados distantes das unidades fabris.

Por outro lado, os custos de transporte e armazenagem de produtos são reduzidos na medida que a tecnologia empregada nos veículos ou armazéns consigam otimizar os custos operacionais envolvidos no processo. Assim repara-se que o aumento da capacidade unitária de transporte na movimentação de cargas e de passageiros é um fenômeno observado nos últimos anos em muitos sistemas de transportes. Essa tendência é evidente na aviação (aviões wide body), na navegação (supergraneleiros), nas ferrovias e nos veículos rodoviários (duplo semi-reboque, bitrem). MCCANN (2001) verificou matematicamente que a eventual redução do custo no transporte não está somente atrelada à capacidade de carga do veículo-embarcação, mas relaciona-se 
também com a freqüência das passagens do veículo ou embarcação ao terminal, o tipo de carga a ser transportada e a distância geográfica. Através do equacionamento desses dados chegou-se na distância econômica para determinados tipos de embarcações e cargas.

O transporte intermodal de carga é definido como o uso de dois ou mais modos de transporte, para movimentar cargas de uma origem para um destino. Uma movimentação intermodal de carga envolve vários fatores, tais como: infra-estrutura física de vias e terminais, movimentos e transferências, fluxo de informação e unificação de documentação (DEWITT \& CLINGER, 2000).

SIQUEIRA (2000) exemplificou a competitividade intermodal, via cabotagem, na rota São Paulo e Manaus. Em 1998, o frete de um caminhão com $90 \mathrm{~m}^{3}$ chegava a custar R $\$ 5$ mil e, em 2000, o valor do frete custava $\mathrm{R} \$ 4$ mil. Em caso de volumes constantes esse valor reduz-se para $\mathrm{R} \$ 3,5$ mil. Neste mesmo trajeto, quando realizado por cabotagem conteinerizada $\left(76,3 \mathrm{~m}^{3}\right.$ - high cube), o frete reduz-se para $\mathrm{R} \$ 2,78$ mil. A Tabela 1.5 e a Tabela 1.6 mostram a economia da cabotagem, do ponto de vista do armador, sobre o transporte rodoviário. A freqüência de navios navegando no sentido Norte-Sul-Norte varia entre 10 e 15 dias, dependendo do armador.

Tabela 1.5: Economia da cabotagem - $\mathbf{R} \$ \mathrm{~m}^{3}$

\begin{tabular}{|c|c|c|c|}
\hline \multicolumn{4}{|c|}{ Custo de Manaus para São Paulo } \\
\hline Itens & US\$ & $\mathrm{R} \$$ & $\mathrm{R} \$ / \mathrm{m}^{3}\left(76,3 \mathrm{~m}^{3}\right)$ \\
\hline Custo do navio & 575,00 & 1035,00 & \\
\hline Custo do contêiner 40 " high cube ( 30 dias - $R \$ 2,75 /$ dia) & 82,50 & 148,50 & \\
\hline Custo do transporte marítimo & 657,50 & 1183,50 & 15,51 \\
\hline Custo de consolidação & & 90,00 & \\
\hline Transporte origem/porto & & 200,00 & - \\
\hline Custo de embarque & & 305,00 & \\
\hline Custo total da coleta e embarque & & 595,00 & 7,80 \\
\hline Custo da descarga & & 365,00 & \\
\hline Transporte porto/destino & - & 550,00 & - \\
\hline Custo da desconsolidação & & 9,00 & \\
\hline Custo total da descarga e entrega & & 1005,00 & 13,17 \\
\hline Total porta-a-porta marítimo & & 2783,50 & 36,48 \\
\hline Custo rodoviário porta-a-porta para $90 \mathrm{~m}^{3}$ & & 4000,00 & 44,44 \\
\hline Redução de custo (\%) & & & 21,83 \\
\hline
\end{tabular}


Tabela 1.6: Economia da cabotagem $-\mathbf{R} \$ / \mathbf{t}$

\begin{tabular}{|c|c|c|c|}
\hline \multicolumn{4}{|c|}{ Custo de São Paulo para Manaus } \\
\hline Itens & US\$ & $\mathrm{R} \$$ & $\mathrm{R} \$ / \mathrm{t}(26 \mathrm{t})$ \\
\hline Custo do navio & 6000,00 & 1200,00 & \\
\hline Custo do contêiner $40 "$ (30 dias $-\$ 2,50 /$ dia $)$ & 75,00 & 150,00 & - \\
\hline Custo do transporte marítimo & 675,00 & 1350,00 & 51,92 \\
\hline Custo de consolidação & & 70,00 & \\
\hline Transporte origem/porto & & 550,00 & - \\
\hline Custo de embarque & & 295,00 & \\
\hline Custo total da coleta e embarque & & 915,00 & 35,19 \\
\hline Custo da descarga & & 320,00 & \\
\hline Transporte porto/destino & - & 170,00 & - \\
\hline Custo da desconsolidação & & 35,00 & \\
\hline Custo total da descarga e entrega & & 525,00 & 20,19 \\
\hline Total porta-a-porta marítimo & & 2790,00 & 107,31 \\
\hline Custo rodoviário porta-a-porta & & 4000,00 & 153,85 \\
\hline Redução de custo $(\%)$ & & &, 37 \\
\hline
\end{tabular}

A investigação deste trabalho visa comparar os custos de três diferentes tecnologias de transporte de carga. Duas tecnologias são do modo rodoviário de carga e uma do transporte rodo-hidroviário de cabotagem. Os cenários envolvidos no estudo de caso abrangem a transferência de cargas frigoríficas entre indústrias e centros de distribuição, conforme descrito a seguir:

- Porta a porta rodoviário: este regime abrange a transferência da carga, entre fábricas e centros de distribuição, através de um único modo de transporte e envolvendo veículos rodoviários de diferentes capacidades de carga. As cargas são unitizadas em estrados de madeira (paletes) acondicionados nos baús dos veículos rodoviários. Nestes cenários não são contabilizados os custos de retorno, com a finalidade de retratar as condições operacionais de um contratante de fretes do mercado brasileiro. Esse fato ocorre, pois os caminhões apresentam boa versatilidade na atratividade de novas cargas;

- Porta a porta rodo-hidroviário: neste caso a transferência de carga é uma associação do transporte hidroviário por cabotagem e o transporte rodoviário. Para facilitar a movimentação e a produtividade no transporte intermodal das cargas em embalagens, estas são acondicionadas em unitizadores do tipo contêineres metálicos ISO de 20" (medidas externas: 6,058 x 2,438 x 2,591m) e 
40" (medidas externas: 12,192 x 2,438 x 2,895m) de comprimento. Assim os veículos rodoviários movimentam os contêineres vazios e carregados, entre a origem e o porto de embarque, e o porto de desembarque e o destino final, respectivamente. A intermodalidade rodo-hidroviária é constituída das seguintes etapas: deslocamento do contêiner vazio para o local de origem da viagem; efetivação do carregamento (estufagem) do contêiner; deslocamento do contêiner cheio até o porto de origem; processamento da armazenagem e carregamento do contêiner no navio; deslocamento da embarcação em uma rota com escalas em portos antecessores ao porto de destino; transbordo do contêiner, no porto de destino, da embarcação para um veículo rodoviário; deslocamento do caminhão até o destino final; descarregamento do contêiner (desova); e deslocamento do contêiner vazio até o porto. Com o objetivo de retratar os custos comerciais de afretamento de carga marítima foram considerados somente os custos de movimentação dos contêineres vazios entre os portos de origem e as fábricas, e os centros de distribuição e os portos de destino. A alocação dos novos contêineres para novos fretes é uma responsabilidade operacional e comercial do transportador de carga marítima, o armador. Verifica-se na Figura 1.3, um exemplo hipotético dos movimentos dos contêineres no transporte rodo-hidroviário, para quatro fontes geradoras de viagens e para dois destinos.

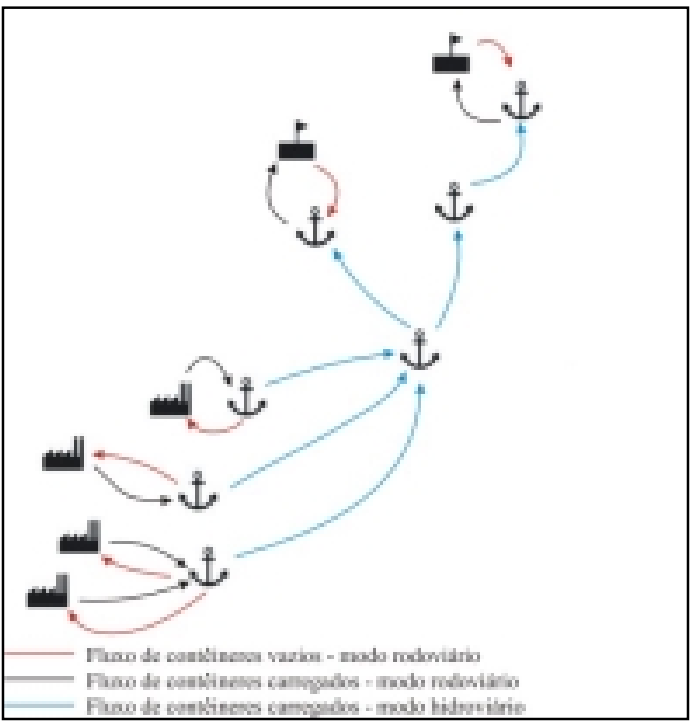

Figura 1.3: Exemplo de movimentos dos contêineres na cabotagem 
O semi-reboque de 26 paletes (Figura 1.4) apresenta uma capacidade máxima legal de carga de 25 toneladas de carga frigorífica (peso específico variando de 140 a $450 \mathrm{~kg} / \mathrm{m}^{3}$ ).

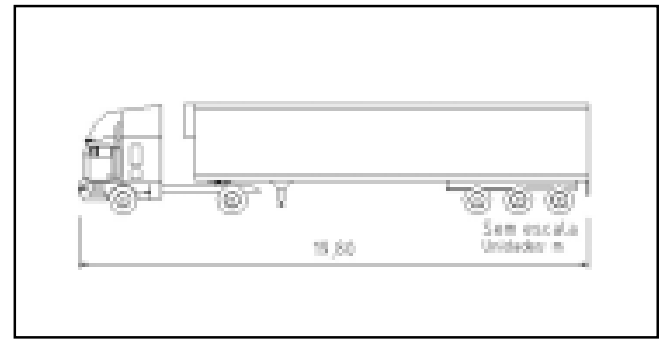

Figura 1.4: Semi-reboque frigorífico 26 paletes $-2 S 3$

O bitrem porta-contêiner (Figura 1.5a) apresenta a capacidade de transporte de uma unidade de 20' e uma unidade de 40'. Este veículo apresenta uma capacidade máxima no transporte de produtos frigoríficos de 30,5 toneladas.

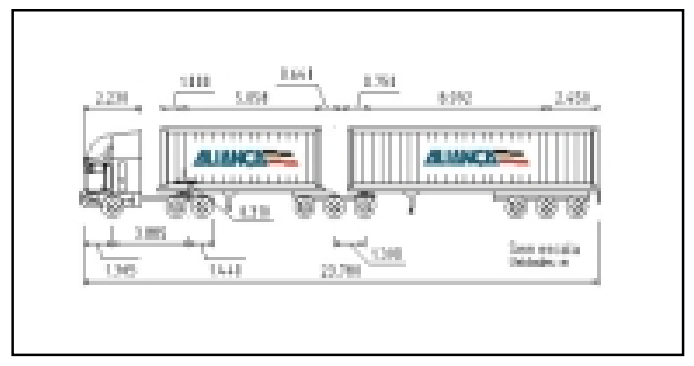

(a)

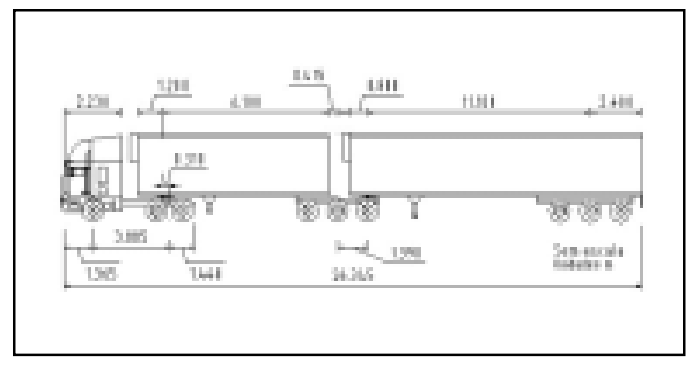

(b)

Figura 1.5: Bitrem porta-contêineres frigoríficos e bitrem frigorífico 40 paletes - 3S3B3

O bitrem frigorífico de 40 paletes (Figura 1.5b) apresenta o mesmo valor máximo legal permitido de PBTC (Peso Bruto Total Combinado) do bitrem porta contêiner. Sendo maior em comprimento e mais leve na estrutura do baú, a capacidade operacional de carga frigorífica é da ordem de 46,5 toneladas.

O navio adotado para o transporte marítimo de cabotagem estudado nesta pesquisa é mostrado na Figura 1.6. Conforme as restrições de calado dos portos brasileiros e o comportamento das taxas de ocupação dessa embarcação, praticadas pelo armador Aliança Transportes e Navegação, a tonelagem líquida operacional de carga deste navio é de 1.050 TEU. Os contêineres refrigerados de 20' e 40' apresentam uma capacidade 
máxima de carga (payload) de 21 e 26 toneladas, respectivamente.

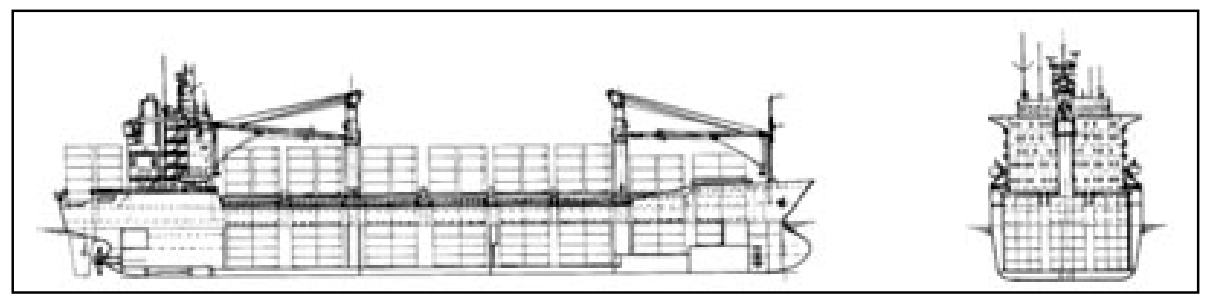

Figura 1.6: Porta contêiner M/V Copacabana I (Fonte: Aliança Transportes e Navegação)

\subsection{Objetivo}

\subsubsection{Objetivos principais}

Com base na representatividade do transporte no custo da cadeia comercial avícola, os objetivos principais deste trabalho são: investigar os ganhos econômicos advindos do uso de transporte intermodal rodo-hidroviário de contêineres ISO de 20 e 40 pés no transporte de cargas frigoríficas entre $n$ fábricas e $m$ centros de distribuição localizados ao longo da costa brasileira e no rio Amazonas; e o impacto de um provável aumento da capacidade de carga das tecnologias rodoviárias de transporte. Os resultados econômicos são provenientes da comparação dos cenários descritos a seguir:

- Custo de distribuição porta-a-porta utilizando um semi-reboque frigorífico 2S3 com capacidade de carga líquida de $25.000 \mathrm{~kg}$.

- Custo de distribuição intermodal rodo-hidroviário utilizando um veículo portacontêineres do tipo bitrem 3S3B3 nas pontas rodoviárias com capacidade de carga de $30.500 \mathrm{~kg}$ e um navio porta-contêiner com capacidade de 1.050 TEUs nas etapas hidroviárias com $k$ escalas intermediárias.

- Custo de distribuição porta-a-porta utilizando um veículo bitrem 3S3B3 com 2 baús frigoríficos e capacidade de carga de $46.500 \mathrm{~kg}$. 


\subsubsection{Objetivo específico}

O objetivo específico desta pesquisa concentrou-se na construção de uma base geográfica brasileira intermodal, para SIG-T, através da atualização de bases existentes, com a adição de novos arcos, a remoção de dados desnecessários, a edição do banco de dados, a elaboração de um teste de conectividade da rede e a validação estatística através do teste de hipótese entre amostras independentes.

\subsection{Estrutura da dissertação}

A estrutura desta dissertação está dividida em seis capítulos.

O Capítulo 1 apresenta ao leitor a idéia principal do problema estudado.

O Capítulo 2 relata os aspectos técnicos e econômicos das tecnologias abordadas, a revisão da representação matemática do problema de transportes e estudos realizados utilizando-se a tecnologia dos Sistemas de Informações Geográficas aplicados ao transporte (SIG-T).

O Capitulo 3 mostra a modelagem do problema de distribuição no SIG-T. Nesse capítulo encontra-se retratada a forma de obtenção e reedição das bases de dados utilizadas para a aplicação do modelo. São retratados o método de geração dos dados, o método de verificação da conectividade da rede e o teste estatístico da significância da base de dados.

Nesse mesmo capítulo são apresentados ainda os seguintes métodos: dimensionamento de frota, custos para os veículos rodoviários, custos de contêineres, custos de embarcações marítimas, tarifas de pedágios, custos de transferência em terminais portuários; procedimentos de análise no SIG-T e as restrições do modelo de custo.

No Capítulo 4 apresentam-se: a criação dos cenários e os itens de entrada do modelo, os 
principais dados obtidos e a análise de sensibilidade para o modelo proposto.

No Capítulo 5 são comparados os resultados obtidos nos cenários de transporte.

No Capítulo 6 são descritas as principais conclusões deste trabalho e as sugestões para trabalhos futuros. 


\section{ASPECTOS DAS TECNOLOGIAS DE TRANSPORTE}

Os requisitos de uma tecnologia de transporte são de gerar a mobilidade, de controlar o deslocamento e a trajetória e de proteger, o item transportado e a infra-estrutura, da deterioração gerada pelo movimento (MORLOK, 1978). As inovações tecnológicas na área de transporte permitiram deslocamentos mais rápidos sobre distâncias mais longas. Também é observado o aumento da capacidade unitária de transporte para todas as formas de movimentação de cargas e de passageiros, tendo como objetivo atingir maiores níveis de eficiência para o atendimento das demandas de carga ou passageiros. Essa tendência é evidente no transporte aéreo, marítimo, ferroviário e rodoviário.

Por outro lado, o aumento da capacidade de carga é proporcional as dimensões físicas dos veículos e essas dimensões são limitadas por fatores como: limitações tecnológicas de construção dos veículos e das vias, condições de estabilidade e controle dos veículos e a eficiência energética e econômica da tecnologia.

Assim sendo, em particular os veículos rodoviários necessitam de uma padronização dos parâmetros de performance como uma forma de regulamentação para o projeto e a operação das vias, sendo especificados os níveis mínimos e máximos aceitáveis, tais como, a trajetória de varredura (off-tracking), a capacidade de aceleração, a velocidade em rampas e contra-rampas, a capacidade de frenagem, a capacidade por faixa de rolagem (lane change capability), a capacidade de manobra para evitar colisão (crash avoidance maneuvering), a estabilidade, o fator de equivalência de carga (load equivalency factors), e o fator de equivalência de veículo (passenger car equivalencies). 
Os principais itens de projeto dos implementos e das unidades tratoras, conforme a Figura 2.1, são as dimensões lineares e os componentes do peso, conforme descrito a seguir:

- distância entre eixos geométrico: definida como a distância entre o centro do eixo ou conjunto de eixos traseiros da unidade tratora e o centro geométrico do eixo ou conjunto de eixos do implemento rodoviário;

- balanço dianteiro e balanço traseiro: definido como a distância entre centro do primeiro e do último eixo e as extremidades do veículo;

- altura;

- largura;

- comprimento total;

- peso útil máximo: definido como capacidade máxima em peso de carga que o veículo pode transportar;

- tara: definido como o peso do equipamento rodoviário contendo somente combustível e operador;

- peso bruto: soma do peso útil e a tara;

- peso bruto total combinado: soma dos pesos brutos das unidades que compõem o veículo.

Através destes itens de projeto e o tipo de carga a ser transportada são projetados os itens mecânicos, tais como: potência de motor, tipo de suspensão, quantidade de eixos, sistema de frenagem, dimensões internas do implemento (baú, tanque, etc), entre outros.

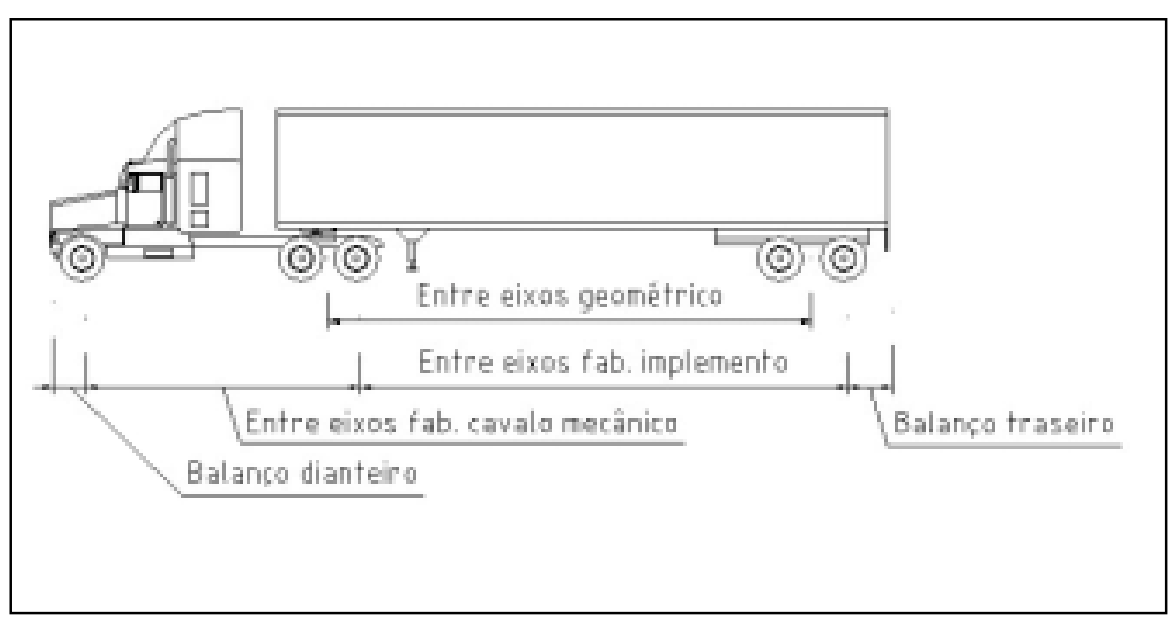

Figura 2.1: Geometria dos veículos rodoviários 
Historicamente, os incrementos da capacidade unitária de carga, no peso e nas dimensões em veículos rodoviários norte-americanos são expostos na Tabela 2.1.

Tabela 2.1: Evolução dos pesos e medidas dos veículos de carga

\begin{tabular}{|c|c|c|c|c|c|c|}
\hline \multirow[b]{2}{*}{ Ano } & \multicolumn{2}{|c|}{ Carga Eixos (t) } & \multirow{2}{*}{ Peso Bruto (t) } & \multicolumn{2}{|r|}{ Dimensões (m) } & \multirow{2}{*}{ Tráfego } \\
\hline & Simples & Tandem & & Largura & Comprimento & \\
\hline 1956 & 8,2 & 14,5 & 33,3 & 2,44 & Variável & Interstate highways \\
\hline 1975 & \multicolumn{5}{|c|}{ Bridge Formula B } & Interstate highways \\
\hline 1982 & 9,1 & 15,4 & $\begin{array}{c}36,3 \\
\text { Bridge Formula B }\end{array}$ & 2,60 & $\begin{array}{c}\text { 14,6 (carretas semi-reboque) } \\
8,53 \text { (carretas composição) }\end{array}$ & National network \\
\hline
\end{tabular}

Fonte: FHWA (1995)

A intervenção nos pesos e medidas, no ano de 1956, foi praticada através do FederalAid Highway Act, legislada pelo governo federal norte americano, porém a autonomia e as diferenças na legislação dos Estados ocasionaram uma falta de uniformidade na operação dos veículos. Os legisladores do transporte rodoviário, impulsionados pela crise do petróleo ocorrida entre os anos de 1974 e 1978, buscaram a homogeneidade na regulamentação dos pesos através do desenvolvimento da Bridge Formula B, que determina os limites de peso bruto total (PBT) em função da distância entre eixos extremos e o número de eixos do veículo (FHA, 1995). A partir de 1982, a Bridge Formula $B$, obteve maior efetivação na regulamentação dentro dos Estados. Isso ocasionou a criação da National Network for Large Trucks and Longer Combination Vehicles Networks: rodovias capazes de suportar o tráfego de composição de veículos maiores. Segundo REIS (1996), as CVC legalizadas nos Estados Unidos de acordo com o Western Highway Institute e o U.S. Departament of Transportation, mostradas na Figura 2.2 e Figura 2.3, apresentam as seguintes configurações:

- Unitários: caminhões rígidos com unidade de acondicionamento da carga e sistema motriz em um único bloco;

- Semi-reboques: caminhões articulados e com unidade de acondicionamento de carga e sistema motriz independentes. Apresenta um cavalo mecânico de três eixos e reboque de $16,2 \mathrm{~m}$;

- Western Double: cavalo mecânico de dois eixos, duas composições com eixos simples, 7,9m ou 8,8m, mais dole intermediário, peso máximo de 36 toneladas;

- Rocky Moutain Double: cavalo mecânico de três eixos, uma composição 13,7m ou 14,6m, dole e uma composição de $8,8 \mathrm{~m}$, peso máximo variando entre 48 a 58 toneladas; 
- 8-Axle B-Train Double Trailler Combination: CVC de oito eixos composta por um cavalo mecânico de três eixos e dois reboques acoplados por uma conexão do tipo B dole e conjunto de eixos tadem triplo;

- Turnpike Double: cavalo mecânico de três eixos, duas composições com eixos duplos de 14,6m, ligadas por dois doles, peso máximo variando entre 48 e 67 toneladas;

- Triple: Três composições 7,9 ou 8,8m, ligadas por dois doles, variando de 48 e 59 toneladas.

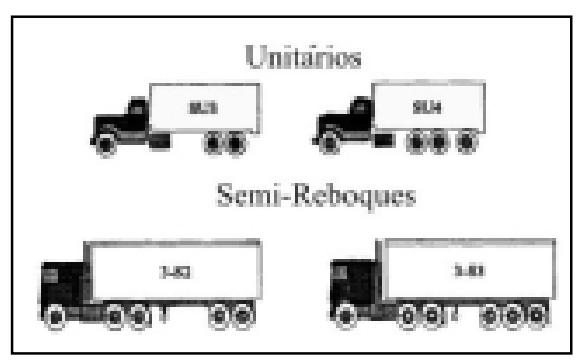

Figura 2.2: Combinações de veículos de carga norte americanos: unitários e semireboques (NIX et al., 1990)

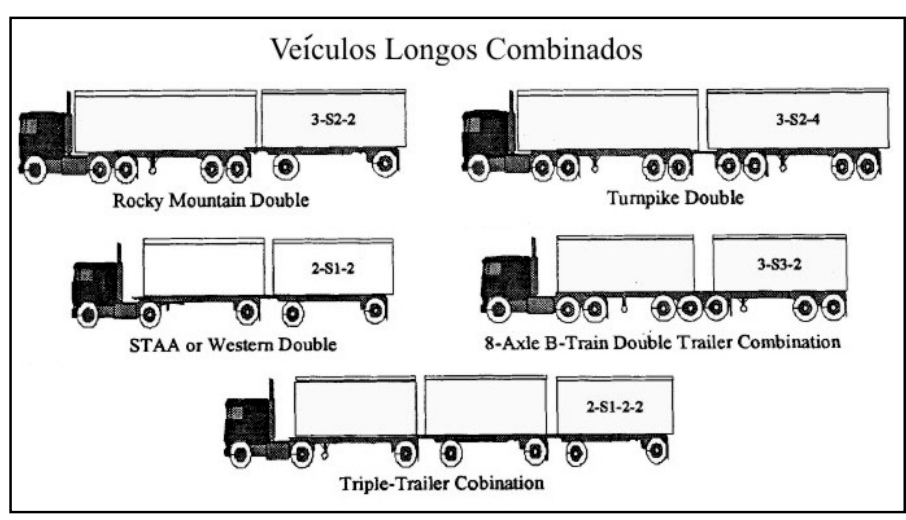

Figura 2.3: Combinações de veículos de carga norte americanos: veículos longos combinados (NIX et al., 1990)

Os veículos hidroviários constituem-se de uma tecnologia totalmente diferente dos veículos rodoviários. Uma das grandes diferenças está no deslocamento da tecnologia, que ocorre envolvida por dois diferentes tipos de fluidos: a água e o ar. Para FONSECA (1989), os principais fatores de dimensões lineares e de carregamento, relevantes ao projeto e a operação desta tecnologia são definidos a seguir:

- perpendiculares: duas retas normais à linha d'água projetada, contidas no plano diametral e traçadas em dois pontos especiais na proa e na popa, no desenho de linhas do navio; 
- comprimento entre perpendiculares: distância entre as perpendiculares à vante e à ré (Figura 2.4);

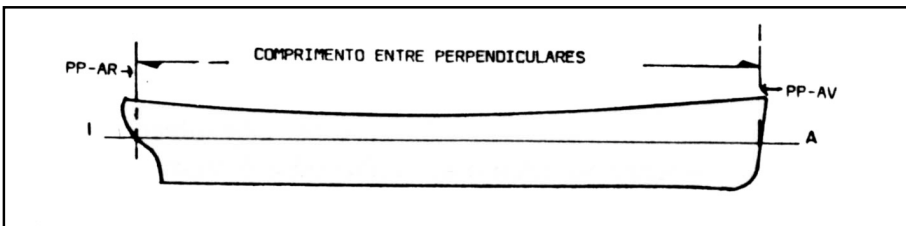

Figura 2.4: Comprimento entre perpendiculares (FONSECA, 1989)

- comprimento de roda a roda: é a distância medida entre os extremos da embarcação (Figura 2.5);

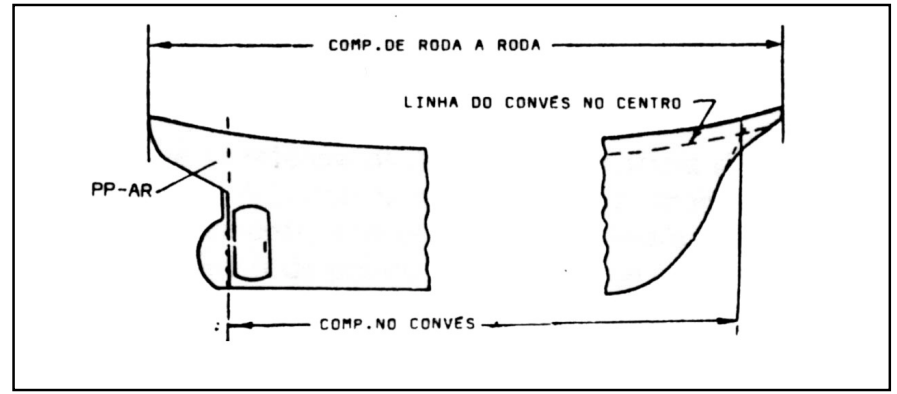

Figura 2.5: Comprimento de roda a roda (FONSECA, 1989)

- pontal: distância vertical medida sobre o plano diametral e a meia-nau, entre a linha reta do vau do convés principal e a linha da base moldada;

- calado: distância vertical entre a superfície da água e a parte mais baixa do navio;

- boca: é a largura da seção transversal da embarcação (Figura 2.6);

- deslocamento: peso da água deslocado por um navio;

- peso morto (deadweight, total deadweight ou gross deadweight): peso total da embarcação, do combustível e da tripulação;

- tonelagem de arquação (tonnage): volume interior do navio, em metros cúbicos ou litros;

- $\quad$ tonelagem líquida (net tonnage): capacidade máxima de carga, em peso.

Segundo FONSECA (1989), os navios são classificados da seguinte forma:

- quanto à finalidade: navios militares, navios mercantes, navios para recreio, navios para serviços especiais; 


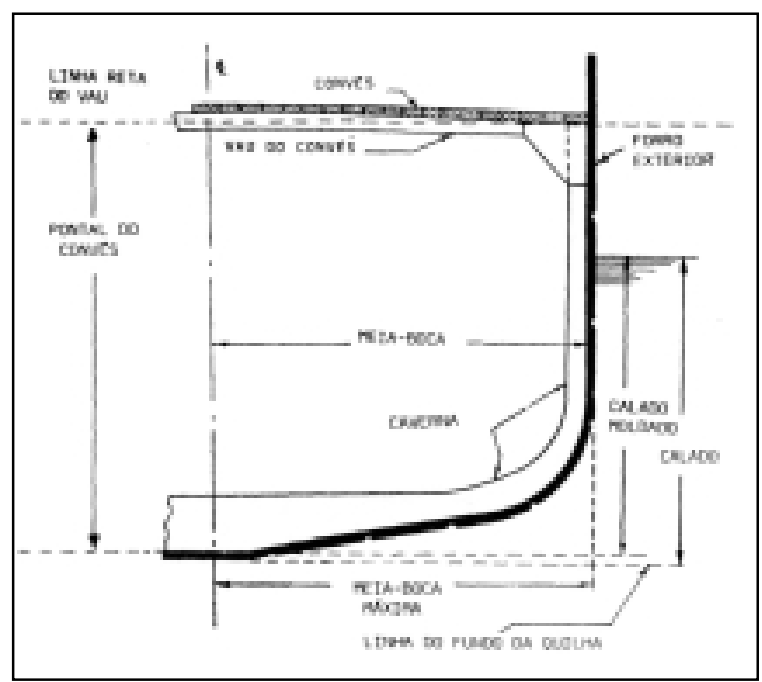

Figura 2.6: Geometria de embarcações marítimas (FONSECA, 1989)

- quanto ao material de construção do casco: madeira, ferro ou aço, compósitos, concreto armado, plástico e alumínio;

- quanto ao sistema de propulsão: vela, remos e mecânica .

As embarcações mercantes apresentam configurações distintas, variando conforme o tipo de carga a ser transportada, conforme observado na Figura 2.7. Os principais navios mercantes, segundo FONSECA (1989) e EYRES (1988) são: navios de carga geral (multipurpose e general cargos), navios de granéis sólidos ou líquidos (bulk carriers), navios para produtos químicos (chemical), navios porta-contêineres (full containers), e navios rolantes (roll on - roll off).

A evolução do aumento da capacidade de carga nos veículos hidroviários foi impulsionada pelos seguintes itens: estrutura do casco formada por chapas metálicas soldadas, aumento da tensão máxima admissível dos materiais estruturais, sistemas de propulsão e automação.

O crescimento da capacidade dos navios também se deve a maior unitização das cargas proveniente do uso de contêineres. No ano de 1984, as cargas transportadas nas três principais rotas comerciais mundiais (Trans Pacífico, Trans Atlântico e Europa-Extremo Leste) apresentaram um percentual de $75 \%$ da carga transportada, em contêineres, 
relacionadas com toda a carga possível de ser contenerizada. No ano de 1985, o percentual aumentou para níveis de aproximadamente 95\% (CULLINANE \& KHANNA, 2000). A Tabela 2.2 mostra a evolução do desenvolvimento de projeto e capacidade de carga, em TEU (Twenty-feet Equivalent Unit), para navios portacontêineres.

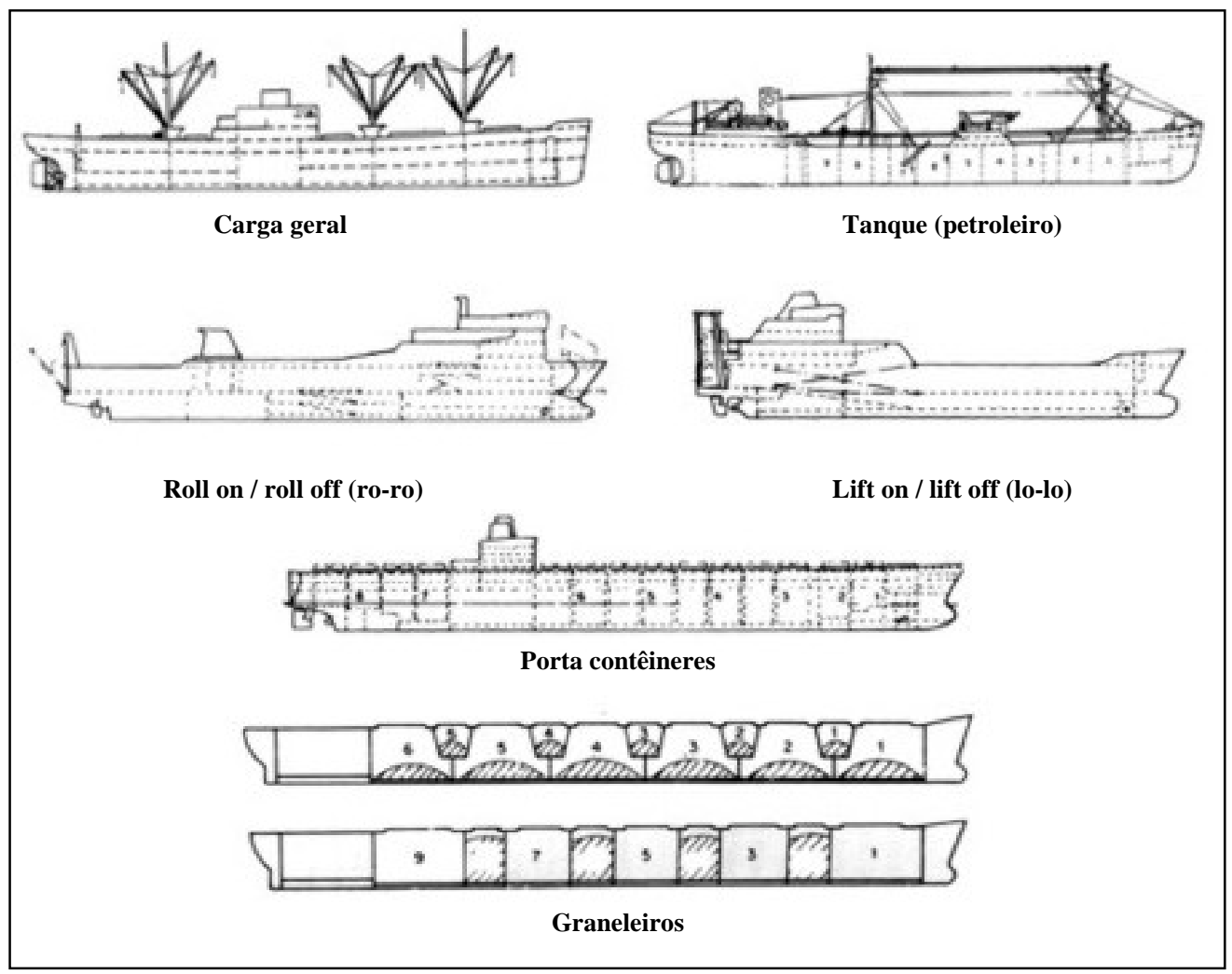

Figura 2.7: Tipos de navios mercantes (EYRES, 1988 e FONSECA, 1989)

Tabela 2.2: Evolução dos navios porta-contêineres

\begin{tabular}{ccc}
\hline Ano & Classe/tipo & Capacidade máxima (TEU) \\
\hline \hline 1964 & $1^{\underline{a}}$ geração & 1000 \\
& $2^{2}$ geração & 1500 \\
$1967-1972$ & $3^{\text {a }}$ geração & 3000 \\
1984 & $4^{\text {a }}$ geração & 4500 \\
1995 & $5^{\text {a }}$ geração & $>6000$ \\
\hline
\end{tabular}

Fonte: CULLINANE \& KHANNA (2000) 


\subsection{Competitividade entre tecnologias e modos de transporte}

A competitividade entre modos de transporte tem sido um tema vastamente abordado e encontrado na literatura científica brasileira. Pesquisas abordando intermodalidade e a competitividade dos fretes e custos entre ferrovias e rodovias ou hidrovias e ferrovias são encontrados nos estudos realizados por COSTA (1979), MASSELLA (1979), MESQUITA (1980) e KOMAROVA (2000).

Alguns dos estudos envolvendo os custos de transporte e a competitividade entre o transporte marítimo de cabotagem e o transporte rodoviário de cargas são apresentados nos itens 2.1.2 e 2.1.3.

\subsubsection{Tecnologia rodoviária no Brasil: estudos envolvendo CVCs}

No Brasil, a importância que adquiriu o caminhão como meio de transporte é um dos fenômenos de maior significado na distribuição de cargas. Assim, faz-se necessário o conhecimento de vários fatores que afetam a escolha do modelo e do implemento rodoviário a ser utilizado. As alternativas de solução na escolha do veículo e do implemento consideram itens como: a relação potência/peso, o torque, o tipo de tração, a transmissão, o tipo de pneumático, a tara, o peso bruto total, a distância entre eixos, a capacidade de frenagem, o raio de giro, a suspensão, a autonomia de combustível e de lubrificantes, o tipo de composição e as dimensões.

Os pesos e dimensões dos veículos de carga no Brasil são regulamentos pelo Código de Trânsito Brasileiro, do Conselho Nacional de Trânsito (BRASIL, 1999a). A lei que estabelece os limites de peso por eixo, comprimento e largura para veículos que transitam por vias terrestres está descrita na Resolução $N^{\circ} 12$ de 06 de fevereiro de 1998 (BRASIL, 1999b). A lei prescreve que o uso de Combinações de Veículos de Carga (CVC) apresentando comprimento entre 19,8m e 30,0m necessita a utilização da Autorização Especial de Trânsito (AET) descrita na Resolução No 68 de 23 de setembro de 1998 (BRASIL, 1999c), apresentando restrições de horário de tráfego e rodovias, sistemas de sinalização e qualificação do motorista. Segundo a legislação, as CVC 
permitidas não devem ultrapassar de $10 \mathrm{t}$ por eixo simples, $17 \mathrm{t}$ para conjunto de eixos tandem duplo, 25,5t para conjunto de eixos tandem triplo e 6t o eixo dianteiro da unidade tratora. As principais configurações de veículos rodoviários de carga encontrados no Brasil são observadas na Figura 2.8:

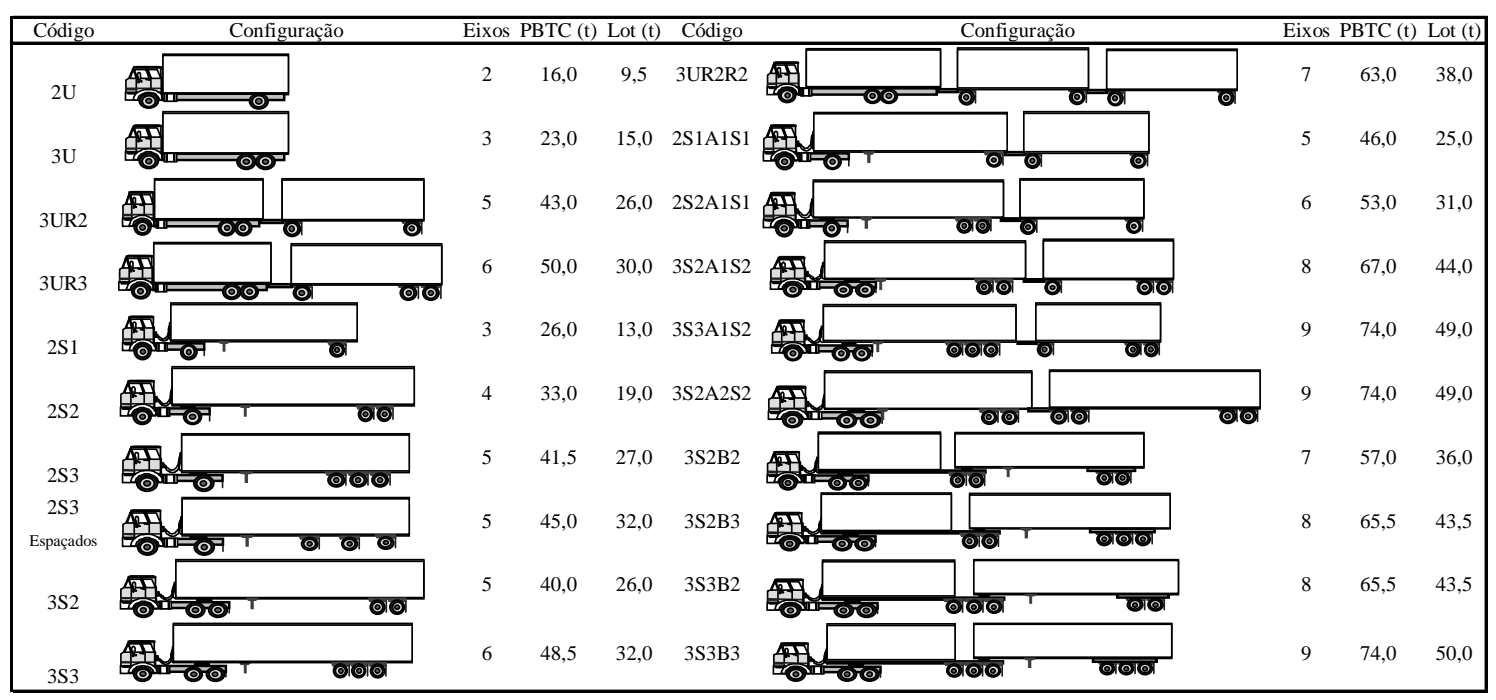

Figura 2.8: Configurações de veículos de carga encontradas no Brasil

$\mathrm{Na}$ literatura científica brasileira encontram-se pesquisas envolvendo o aspecto da interferência física da tecnologia CVC. Os estudos abordam os aspectos técnicos que afetam a infra-estrutura e a operação de veículos rodoviários. Sobre a influência das CVCs em pavimentos citam-se FERNANDES JR. (1994) e FABBRI et al. (1990); sobre a influência das CVCs em obras de arte, tais como pontes e viadutos, cita-se DER-SP (2001a); MACHADO NETO (1995) estudou o tempo de ultrapassagem de veículos unitários e composições de veículos de carga; DEMARCHI (1995) pesquisou os tempos e as distâncias de visibilidade para cruzamentos em interseções viárias; RUSSO (1995) descreveu o problema da sobrelargura de curvas de baixa velocidade e o problema de arraste para CVC; FERNANDES et al. (1995a e 1995b), FERNANDES (1997, 2000) estudaram o desempenho mecânico da frenagem de CVC; e WIDMER (2002a) estudou a eficiência de frenagem de algumas CVCs,

A bibliografia referente a estudos sobre custos e tarifas no transporte de carga é vasta. Foram consultados trabalhos como o realizado por OYOLA (1988), que estudou os 
valores tarifários calculados na realidade operacional das rodovias do Estado de Santa Catarina, utilizando o HDM III (Highway Design and Maintenance), e planilhas para o cômputo dos custos de transferência e custos de terminais de carga. VIEIRA (1986) estudou um método para a determinação de custos de transporte rodoviário de carga. CARDOSO \& WIDMER (1993) desenvolveram uma planilha de custos operacionais para veículos rodoviários de carga. VALENTE et al. (1997) e KAWAMOTO (1999) também apresentaram métodos para determinação de tarifas para transporte público urbano e transporte de cargas. Todos estes trabalhos envolveram os principais custos fixos e variáveis envolvidos na composição tarifária, dentre os quais pode-se citar: aquisição da unidade tratora e de implementos rodoviários, depreciação, remuneração de capital, salários, pedágios, combustíveis, lubrificantes e pneumáticos.

Cita-se também PINTO (1996), que estudou procedimentos de apoio a decisão gerencial, capaz de indicar a melhor alternativa de investimento para um sistema de distribuição física, considerando todos os custos operacionais, os custos administrativos, os custos do tempo de estoque e investimentos para o sistema de distribuição física do suco de laranja brasileiro de exportação.

\subsubsection{Tecnologia marítima no Brasil: a cabotagem}

O cenário da cabotagem vem sofrendo oscilações nos setores operacionais, de serviço e também no campo econômico-financeiro. Até a década de 30, a cabotagem foi muito utilizada para o transporte de carga a granel, devido à falta ou a precariedade da rede rodoviária e ferroviária (BOTTER et al., 2000).

O modo marítimo de cabotagem perdeu competitividade nos fretes devido ao desenvolvimento do modo rodoviário, através da construção e manutenção de rodovias, do desenvolvimento tecnológico dos veículos e do subsídio aos combustíveis, dado pelo Governo Federal, ocorrido entre as décadas de 50 e 90.

O contexto para o transporte marítimo começou a mudar em meados do ano de 1999. A estabilização da economia, a lei de modernização dos portos (BRASIL, 2001a), a lei de 
fretamento de navios com bandeira estrangeira (BRASIL, 2001b) e a lei de regulamentação do operador de transporte multimodal (BRASIL, 2001c) foram os principais fatores que beneficiaram o transporte marítimo no Brasil na última década. A viabilidade do segmento de cabotagem depende do nível e da qualidade de serviços, da confiabilidade, da regularidade e do tempo de viagem. Um exemplo sobre a vantagem da economia energética do transporte marítimo sobre o rodoviário quando se trata de grandes volumes a serem transportados, é mostrado por BOTTER et al. (2000): para o trecho Santos-Manaus, numa embarcação de 700 TEU, o custo de combustível representa $5 \%$ do frete, enquanto numa viagem rodoviária esse custo representa $23 \%$.

O cenário da evolução do transporte de contêineres por cabotagem, no Brasil, é mostrado na Figura 2.9.

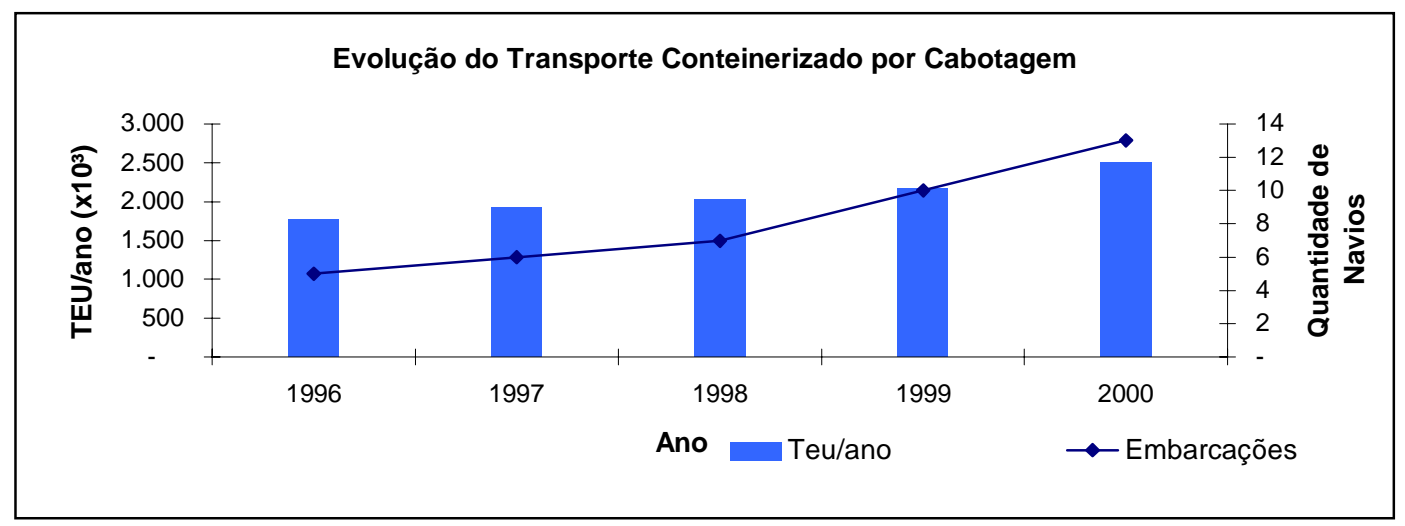

Figura 2.9: Evolução do transporte de contêineres por cabotagem (BOTTER et al., 2000 e TRANSPORTES, 2001)

A competitividade entre o transporte rodoviário e marítimo de cabotagem é vastamente retratada na literatura científica e não-científica no Brasil. Outros trabalhos são citados, tais como, SANTOS (1981), SEIBLITZ (1986) e BOTTER \& ROQUE. (1987).

CUNHA (2000) desenvolveu um procedimento para o levantamento dos custos marítimos e portuários na navegação de cabotagem para o transporte de granéis agrícolas e elaborou um programa computacional em linguagem Delphi, baseado em método proposto por NOVAES (1976). Na aplicação do modelo desenvolvido por CUNHA (2000), no estudo de caso para o transporte entre três filiais A, B e C com produção semanal de $2.000 \mathrm{t}$ e com distâncias aos destinos de $1.500,2.000$ e $2.500 \mathrm{~km}$ 
respectivamente, e supondo que no caso o modo rodoviário apresente $50 \%$ de carga de retorno e o modo marítimo apresente um período de armazenagem de 3 semanas, têm-se os resultados verificados na Tabela 2.3.

Tabela 2.3: Competitividade no transporte de grãos

\begin{tabular}{lclll}
\hline & Produção & \multicolumn{2}{c}{ Filiais } \\
\multicolumn{1}{c}{ Período } & $(\mathrm{t})$ & $\mathrm{A}(1500 \mathrm{~km})$ & \multicolumn{1}{c}{$\mathrm{B}(2000 \mathrm{~km})$} & \multicolumn{1}{c}{ C $(2500 \mathrm{~km})$} \\
\hline \hline 1- Semana $^{\text {a }}$ Semana & 2000 & Rodoviário & Rodoviário & Cabotagem (regular) \\
2 $^{\text {a }}$ Semana & 4000 & Rodoviário & Rodoviário & Cabotagem (regular) \\
\hline Fonte: CUNHA, 2000 & 6000 & Rodoviário & Cabotagem (regular) & Cabotagem (não regular) \\
\hline
\end{tabular}

ONO (2001) verificou a viabilidade do transporte marítimo de contêineres por cabotagem no Brasil através de dois modelos: o primeiro analisou as rotas viáveis e o segundo selecionou a melhor rota, para diferentes modelos de embarcações portacontêineres, atendendo às restrições de demanda entre cada origem e destino, através de um modelo matemático utilizando programação linear mista. Foram analisados três cenários hipotéticos variando a quantidade de navios e escalas em portos, navegando nos sentidos Norte-Sul e Sul-Norte. No último cenário analisado, ONO (2001) utilizou dados reais da empresa HSAC (Hamburg-Süd Aliança Crowley Logística) para embarcações com 670, 900 e 1.400 TEU computando um custo médio de $\mathrm{R} \$ 841,61$ por TEU transportado na rota.

\subsection{Modelos de redes de transportes}

A rede de transporte é uma concepção matemática que pode ser aplicada para descrever quantitativamente os sistemas de transportes e outros sistemas com características espaciais (MORLOK, 1978). Pode-se localizar pontos notáveis como clientes, terminais, cidades, escolas, e outros, representados por nós, e conectá-los através dos arcos. O grafo é definido pelo conjunto de pontos, denominados nós, e ligados entre si por arcos orientados ou não. Uma rede de transporte é representada matematicamente através de um grafo finito, onde cada arco $u_{i}$ é associado a uma capacidade $W\left(u_{i}\right) \geq 0$; existe apenas um nó fonte $(F)$ e um nó dreno $(Z)$ onde, respectivamente, saem somente arcos efluentes e chegam somente arcos afluentes. Uma trilha $(t)$, em um grafo, é definida como a seqüência de arcos tal que o nó terminal de um arco é o nó inicial do 
seguinte, exceto do primeiro e do último nó (NOVAES, 1978). A representação de um grafo é dada pela seguinte simbologia.

$$
G=(X, U)
$$

onde,

G: Grafo;

$X$ : Conjunto de nós;

$U$ : Conjunto de arcos.

A determinação da trilha $(t)$ mais curta entre os pontos $F$ e $Z$ contida em um grafo $G=$ $(X, U)$, e cujos comprimentos dos arcos não são nulos $\left(L\left(u_{i}\right)>0\right)$ é dado pelo mínimo valor da soma dada na eq. (2.1).

$$
L(t)=\sum_{u_{i} \in t} l\left(u_{i}\right)
$$

Através da teoria dos grafos e de programação linear, HITCHCOCK (1941) formula o Problema de Transporte, aplicado a uma situação comum em transportes (NOVAES, 1978). Uma das formulações do modelo matemático e observado na eq. (2.2).

$$
\min \sum_{i=1}^{m} \sum_{j=1}^{n} C_{i j} \times x_{i j}
$$

s.a.

$$
\begin{gathered}
\sum_{j=1}^{n} x_{i j}=a_{i} \quad i=1,2, . ., m \\
\sum_{i=1}^{m} x_{i j}=b_{j} j=1,2, \ldots, n \\
x_{i j} \geq 0 \quad \forall i \mathrm{e} j
\end{gathered}
$$

onde,

$C_{i j}$ : Custo de transporte entre $i$ e $j$;

$x_{i j}$ : Quantidade de produto transportado entre $i$ e $j$;

m: Número total de origens; 
n: Número total de destinos;

a: Quantidade de um produto;

$b$ : Demanda de um produto.

\subsection{O SIG-T TransCAD}

O SIG - Sistema de Informação Geográfica (Geographic Information System) é definido como um sistema de gerenciamento de banco de dados computacional com função de capturar, armazenar, recuperar, analisar e visualizar dados espaciais (LEWIS, 1990). O primeiro SIG desenvolvido no Canadá, em 1962, foi o CGIS (Canada Geographic Information Systems). Seu principal uso era para cadastro de terras em âmbito nacional, envolvendo vários aspectos sócio-econômicos e ambientais (ROSE, 2001).

Segundo VIVIANI (1998), uma coleção de elementos tais como, hardware, software, dados geográficos e pessoal, criam um SIG, e este sistema apresenta como entrada (inputs) funções como: captura dos dados (gráficos ou atributos na forma de importação de dados, digitalização com scanner, importação dos formatos CAD - Computer Aided Design e levantamentos de campo), gerência dos atributos (edição, gerência da base de dados), manipulação espacial (edição), análise dos dados (consultas condicionadas, sobreposições, modelagens). As principais saídas (outputs) de um SIG são a geração de estatísticas espaciais, os mapas temáticos, a resposta para decisão multi-critério, a localização de instalações (escolas, lojas, hospitais, plataformas de petróleo, terminais, entre outros). A aplicação de um SIG é observada em diversos campos, tais como: planejamento urbano, geografia, agronomia, ambiental, florestal, engenharia, processamento de dados, pesquisas operacionais, arquitetura e urbanismo, gerenciamento de serviços, engenharia de transportes e outros.

O SIG-t (Sistema de Informação Geográfica aplicada ao Transporte) é uma derivação do SIG aplicado na área de planejamento e operação de transportes. Dentre as diversas aplicações do SIG-t pode-se citar: projeto geométrico de vias, monitoramento e controle de tráfego, oferta e demanda de transportes, prevenção de acidentes, otimização de 
rotas, monitoramento e controle de operações rodoviárias, dentre outras (VIVIANI et al., 1994, SILVA, 1998a).

Vários trabalhos têm sido publicados descrevendo aplicações de SIG em transportes, alguns dos quais são citados a seguir. Na área de roterização de veículos (PELIZARO, 2000 e SARKIS, 2000), gerenciamento de frotas - dimensionamento e alocação (DINIZ, 2000), pesquisa operacional (LINS \& FERREIRA FILHO, 2001); e gerência de vias (VIVIANI, 1998). Sobre instalação de terminais intermodais e redes intermodais de transporte são citadas os trabalhos de GUIMARÃES (1999); SOUTHWORTH \& PETERSON (2000); e TIAGO (2002).

SOUTHWORTH \& PETERSON (2000), através de um contrato com o governo norteamericano, criaram uma rede intermodal e internacional de transportes em um SIG, com a finalidade de simular um montante de 5 milhões de origens e destinos em fretes e mais o montante de transporte intermodal. A criação desta base de dados foi alimentada com dados estatísticos do Commodity Flow Survey, do Bureau of the Census e do Bureau of Transportation. Na criação desta base foram criados 133 mil arcos totalizando 3,3 milhões de milhas englobando rodovias, ferrovias, hidrovias e navegação intercontinental.

TIAGO (2002) estudou o problema de localização estratégica de terminais intermodais rodo-ferroviários para contêineres no Estado de São Paulo, utilizando uma matriz O/D de contêineres movimentados. Foram selecionados pontos de distribuição de contêineres e simulada a instalação de novos terminais através de uma rede de transportes contendo os custos fixos e variáveis rodo-ferroviários. A conclusão do trabalho foi que, nas regiões próximas a Santos, como os municípios de São Paulo, Campinas, Mogi-Guaçú e São José dos Campos, a implantação dos terminais só se viabiliza para condições muito particulares de acesso ao modo ferroviário.

O TransCAD soluciona o problema de transporte teoricamente fundamentado no estudo feito por HITCHCOCK (1941) através de um algoritmo adaptado pelo método Simplex para programação linear. O algoritmo do TransCAD utiliza-se de uma importante 
característica do problema de Hitchcock: quando uma solução ótima é atingida, os números de arcos em fluxo são iguais ao mínimo número de "arcos capacitados", que podem conectar os nós de origem e os nós de destino, e os demais "arcos não capacitados" da rede são desconsiderados. O algoritmo inicia as interações através de uma solução viável com este número mínimo de "arcos capacitados" e busca através das interações com os "arcos não capacitados" a melhoria na solução. Se uma nova trilha for encontrada, o algoritmo quantifica o fluxo que deve ser direcionado para o novo arco e atualiza a rede (CALIPER, 1996b). Este caso de programação linear do problema de transporte apresenta $m+n-1$ restrições linearmente independentes, havendo assim igual número de variáveis básicas (NOVAES, 1978).

Outra heurística utilizada pelo TransCAD é o algoritmo de fluxo mínimo que utiliza dois métodos desenvolvidos por BERTSEKAS \& TSENG (1988, 1994). O método interativo é baseado na ascensão de duas restrições: custo e capacidade. O "vetor custo", associado com a rede de transportes, é atualizado simultaneamente com a capacidade dos arcos. O algoritmo acaba as interações quando o fluxo atingir a solução mínima viável (CALIPER, 1996b).

Nesta pesquisa não foram conferidas e comparadas as heurísticas descritas no manual do TransCAD (CALIPER, 1996b) com as heurísticas descritas por HITCHCOCK (1941) e BERTSEKAS \& TSENG $(1988,1994)$ por não fazer parte do escopo deste trabalho. 


\section{MODELAGEM DO PROBLEMA DE TRANSPORTE}

O primeiro passo da pesquisa foi a busca de informações no meio acadêmico, nas agroindústrias, em centros de pesquisas, em empresas de prestação de serviços de transporte rodoviário, em empresas de transporte marítimo e em órgãos governamentais. As informações buscadas foram:

- dados para edição da matriz O/D de cargas frigoríficas transportadas entre fábricas e centros de distribuição;

- verificação da existência de bases de dados geográficas, rodoviária e hidroviária, aplicadas em SIG;

- valores de custos de insumos, mão-de-obra e equipamentos para o cálculo dos operacionais de transporte rodoviários e hidroviários;

- custos portuários no Brasil.

\subsection{Base de dados para SIG-T TransCAD}

$\mathrm{Na}$ verificação da existência de bases cartográficas digitais das principais rodovias e hidrovias brasileiras, compatíveis com SIG, efetuaram-se contatos com três instituições de ensino e pesquisa: o Instituto Brasileiro de Geografia e Estatística (IBGE), através da engenheira cartográfica Célia Regina, do DGC/DECAR, o Instituto Nacional de Pesquisas Espaciais (INPE), através da srta. Juliana, do DPI e o Programa de Engenharia de Transportes da Universidade Federal do Rio de Janeiro, através de publicação eletrônica em PET-COPPE (2001). O IBGE, no ano de 2001, apresentava-se em fase de implantação de projeto de criação de cadastro eletrônico em SIG, em parceria com o Exército Brasileiro. O INPE forneceu uma base de dados com toda a rede de rodovias implantadas e projetadas, segundo o DNER, desenvolvido para o SIG Spring, porém neste trabalho não se verificou o conteúdo e o ano da criação da base de dados. 
A escolha pelo TransCAD deu-se pela posse e utilização do programa pelo Departamento de Transportes da Escola de Engenharia de São Carlos - USP em linhas de pesquisa científica nas áreas de planejamento e infra-estrutura de transportes. Assim, a base de dados utilizada neste trabalho teve origem em arquivos disponibilizados pela PET-COPPE.

Os dados encontrados em PET-COPPE (2001) são constituídos por um conjunto de arquivos de pontos, linhas e áreas apresentando as características descritas a seguir.

O arquivo rod_cdfl.cdf, representa a malha rodoviária brasileira, é constituído por duas camadas: a camada de arcos-Rodovias e a camada de pontos-CDF Node Layer. Os arcos representam os trechos rodoviários e os nós representam, basicamente, interseções rodoviárias e os nós de final de arco (endpoints), totalizando 6756 arcos e 6254 nós registrados. O respectivo conteúdo do banco de dados referente à camada Rodovias tem a configuração apresentada na Figura 3.1.

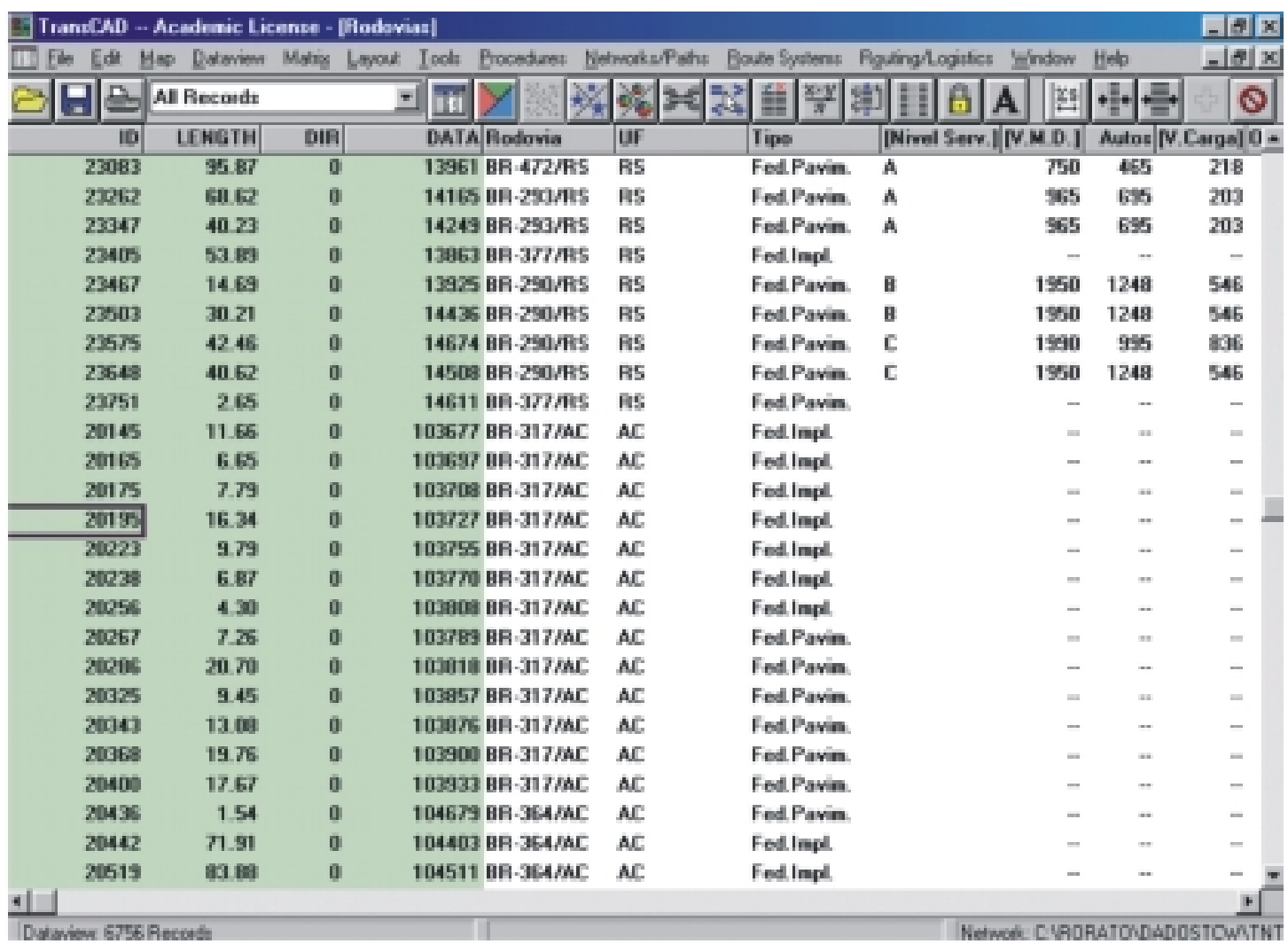

Figura 3.1: Camada Rodovias (PET-COPPE, 2001) 
Os campos ID, Lenght e Dir representam o código de identificação do arco, o comprimento teórico do arco e o sentido de fluxo do arco, respectivamente. Esses campos são gerados automaticamente com a criação de um novo arco. Os demais campos que compõe o banco de dados apresentam a atribuição gerada por PET-COPPE (2001), e são constituídos das respectivas informações: Rodovia classifica a jurisdição e nomenclatura do arco; $U F$ corresponde à respectiva unidade federativa; Tipo classifica o arco em rodovia existente ou projetada; V.M.D., Autos, V. Carga referem-se a estatísticas de tráfego; e Nivel Serv refere-se ao nivel de serviço do trecho da rodovia.

$\mathrm{O}$ arquivo de linhas brhidrov.cdf representa todas a rede hidrográfica brasileira, contendo os rios navegáveis, os rios não navegáveis e um banco de dados referente a nomenclatura, classificação, bacia hidrográfica, entre outros. Também estão contidos arcos que representam as rotas marítimas de cabotagem conectando os portos brasileiros. Os registros de arcos e nós na base de dados totalizam 1526 nós e 1499 arcos.

Os arquivos br_stat3.cdf e mmd947.cdf são arquivos de área e de pontos, respectivamente. $\mathrm{O}$ arquivo de área contém as 26 Unidades Federativas e o Distrito Federal, apresentando informações como as capitais dos Estados, a região, a área e a população. $\mathrm{O}$ arquivo de pontos apresenta a distribuição geográfica dos municípios brasileiros. Esse arquivo apresenta 4974 pontos, informando as coordenadas geográficas, município, população, unidade federativa e região, com base em dados do IBGE.

A necessidade de reformulação das bases de dados encontrados em PET-COPPE (2001) provém do fato de não haver a possibilidade de utilizar a matriz da rede viária e hidroviária original, dado que determinados arcos representavam rodovias e hidrovias sem uma definição clara de sua condição de tráfego. Esse problema pode ser visualizado na Figura 3.1, tendo como exemplo o arco de $I D=20195$, representando a rodovia BR317/AC. Conforme a classificação do campo Tipo, esta rodovia apresenta a informação em implantação. Não se utilizando as ferramentas de seleção, o Trans $C A D$ interpreta este arco como existente, quando na realidade esta rodovia não se encontra implantada. 
Outra dificuldade foi a utilização do campo Tipo para classificar o tipo de pista, a jurisdição e o tipo de pavimento.

Logo, para adequar a base de dados a este trabalho tornou-se necessária a complementação do cadastro introduzindo assim, as seguintes modificações:

- exclusão dos arcos com o campo Tipo classificados em Fed.Impl., Fed.Ob.Pav., Fed.L.Nat. e Fed.Plan: o objetivo da exclusão destes arcos foi de gerar uma base somente com rodovias reais, evitando respostas de cenários divergentes da realidade e a utilização do comando Dataview $\rightarrow$ Select by Condition toda vez que desejava-se criar um arquivo de rede, para selecionar as rodovias e as hidrovias vigentes nas análises;

- utilização do campo Tipo para classificar somente em jurisdição e tipo de pavimento

- inclusão do campo Pista para classificar as rodovias em pista simples ou dupla;

- exclusão dos nós em excesso provenientes da exclusão de arcos com a camada Endpoints estando desabilitada;

- edição de novos arcos não incluídos anteriormente;

- edição de novos nós próximos a municípios e as praças de pedágios não cadastrados na rede;

- criação de um arquivo de ponto (pedagios.dbd) representando as praças de pedágio, segundo mapas gráficos de ABCR (2001), através do método proposto por SILVA (1998b);

- exclusão dos arcos da navegação de interior, exceto os arcos principais da Bacia Amazônica Ocidental e Oriental;

- união da base de dados rodoviária e hidroviária numa única base geográfica, sem ocorrer sobreposição de códigos de identificação (ID);

A complementação da base de dados, para este trabalho, efetivou-se através da obtenção, digitalização em scanner de mesa A4 e a vetorização dos arquivos gráficos, segundo o método descrito em SILVA (1998b), sendo consumidos aproximadamente quatro meses do período da pesquisa. Os dados foram obtidos através de cadastro técnicos oficiais e de mapas comerciais da malha rodoviária brasileira, encontrados no 
DER-SP (2001), no DAER-RS (2001), em DER-SC (2001) e em ABRIL (2000). A comparação da base de dados original e a complementada por este trabalho é observada na Tabela 3.1.

Tabela 3.1: Comparação da base rodoviária de dados inicial versus final

\begin{tabular}{lcccccc}
\hline \multicolumn{7}{c}{ Reedição da rede intermodal $(\mathrm{km})^{1}$} \\
\hline \hline Banco de dados & Federais & Estaduais & Sem classificação & Subtotal Rodoviário & Cabotagem ${ }^{2}$ & Total da Rede $^{\prime}$ \\
PROJETO GIS & 41.043 & 21.197 & 17.875 & 80.115 & 9.485 & 89.600 \\
STT-EESC-USP & 60.228 & 48.196 & 34.123 & 142.547 & 9.485 & 152.032 \\
\hline${ }^{1}$ Comprimento teórico dos arcos atribuído pelo TransCAD & \multicolumn{4}{c}{} \\
${ }^{2}$ Incluindo Bacia Amazonica Oriental e Ocidental & & & &
\end{tabular}

A integridade da rede construída foi testada através do método expedito para verificação da consistência de redes, apresentado por RAIA JR. \& SILVA (1998), no qual cria-se um mapa temático representando a acessibilidade em cada nó. A acessibilidade pode ser definida como a facilidade com que a pessoa em um dado ponto pode ter acesso a todos os outros lugares em uma área definida, dentro de um sistema de transportes, sendo consideradas as variações de atratividade e o custo percebido para atingi-la (DAVIDSON, 1995).

ALLEN et al. (1993) não consideram os parâmetros comportamentais e define como acessibilidade somente o custo da separação espacial entre os pontos dentro de uma área. Matematicamente a medida de acessibilidade proposta por ALLEN et al. (1993) pode ser expressa por:

$$
A_{i}=\frac{1}{N-1} \times \sum_{j} C_{i j}
$$

onde,
$A_{i}:$ Acessibilidade da zona $i$
$N$ : Número de localidades (pontos ou nós);
$C_{i j}$ : Custo de viagem entre os pontos $i$ e $j$.

O método proposto por RAIA JR. \& SILVA (1998) aplica o índice de ALLEN et al. (1993) de acessibilidade, para a criação de um mapa temático, que permite uma análise visual de inconsistência na distribuição dos valores. O custo empregado na eq. (3.1) 
para calcular o índice de acessibilidade limita-se à distância entre os nós da rede. $\mathrm{O}$ resultado obtido pelo método expedito para a rede intermodal é apresentado na Figura 3.2. Aplicando o método proposto por RAIA JR. \& SILVA (1998) em uma rede sem problemas de conectividade entre os arcos, gera-se um mapa temático de distribuição cromática exocêntrica acompanhando o crescimento dos valores da acessibilidade propostos por ALLEN et al. (1993). No caso de um mapa temático construído sobre uma rede descontínua, a distribuição das cores é irregular, surgindo assim faixas cromáticas de índices de menor valor ou de índice de acessibilidade nula a jusante de um conjunto de nós com índice de maior "custo de acessibilidade". Nota-se na Figura 3.2 que alguns pontos escuros, de índices nulos, surgem nos Estados do Pará, Tocantins, Piauí e Mato Grosso do Sul. Estes pontos são pequenos trechos de rodovias pavimentadas, conectadas a outras rodovias não pavimentadas, que não apresentam interferência com os objetivos propostos por este trabalho.

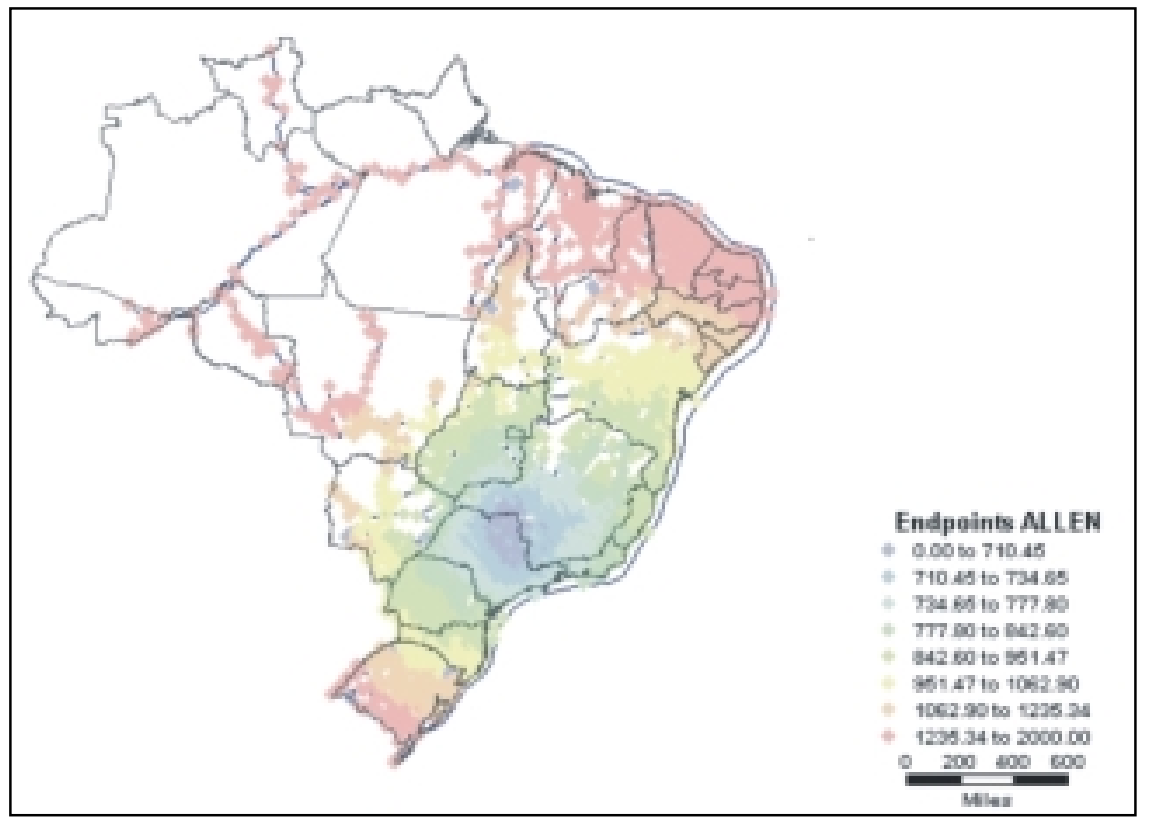

Figura 3.2: Mapa temático de acessibilidade - teste de conectividade da rede

Além do teste de conectividade foram realizados testes estatísticos com a finalidade de quantificar a diferença da rede trabalhada na pesquisa e outra fonte de informação de distâncias. Segundo o banco de dados do arquivo mmd947.cdf foram selecionados 190 municípios com população maior que 100 mil habitantes. Assim gerou-se uma matriz O/D de distância entre a seleção e as respectivas capitais: Porto Alegre, Florianópolis, 
Brasília, São Paulo, Salvador, Fortaleza e Manaus. A outra amostra, com 1130 valores de distâncias, foi obtida no sítio do BRExpress ${ }^{1}$. Com as duas amostras foram realizadas análise de regressão dos dados e teste de hipótese conforme descrito em ANDERSON et al. (2002), tomando como referência as distâncias obtidas no BRExpress.

Nos testes de hipóteses foram verificadas as estimativas das diferenças entre as médias das duas populações para as amostras independentes. O cálculo da probabilidade $\mathrm{z}$, segundo ANDERSON et al. (2002), é dado pela eq. (3.2).

$$
z=\frac{\left(\bar{x}_{1}-\bar{x}_{2}\right)-\left(\mu_{1}-\mu_{2}\right)}{\sqrt{\frac{\sigma_{1}^{2}}{n_{1}}+\frac{\sigma_{2}^{2}}{n_{2}}}}
$$

onde,

$\bar{x}_{1}-\bar{x}_{2}:$ Diferença entre as médias da amostra;

$\mu_{1}-\mu_{2}$ : Diferença entre as médias da população;

$\sigma_{1}$ e $\sigma_{2}$ : Desvio padrão da população;

$n_{1}$ e $n_{2}$ : Tamanho da amostra, sendo $n_{1} \geq 30$ e $n_{2} \geq 30$.

O teste de hipótese elaborado está descrito a seguir:

- Teste: As diferenças entre as distâncias encontradas no BRExpress e as distâncias da rede no SIG-T são iguais a zero?

$$
\begin{aligned}
& H_{0}: \mu_{1}-\mu_{2}=0 \\
& H_{1}: \mu_{1}-\mu_{2} \neq 0
\end{aligned}
$$

Rejeitar $\mathrm{H}_{0}$ se $\mathrm{z}<-\mathrm{z}_{\alpha / 2}$ ou se $\mathrm{z}>\mathrm{z}_{\alpha / 2}$

A diferença média entre as duas amostras variou entre 2,5 a 8\%. Este erro justifica-se no conjunto de erros de imprecisão das bases de dados obtidas, distorções de digitalização e no não conhecimento da construção da base de dados utilizada no programa do BRExpress, comparada na análise estatística. O resumo dos resultados obtidos nos

\footnotetext{
${ }^{1}$ http://www.brexpress.com.br
} 
testes de hipótese é mostrado na Tabela 3.2. Os demais dados da regressão e do teste de hipótese encontram-se no Apêndice A.

Tabela 3.2: Resumo dos resultados do teste de hipótese

\begin{tabular}{lccccc}
\hline \multicolumn{1}{c}{ Origem } & $\mathrm{z}$ & $\mathrm{x}_{1}$ & $\mathrm{x}_{2}$ & Teste de hipótese & Diferença amostra 1 e 2 (\%) \\
\hline \hline Porto Alegre & 0,9359 & 1987,86 & 1863,17 & Não rejeitar $\mathrm{H}_{0}$ & 6,3 \\
Florianópolis & 0,6758 & 1662,25 & 1579,29 & Não rejeitar $\mathrm{H}_{0}$ & 5,0 \\
São Paulo & 0,2230 & 1167,55 & 1142,18 & Não rejeitar $\mathrm{H}_{0}$ & 2,2 \\
Brasília & 0,5273 & 1438,02 & 1401,33 & Não rejeitar $\mathrm{H}_{0}$ & 2,6 \\
Salvador & 1,6476 & 1914,32 & 1768,87 & Não rejeitar $\mathrm{H}_{0}$ & 7,6 \\
Fortaleza & 1,2669 & 2653,17 & 2506,67 & Não rejeitar $\mathrm{H}_{0}$ & 5,5 \\
Manaus & $-1,0642$ & 4165,33 & 4272,94 & Não rejeitar $\mathrm{H}_{0}$ & $-2,6$ \\
\hline
\end{tabular}

\subsection{Composição de custos do transporte rodoviário}

\subsubsection{Dimensionamento da frota rodoviária}

O número de veículos necessários em uma frota, segundo VALENTE et al. (1997), é determinado pela razão do número de viagens mensais e o número de viagens que um veículo realiza em um mês, como descrito na eq. (3.4). O número de viagens mensais é uma melhoria da proposta por VALENTE et al. (1997), e se determina pela demanda de transporte entre uma origem $i$ e um destino $j$, dividido pela densidade média ou peso específico da carga na origem $i$ e a capacidade, em metros cúbicos, do veículo $\mathrm{k}$, conforme a eq. (3.5).

$$
\begin{gathered}
N V=\frac{V_{\text {mês }}}{V V e i c_{m \hat{e} s}} \\
V_{m \hat{e} s}=\frac{Q_{i j}}{d_{i} \times C U C_{k}}
\end{gathered}
$$

onde,

$N V$ : Número de veículos da frota;

$V_{m e ̂ s}:$ Número de viagens mensais necessárias;

Vveic $_{m e ̂}$ : Número de viagens mensais que um veículo realiza;

$Q_{i j}$ : Demanda de transporte entre $i$ e $j(\mathrm{t})$; 
$d_{i}$ : Peso específico do produto, na origem i $\left(\mathrm{t} / \mathrm{m}^{3}\right)$;

$C U C_{k}$ : Capacidade de transporte de carga $\left(\mathrm{m}^{3}\right)$.

As viagens mensais dos veículos são determinadas pelo produto dos dias de operação em um mês, pela razão do tempo diário da operação e tempo total do ciclo da rota, conforme visto na eq. (3.6) (VALENTE et al., 1997).

$$
\text { Veic }_{m \hat{e} s}=D O M_{k} \times \frac{T D O_{k}}{T C_{i j}}
$$

onde,

$D O M_{k}$ : Dias de operação em um mês;

$T D O_{k}$ : Tempo diário de operação;

$T C_{i j}$ : Tempo de ciclo de viagem entre $i$ e $j$.

\subsubsection{Custos operacionais rodoviários}

O método utilizado para o cálculo dos custos operacionais de um veículo de carga é baseado nos custos médios desagregados (VALENTE et al. 1997). São calculados custos fixos e variáveis como: depreciação, remuneração de capital, salário motorista, licenciamento, autorização especial de tráfego, administrativo, sistema de monitoramento por satélite, lubrificantes, pneumáticos, combustíveis e manutenção. Os principais itens calculados na planilha são o custo operacional total por quilômetro rodado e custo total da tonelada transportada por quilômetro mostrados na eq. (3.7) e na eq. (3.8), respectivamente.

$$
C O Q=\frac{[(C V Q \times Q M M)+C F M] \times[1+I D I]}{Q M M}
$$

onde,

$C O Q:$ Custo total por quilômetro rodado $(\$ / \mathrm{km})$;

$C V Q$ : Custo variável da composição de veículo de carga $(\$ / \mathrm{km})$;

QMM: Quilometragem média do veículo ( $\mathrm{km} / \mathrm{mês})$; 
CFM: Custo fixo mensal (\$);

IDI: Custos indiretos da empresa (\%).

$$
C T Q=\frac{C O Q}{C C V \times I A V}
$$

onde,

CTQ: Custo por tonelada transportada $(\$ / \mathrm{t})$;

$C C V$ : Capacidade líquida de carga $(\mathrm{t})$;

$I A V$ : Índice de aproveitamento do veículo (\%).

Custo fixo mensal do cavalo mecânico e implemento - CFM

O custo fixo mensal é composto pela soma dos custos de depreciação, dos custos de remuneração de capital, dos custos com salário, dos custos de licenciamento, do custo da AET, do custo do sistema de monitoramento de veículos via satélite e do custo de seguro do casco.

- Depreciação (D):

$$
D=\frac{V-R}{n}
$$

onde,

$V$ : Custo de aquisição do cavalo mecânico ou implemento;

$R$ : Valor residual do bem em $\mathrm{n}$ anos de uso;

n: Vida útil do bem ou tempo de depreciação.

- Remuneração de Capital (RC):

$$
R C=\frac{(V-R) \times(n+1) \times j}{2 \times n}+(R \times j)
$$

onde, 
$j$ : Taxa de juros (\%aa).

- Salário (CS):

$$
C S=\frac{S_{m} \times N_{m} \times(100+E S)}{100}
$$

onde,

$S_{m}:$ Salário médio do motorista;

$N_{m}$ : Número de motoristas;

ES: Encargos sociais (\%).

- Licenciamento (CL):

$$
C L=\frac{S O+I P}{12}
$$

onde,

SO: Seguro do obrigatório;

$N_{m}$ : Imposto sobre propriedade de veículos automotores (IPVA).

- Autorização Especial de Tráfego $\left(\mathrm{C}_{\mathrm{AET}}\right)$ :

$$
C_{A E T}=\sum A E T_{i}
$$

onde,

$A E T_{i}:$ Custo das AET para as $i$ jurisdições rodoviárias.

- Monitoramento (CM):

$$
C M=\frac{V M}{12}+\overline{C T}
$$

onde,

$V M$ : Custo de aquisição do equipamento de monitoramento;

$\overline{C T}$ : Custo médio de comunicação. 
- Seguro do casco (SC):

$$
\begin{gathered}
I S P=\frac{N V S}{N V \times 12} \\
S C_{1}=I S P \times V \\
S C_{2}=\frac{C A S}{12}
\end{gathered}
$$

para,

$$
S C_{1} \leq S C_{2} \Rightarrow S C=S C_{1}
$$

caso contrário,

$$
S C_{2} \leq S C_{1} \Rightarrow S C=S C_{2}
$$

onde,

ISP: Índice de perda de veículo;

NVS: Número de veículos sinistrados;

CAS: Valor da apólice de seguro para o conjunto;

$S C_{1}$ : Seguro de casco - custo mensal do auto-seguro;

$S C_{2}$ : Seguro de casco - custo mensal da apólice.

Custo variável do cavalo mecânico e do implemento - CVQ

O custo variável total do cavalo mecânico e do implemento rodoviário é constituído pela somatória dos custos de insumos tais como: pneumáticos, manutenção, lavagem, lubrificação, combustível do cavalo mecânico, lubrificantes e combustível do sistema de refrigeração.

- Pneumáticos (CP):

$$
\begin{gathered}
C P=\frac{U p \times Q p}{n t p} \\
U p=P p c+G r e+G c r \\
P p c=P p n+P c a \\
G r e=\operatorname{Pr} e \times i m r
\end{gathered}
$$




$$
\begin{gathered}
\text { Gcr }=P c a \times i m r \\
n t p=(n p r \times i m r)+n p n
\end{gathered}
$$

onde,

Up: Custo unitário por pneu;

Qp: Quantidade de pneus;

ntp: Vida útil total do pneumático;

Ppc: Preço de um pneumático e uma câmara;

Gre: Gastos com recapagem;

Gcr: Gastos com câmara quando recapagem;

Pre: Preço da recapagem;

Ppn: Preço do pneumático;

Pca: Preço da câmara;

npr: Vida média do pneu recapado / recauchutado;

imr: Índice médio de recapagens;

npn: Vida média do pneu novo.

- Manutenção (CM)

$$
C M=\frac{V s p \times i m}{m a c}
$$

onde,

Vsp: Custo de aquisição do cavalo mecânico ou implemento, sem pneus;

im: Índice de manutenção;

mac: Intervalo médio de manutenções.

- $\quad$ Lavagem e lubrificação (LL)

$$
\begin{gathered}
L L=C l a+C l u \\
C l a=\frac{P l a}{i l a} \\
C l u=\frac{P l u}{i l u}
\end{gathered}
$$

onde, 
Cla: Custo de lavagem por quilômetro;

Clu: Custo de lubrificação por quilômetro;

Pla: Preço de uma lavagem;

Plu: Preço de uma lubrificação

ila: Intervalo entre lavagens;

ilu: Intervalo entre lubrificações.

- Combustível do cavalo mecânico (CC):

$$
C C=\frac{P l c}{A m l}
$$

onde,

Plc: Custo do litro de combustível;

Aml: Autonomia média.

- Combustível do sistema de refrigeração do baú (CRF):

$$
C R F=\frac{P l c}{A s r}
$$

onde,

Plc: Custo do litro de combustível;

Asr: Autonomia média do sistema de refrigeração.

- Lubrificantes (CO)

$$
\begin{gathered}
C O=O c m+O c t+O s d+\text { Tom }+ \text { Com }+ \text { Frad }+ \text { Odif } \\
O c m=\frac{P c m \times Q c m}{i c m} \\
O c t=\frac{P c t \times Q c t}{i c t} \\
O s d=\frac{P s d \times Q s d}{i s d}
\end{gathered}
$$




$$
\begin{gathered}
\text { Tom }=\frac{\text { Pom } \times \text { Qto }}{\text { ito }} \\
\text { Com }=\frac{\text { Pom } \times \text { Qto }}{\text { itoc }} \\
\text { Frad }=\frac{\text { Pfrad } \times Q f r}{\text { ifr }} \\
\text { Odif }=\frac{\text { Podif } \times \text { Qdif }}{\text { ito }}
\end{gathered}
$$

onde,

Ocm: Custo óleo para caixa de mudanças;

Oct: Custo óleo para eixo traseiro;

Osd: Custo óleo para sistema de direção;

Tom: Custo óleo para motor;

Com: Custo complementação óleo para motor;

Frad: Custo fluído para radiador;

Odif: Custo óleo diferencial;

P: Preço litro de óleo/lubrificante/fluído;

Q: Quantidade de óleo/lubrificante/fluído;

icm, ict, isd, ito, itoc e ifr: Intervalos de troca dos respectivos insumos.

\subsubsection{Custos de pedágios}

Na obtenção das tarifas de pedágios e para a localização das praças de pedágios em operação no Brasil consultou-se a Associação Brasileira de Concessionárias de Rodovias (ABCR, 2001), totalizando 158 praças de pedágios geograficamente distribuídas em rodovias nos Estados da Bahia, do Espírito Santo, de Minas Gerais, do Paraná, do Rio de Janeiro, do Rio Grande do Sul e de São Paulo.

\subsection{Composição de custos do transporte marítimo}

O modelo de custo do transporte marítimo é um conjunto de custos que são provenientes do custo da embarcação, dos custos de contêineres de 20 e 40 pés e dos 
custos portuários. Para o cômputo destes custos, foram utilizadas partes do método proposto para o transporte de grãos, estudado por CUNHA (2000) e NOVAES (1976); dados operacionais e custos de insumos obtidos em ONO (2001), DREWRY (1999), TOLOFARI (1951), TIAGO (2002) e CAMELLO (2002). Os custos portuários foram obtidos no relatório de acompanhamento de preços e desempenho operacional dos serviços portuários desenvolvido pelo GEIPOT (2000). Os itens que envolvem os custos portuários são: estiva das embarcações, conferência de cargas, remuneração dos trabalhadores que atuam nas instalações portuárias, aluguel de material de estiva, vistoria de lacres, taxas de administração da estiva, serviços de praticagem, rebocadores, taxas portuárias de atracação ou acostagem, defensas, amarradores, vigias e despacho.

Devido à dificuldade do levantamento do custo do transporte hidroviário de interior, praticado na Bacia Amazônica Oriental, adotaram-se como valores de custo de balsas hidroviárias o custo de um navio de navegação com capacidade de projeto de 800TEU e uma capacidade operacional de navegação, para o caso, de. 600TEU.

\subsubsection{Dimensionamento de frota de contêineres}

O método do dimensionamento dos contêineres segue conforme proposto por VALENTE et al. (1997).

$$
\begin{gathered}
N C=\frac{V_{m \hat{e} s}}{V V c a b_{m \hat{e} s}} \\
V_{m \hat{e} s}=\frac{Q_{i j}}{d_{i} \times C U C_{k}}
\end{gathered}
$$

onde,

$N C$ : Número de contêineres;

$V_{m e ̂ s}:$ Número de viagens mensais necessárias;

$V V c a b_{m e ̂ s}:$ Número de viagens mensais que a cabotagem realiza;

$Q_{i j}$ : Demanda de transporte entre $i$ e $j(\mathrm{t})$;

$d_{i}$ : Peso específico do produto, na origem i $\left(\mathrm{t} / \mathrm{m}^{3}\right)$;

$C U C_{k}$ : Capacidade de transporte de carga $\left(\mathrm{m}^{3}\right)$. 


\subsubsection{Custos operacionais da embarcação}

O custo operacional do navio é constituído pela soma de um custo marítimo diário $(C M D)$ e um custo portuário diário $(C P D)$ sendo a composição de ambos observados na eq.(3.40) e na eq. (3.41), respectivamente.

$$
\begin{gathered}
C M D=C C_{n}+C T+C M O_{n}+C M B+C M_{n}+C S+C C M+C L M+C R \\
C P D=C C_{n}+C T+C M O_{n}+C M B+C M_{n}+C S+C C P+C L P+C R
\end{gathered}
$$

onde,

$C C_{n}$ : Custo diário de capital;

CT: Custo diário da tripulação;

$C M O_{n}$ : Custo diário administrativo;

$C M B$ : Custo diário de material de bordo;

$C M_{n}$ : Custo diário de manutenção e reparo;

CS: Custo diário de seguro;

CCM: Custo diário de combustível no mar;

$C C P$ : Custo diário de combustível no porto;

CLM: Custo diário de lubrificante no mar;

CLP: Custo diário de lubrificante no porto;

CR: Custo diário de rastreamento.

- Custo diário de capital $\left(C C_{n}\right)$ :

$$
\begin{gathered}
C C_{n v}=D_{n v}+R C_{n v} \\
D_{n v}=\frac{V_{n v}-R_{n v}}{n} \\
R C_{n v}=\frac{\left(V_{n v}-R_{n v}\right) \times(n+1) \times j}{2 \times n}+\left(R_{n v} \times j\right)
\end{gathered}
$$

onde,

$D_{n v}$ : Depreciação do navio;

$R C_{n v}$ : Remuneração de capital investido; 
$V_{n v}$ : Custo de aquisição do navio;

$R_{n v}:$ Valor residual do navio em $\mathrm{n}$ anos de uso;

n: Vida útil do bem ou tempo de depreciação;

$j$ : Taxa de juros (\%aa).

- Custo diário da tripulação $(C T)$ :

Os custos diários com tripulação do navio foram obtidos em CUNHA (2000) e CAMELLO (2002). Considerou-se uma tripulação total de 17 funcionários, contendo os seguintes cargos: comandante, imediato, primeiro oficial, contramestre, marinheiro de convés, oficial de máquina, eletricista, marinheiro de máquina e cozinheiro. O custo total mensal adotado, incluindo encargos sociais, é de US\$15.576,15.

Soma-se também no custo diário da tripulação, os custos referentes a refeições da tripulação. Segundo CUNHA (2000), o valor adotado para a refeição por tripulante em um dia é de US\$6,00.

- Custo diário administrativo $\left(C M O_{n}\right)$ :

O custo de mão-de-obra administrativa encontrada é da hipótese adotada de uma estrutura administrativa com cinco filiais, um total de noventa funcionários e dois navios de 1400TEU. Os valores salariais adotados foram obtidos em CUNHA (2000) e adotou-se o acréscimo de 77,39\% de encargos sociais administrativos. O custo total mensal da estrutura é de US\$62.434,40, sendo repassada a metade do custo para cada navio.

- Custo diário de seguro $(C S)$ :

O custo anual do seguro adotado para o estudo do caso foi de $3 \%$ do valor do navio (CUNHA, 2000). 
- Custo diário de manutenção e reparo $\left(C M_{n}\right)$ :

$$
\begin{gathered}
C M_{n}=C d m+C d d \\
C d m=\frac{C a p r}{d o p} \\
C d d=\frac{C a d}{d o p} \\
d o p=365-h d
\end{gathered}
$$

onde,

Cdm: Custo diário de manutenção;

Cdd: Custo diário de docagem;

Capr: Custo anual de manutenção e reparo;

Cad: Custo anual de docagem;

dop: Dias de operação;

hd: Hire days (dias em estaleiro).

Os dias de manutenção (hire days) em estaleiro adotado neste modelo, segundo TOLOFARI (1951) são de 15 dias durante o ano.

- Custo diário de material de bordo $(C M B)$ :

As despesas com material de bordo, segundo LOFRANO (1985 apud CUNHA, 2000)² são bastante variáveis conforme o tipo de navio. Foi adotado um valor mensal de US $\$ 520,00$.

- Custo diário de combustível no mar $(C C M)$ :

Para o computo do custo diário do consumo de combustível durante a viagem da embarcação foi adotado o maior valor obtido entre os métodos propostos por NOVAES

\footnotetext{
${ }^{2}$ LOFRANO, C.S. (1985). Critérios para implantação de terminais marítimos especializados. Rio de Janeiro. Dissertação (Mestrado), UFRJ apud CUNHA, W.C. (2000),
} 
(1976) e DREWRY (1999), conforme observado na eq. (3.51) e na eq. (3.52), respectivamente.

$$
\begin{gathered}
C C M_{1}=24 \times \alpha_{c} \times\left(\frac{B H P}{1000}\right) \times P_{c} \\
C C M_{2}=C_{H F O} \times P_{H F O}
\end{gathered}
$$

para,

$$
C C M_{1} \leq C C M_{2} \Rightarrow C C M=C C M_{2}
$$

caso contrário,

$$
C C M_{2} \leq C C M_{1} \Rightarrow C C M=C C M_{1}
$$

onde,

$C C M_{1}$ : Consumo de combustível - método NOVAES (1976);

$C C M_{2}$ : Consumo de combustível - método DREWRY (1999);

$\alpha_{c}$ : Consumo específico de combustível;

BHP: Potência de serviço da máquina;

$P_{c}$ : Preço combustível - proporcional ao consumo de HFO (High Fuel Oil) e MDO (Maritime Oil);

$C_{H F O}$ : Consumo do $H F O$;

$P_{H F O}:$ Custo do $H F O$;

- Custo diário de combustível no porto $(C C P)$ :

O custo de combustível da embarcação atracada no porto é calculado através de índice proposto por NOVAES (1976). Sugere-se adotar que o custo de combustível representa $17,1 \%$ do custo de combustível da embarcação em trânsito.

- Custo diário de lubrificante no mar $(C L M)$ e custo diário de lubrificante no porto $(C L P)$ :

Igualmente ao custo de combustível consumido pelo navio atracado, NOVAES (1976) adota outro índice para o consumo de lubrificantes. Para o navio em trânsito e atracado são adotados $10 \%$ do custo do consumo de combustível, para o navio navegando ou 
atracado em algum terminal portuário. Esses índices são validados para navios em condições normais de manutenção, conservação e para o padrão tecnológico da Engenharia Naval proposto por NOVAES (1976).

- Custo diário de rastreamento $(C R)$ :

$$
C R=\frac{\left(\frac{V M}{12}\right)}{d o p}+\overline{C T_{d}}
$$

onde,

VM: Custo de aquisição do equipamento de monitoramento;

$\overline{C T}_{d}$ : Custo médio diário de comunicação.

\subsubsection{Custos operacionais dos contêineres}

Os custos diários dos contêineres refrigerados de 20' e 40' $\left(C D C_{k}\right)$ foram calculados através da eq. (3.54).

$$
C D C_{k}=C C_{k}+C R_{k}+C M O_{k}+C M_{k}
$$

onde,

$C C_{k}$ : Custo diário de capital para os $k$ contêineres;

$C R_{k}$ : Custo diário de refrigeração para os $k$ contêineres;

$C M O_{k}$ : Custo diário de mão-de-obra administrativa para os $k$ contêineres;

$C M_{k}$ : Custo diário de manutenção para os $k$ contêineres.

- Custo diário de capital $\left(C C_{k}\right)$ :

$$
\begin{gathered}
C C_{k}=D_{k}+R C_{k} \\
D_{k}=\frac{V_{k}-R_{k}}{n} \\
R C_{k}=\frac{\left(V_{k}-R_{k}\right) \times(n+1) \times j}{2 \times n}+\left(R_{k} \times j\right)
\end{gathered}
$$


onde,

$D_{k}$ : Depreciação dos $k$ contêineres $\left(k_{l}=20\right.$ ' e $k_{2}=40$ ');

$R C_{k}$ : Remuneração de capital investido nos $k$ contêineres;

$V_{k}$ : Custo de aquisição dos $k$ contêineres;

$R_{k}$ : Valor residual do contêiner $k$ em $\mathrm{n}$ anos de uso;

$N$ : Vida útil do bem ou tempo de depreciação;

$J$ : Taxa de juros (\%aa).

- Custo diário de refrigeração $\left(C R_{k}\right)$ :

$$
C R_{k}=\frac{P l c}{A m l_{k}}
$$

onde,

Plc: Custo do litro de combustível;

$A m l_{k}$ : Autonomia média do motor de refrigeração do contêiner $k$.

- Custo diário de mão-de-obra administrativa $\left(C M O_{k}\right)$ :

$$
C M O_{k}=\left(\frac{C m o}{30}\right) \times\left(1+\frac{E S}{100}\right)
$$

onde,

Cmo: Custo mensal da mão-de-obra administrativa.

- Custo diário de manutenção $\left(C M_{k}\right)$ :

$$
C M_{k}=\frac{C m a_{k}}{\operatorname{dop} \times 12}
$$

onde,

$C m a_{k}$ : Custo mensal de manutenção para o contêiner $k$. 


\subsubsection{Custos operacionais portuários}

Os custos portuários utilizados no modelo foram obtidos através do acompanhamento dos preços e desenvolvimento operacional dos serviços portuários realizado pelo GEIPOT (2000). Os principais custos envolvidos relacionados são: a estiva das embarcações, as conferências de cargas, a remuneração dos trabalhadores portuários, o aluguel de material de estiva, as taxas da vistoria de lacres, as taxas administrativas, os serviços de praticagem e de rebocadores, as taxas portuárias de atracação, as defensas, a segurança, o despacho e a tradução de manifestos.

Os custos fornecidos pelo GEIPOT (2000) são correspondentes a unidades de contêineres cheios e vazios para os padrões de 20' e 40'. O tempo médio de permanência de contêineres nos portos neste modelo foi adotado conforme os dados de tempo médio de atracação de navios nos portos, sugerido por ONO (2001). Para os portos que não apresentavam tempo de estadia dos navios adotou-se o valor médio de um dia de permanência. Assim, esse modelo não leva em consideração tempos e custos monetários de armazenagem de contêineres cheios, em terminais na área retroportuária, no processo de transbordo do modo rodoviário para o hidroviário. Os portos escolhidos e os respectivos custos estão relacionados na Tabela 3.3.

Tabela 3.3: Resumo dos custos portuários dos portos e terminais escolhidos

\begin{tabular}{|c|c|c|c|c|c|c|}
\hline Porto & Terminal & $\begin{array}{c}\text { Tempo médio do } \\
\text { contêiner no porto }(h)^{1}\end{array}$ & $\begin{array}{c}\text { Manuseio de carga } \\
(\text { US } \$ / \text { teu })^{2}\end{array}$ & $\begin{array}{c}\text { Tarifas portuárias } \\
{\text { (US } \$ / \text { teu })^{2}}^{2}\end{array}$ & $\begin{array}{c}\text { Entrada e saída de navios } \\
\text { (US } \$ / \text { teu })^{2}\end{array}$ & $\begin{array}{c}\text { Total } \\
\text { (US\$/teu) }\end{array}$ \\
\hline $\begin{array}{l}\text { Manaus } \\
\end{array}$ & - & 36 & 88,98 & 31,91 & 28,45 & 1499,33 \\
\hline Belém & - & 24 & 88,98 & 31,91 & 28,45 & 149,33 \\
\hline Fortaleza & - & 20 & 112,01 & 23,90 & 47,11 & 183,02 \\
\hline Recife & - & 24 & 84,62 & 24,18 & 28,98 & 137,78 \\
\hline Suape & - & 30 & 98,85 & 10,15 & 47,57 & 156,57 \\
\hline \multirow[t]{2}{*}{ Vitória } & Peiú & 24 & 153,51 & 18,76 & 98,36 & 270,63 \\
\hline & $\mathrm{TPD}^{3}$ & 24 & 172,40 & - & 80,87 & 253,27 \\
\hline \multirow{2}{*}{ Rio de Janeiro } & TECON 1 LIBRA & 24 & 118,00 & 23,06 & 23,71 & 164,77 \\
\hline & TECON 2 Multi-terminais & 24 & 128,09 & 18,20 & 33,87 & 180,16 \\
\hline \multirow{2}{*}{ Santos } & TECON SANTOS BRASIL & 18 & 143,76 & 21,67 & 27,41 & 192,83 \\
\hline & MARGEM DIREITA & 18 & 127,39 & 40,32 & 27,45 & 195,16 \\
\hline Rio Grande & TECON & 22 & 146,50 & 9,92 & 30,01 & 186,43 \\
\hline
\end{tabular}


O custo de transbordo para o porto $i\left(C T R S_{i}\right)$ compreende a soma dos custos observados em GEIPOT (2000), o custo portuário diário e os custos operacionais dos contêineres, para um período médio de estadia do navio por porto $\left(T M P_{i}\right)$, conforme a eq. (3.61).

$$
C T R S_{i}=C P R_{\text {Geipot }}+\left[\left(\sum C D C_{k}+C P D\right) \times T M P_{i}\right]
$$

O custo da escala de uma viagem $i\left(C E P_{i}\right)$ nos portos $j$ intermediários, em uma rota, é determinado pela eq. (3.62).

$$
C E P_{i}=C P D \times \sum T M P_{j}
$$

\subsection{Formulação do modelo no SIG-T}

Esta fase do modelo compreende a inserção da formulação dos custos médios desagregados, obtidos em planilha eletrônica, nas funções de comando de análise de rede e análise de rotas observadas em CALIPER (1996a, 1996b). Também são inseridos os custos pontuais de pedágios e transbordos, conforme método de penalidade da rede, descrita em CALIPER (1996b).

\subsubsection{Custos pontuais: pedágios, transbordos e escalas}

Segundo CALIPER (1996b), os custos na transferência de modo de transporte em uma rede ou um custo geograficamente pontual, exemplificado pela tarifa de um pedágio, são computados através da penalidade atribuída a rede [Network/Path $\rightarrow$ Settings $\rightarrow$ Turn Penalties]. Esta penalidade de rede é determinada por um arquivo ( $d b f$ ) onde estão contidos o número de identificação do arco (ID) de montante (From) e o ID do arco de jusante (To) ao nó vinculado aos pontos de representação dos terminais ou das praças de pedágio. $\mathrm{O}$ custo da penalidade encontra-se no campo Penalty, aonde são atribuídos os valores dos pedágios, transbordos e gastos com escalas. Para cada cenário proposto criase um arquivo de penalidade específico. Nos cenários rodoviários, no regime de entrega porta-a-porta, os arquivos de penalidades representam as tarifas de pedágios para os veículos $2 \mathrm{~S} 3$ e $3 \mathrm{~S} 3 \mathrm{~B} 3$, respectivamente. No cenário rodo-hidroviário o arquivo de 
penalidade contém as tarifas de pedágios para o veículo 3S3B3, o custo de transbordo para o porto $i\left(C T R S_{i}\right)$ e o custo da escala da viagem $i\left(C E P_{i}\right)$.

\subsubsection{Custos de arcos: arcos rodoviários e hidroviários}

Depois de configurada a base geográfica do conjunto de arcos que representam as rodovias e as hidrovias, criou-se novos campos no Dataview com a finalidade do preenchimento do custo de transporte para os três tipos de tecnologias de transporte envolvidas nesta pesquisa: os veículos rodoviários 2S3, 3S3B3 e o navio porta contêiner 1400TEU. Selecionando os arcos rodoviários e hidroviários através do comando [Dataview $\rightarrow$ Select by Condition] os novos campos de custos foram preenchidos através da seguinte formulação:

- Custo rodoviário 2S3 baú frigorífico para arcos rodoviários

Comando de seleção:

$[$ Dataview $\rightarrow$ Select by Condition $\rightarrow$ Enter Condition $\rightarrow$ Transporte $=$ "RODOVIARIO" | Modo = "RODOVIARIO"]

Campo do Dataview: C_SR26P[US\$]

$$
C_{-} S R 26 P[U S \$]=C O Q_{S R 26} \times\left[D I S T_{-} \text {MODELO }[K M]\right.
$$

onde,

DIST_MODELO[KM]: Distância teórica do programa (Km).

- Custo rodoviário 2S3 baú frigorífico para arcos hidroviários

Comando de seleção:

$[$ Dataview $\rightarrow$ Select by Condition $\rightarrow$ Enter Condition $\rightarrow$ Transporte $=" C A B O /$ RODO" | Modo = "HIDROVIARIO"]

Campo do Dataview: C_SR26P[US\$] 


$$
\begin{aligned}
& C_{-} S R 26 P[U S \$]=\left(C M D_{800 T E U} \times T E M P O A R C 800[\text { dias }] \div T L O C_{800}\right) \times 2
\end{aligned}
$$

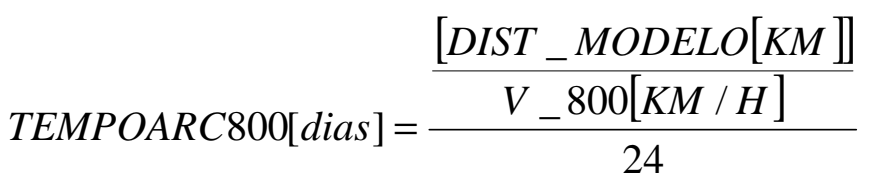

onde,

TEMPOARC800[dias]: Tempo no arco i para um navio de 800TEU (dias);

$T_{L O C}$ : Tonelagem líquida operacional de carga (TEU);

V_800[KM/H]: Velocidade operacional de um navio de 800TEU.

- Custo rodoviário 3S3B3 porta-contêiner para arcos rodoviários

Comando de seleção:

$[$ Dataview $\rightarrow$ Select by Condition $\rightarrow$ Enter Condition $\rightarrow$ Transporte $=$ "RODOVIARIO"

| Modo = "RODOVIARIO"]

Campo do Dataview: NV1400_BTPC[US\$]

$$
C_{-} B T P C[U S \$]=C O Q_{B T P C} \times[D I S T+M O D E L O[K M]
$$

- Custo hidroviário 1400TEU para arcos hidroviários

Comando de seleção:

$[$ Dataview $\rightarrow$ Select by Condition $\rightarrow$ Enter Condition $\rightarrow$ Transporte $=" C A B O /$ RODO"| Modo = "HIDROVIARIO"]

Campo do Dataview: NV1400_BTPC[US\$]

$$
\begin{aligned}
& N V 1400 \_B T P C[U S \$]=C \_20 P E S \_1400+C \_40 P E S \_1400+ \\
& +\left(\left(\left(\text { CMD }_{1400} \times T E M P O A R C 1400[\text { dias }]\right) \div \text { TLOC }_{1400}\right) \times 3\right) \\
& \text { C_ } 20 P E S_{-} 1400=C D C_{20 "} \times T E M P O A R C 1400[\text { dias }] \\
& C_{-} 40 P E S_{-} 1400=C D C_{40 "} \times T E M P O A R C 1400[\text { dias }] \\
& \text { TEMPOARC } 1400[\text { dias }]=\frac{\frac{\left[D I S T_{-} M O D E L O\right.}{V_{-} 1400[K M / H]}}{24}
\end{aligned}
$$

onde, 
C_20PES_1400: Custo no arco i para um contêiner de 20";

C_40PES_1400: Custo no arco i para um contêiner de 40";

TEMPOARC1400[dias]: Tempo no arco i para um navio de 1400TEU (dias);

$T L O C_{1400}:$ Tonelagem líquida operacional de carga (TEU);

$V_{-} 1400[\mathrm{KM} / \mathrm{H}]:$ Velocidade operacional de um navio de 1400TEU.

- Custo rodoviário 3S3B3 baú frigorífico para arcos rodoviários

Comando de seleção:

$[$ Dataview $\rightarrow$ Select by Condition $\rightarrow$ Enter Condition $\rightarrow$ Transporte $=$ "RODOVIARIO" | Modo = "RODOVIARIO"]

Campo do Dataview: $C \_B T B F[U S \$]$

$$
C_{-} B T B F[U S \$]=C O Q_{B T B F} \times\left[D I S T \_M O D E L O[K M]\right.
$$

- Custo rodoviário 3S3B3 baú frigorífico para arcos hidroviários

Comando de seleção:

$[$ Dataview $\rightarrow$ Select by Condition $\rightarrow$ Enter Condition $\rightarrow$ Transporte $=" C A B O /$ RODO" | Modo = "HIDROVIARIO"]

Campo do Dataview: C_BTBF[US\$]

$C_{-}$BTBF $[U S \$]=\left(C M D_{800 T E U} \times T E M P O A R C 800[\right.$ dias $\left.] \div T L O C_{800}\right) \times 3$

As células restantes nos campos C_SR26P[US\$], NV1400_BTPC[US\$] e C_BTBF[US\$] foram extrapoladas com o objetivo de evitar a passagem do fluxo no momento da geração das rotas. Se essa extrapolação não fosse realizada a célula apresentaria um custo zero e o modelo sempre escolheria o ramo de custo zero como solução ótima no grafo. Exemplificando, ter-se-ia um veículo rodoviário 3S3B3 baú frigorífico trafegando em um arco de cabotagem. 


\subsubsection{Análise de rede}

A análise dos cenários de transportes é realizada através do conjunto de comandos de roterização de arcos (Arc Routing) e de análise em rede (Network Analysis), descritos em CALIPER (1996a) e CALIPER (1996b). Geram-se arquivos de rotas (Route System) apresentando os respectivos campos: CUSTO VIAGEM; TEMPO VIAGEM; CUSTO POR T; e CUSTO POR KM. Esses campos foram preenchidos através do comando [Dataview $\rightarrow$ Join] dos arquivos de rotas de caminhos mínimos [Network/Paths $\rightarrow$ Multiple Paths $\rightarrow$ Store Result: Route System], conforme Figura 3.3, minimizando os campos do custo C_SR26P[US\$], NV1400_BTPC[US\$] e C_BTBF[US\$]. Outra ferramenta utilizada foi a geração de mapas temáticos com curvas de isocusto em relação a cada origem da viagem através do comando [Network/Paths $\rightarrow$ Network Bands].

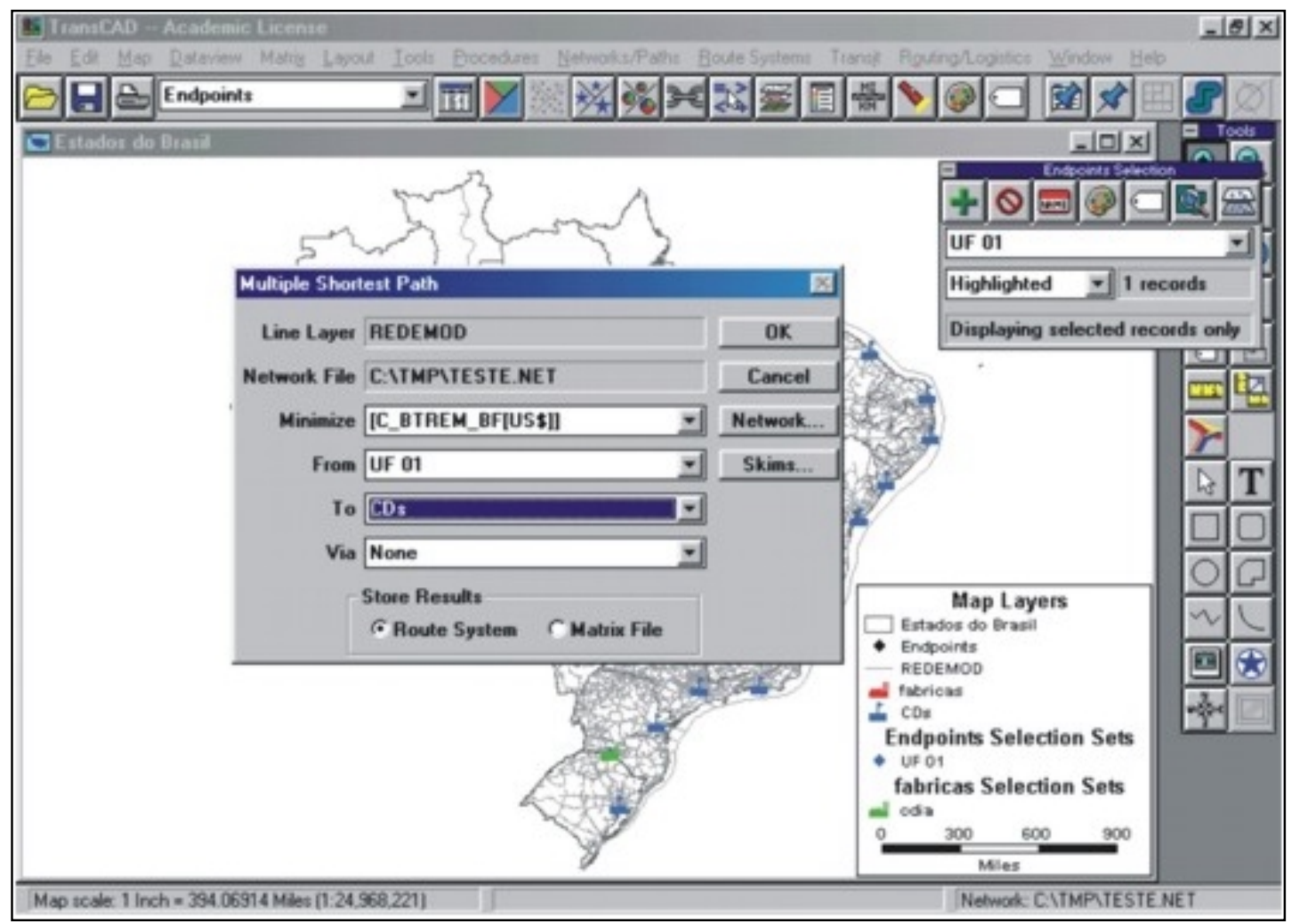

Figura 3.3: Geração de solução ótima de mínimo custo 


\subsection{Aspectos restritivos do modelo proposto}

O modelo proposto caracteriza-se por ser um modelo teórico para a escolha do modo de transporte mais econômico. Assim este modelo leva em consideração os seguintes fatores:

- Infra-estrutura rodoviária compatível com a tecnologia rodoviária proposta:

Considera-se neste modelo que toda a rede cadastrada na base geográfica é compatível com o tráfego do veículo 3S3B3 bitrem porta contêiner e baú frigorífico. Assim toda a infra-estrutura rodoviária brasileira dessa base encontra-se técnicamente compatível aos fatores técnicos estudados por FERNANDES JR. (1994), DEMARCHI (1995), RUSSO (1995), DER-SP (2001a) e a adaptação da legislação descrita em BRASIL (1999a).

- Infra-estrutura portuária e industrial

Também são considerados que os terminais portuários, as unidades fabris e os centros de distribuição são compatíveis na infra-estrutura operacional para os veículos 3S3B3. Os principais itens são: área de manobra, balança de controle de carga para os veículos, piso estruturalmente dimensionado, portões, docas, profundidade do canal de atracação dos navios e demais condições operacionais.

- Aspectos operacionais adotados

O regime de transporte hidroviário apresenta o início do ciclo com o transporte do contêiner vazio no porto de origem e o término do ciclo na entrega do contêiner vazio no porto de destino da viagem. Os tempos de ciclo considerados são até a entrega do contêiner cheio ao centro de distribuição analisado. Ou seja, considera-se apenas a viagem de ida. 
Não são considerados custos com armazenagem de contêineres cheios em terminais retroportuários. Somente são adotados os custos com tempo médio de permanência das embarcações, conforme descrito em 3.3.4.

A freqüência de navios porta-contêineres adotado neste trabalho é de um navio a cada quinze dias. 


\section{ESTUDO DE CASO}

No estudo de caso desta pesquisa escolheu-se uma indústria do ramo agroindustrial de produção, manufatura e comercialização de proteína animal devido ao acesso às informações e séries históricas necessárias para a comparação de custos entre tecnologias de transporte. Os bens manufaturados são formados pelas seguintes categorias: industrializados, suínos e aves. Os industrializados englobam produtos onde as carnes de suínos, aves e bovinos, e a soja são insumos do produto acabado. As categorias de aves e suínos englobam somente os cortes de carnes. Dentro dessas categorias os produtos apresentam a seguinte natureza: congelados, resfriados, secos e hidrogenados. Toda a linha de produtos industrializados, aves e suínos totalizam 666 produtos (MENEGAT, 2001b), sendo os produtos adotados nesta pesquisa limitados somente aos congelados e resfriados. Os principais produtos são os seguintes:

- Industrializados congelados e resfriados: almôndegas de frango, hambúrgueres de frango, kibes, lingüiças, salsichas, salames, presuntos, lasanhas, pratos congelados, pizzas, entre outros;

- Aves congeladas e resfriadas: cortes de peito, cortes de coxa, cortes de asa, cortes de sobre-coxa, entre outros;

- Suínos congelados e resfriados: cortes de lombo, cortes de pernil, entre outros;

- Secos: pele suína salgada, salames, salsichas, massas, entre outros;

- Hidrogenados: margarinas.

A Tabela 4.1 e a Tabela 4.2 mostram o perfil organizacional da estrutura e o fechamento anual de vendas da indústria para o ano de 1999. 
Tabela 4.1: Resumo do perfil organizacional

\begin{tabular}{lr}
\hline \multicolumn{2}{c}{ Estrutura operacional - 1999 } \\
\hline \hline Unidades Industriais & 11 \\
Produtores Integrados de Aves & 4250 \\
Produtores Integrados de Suínos & 4890 \\
Centros de distribuição no Brasil & 18 \\
Filial de vendas no exterior & 7 \\
Clientes no Brasil & 60000 \\
Clientes no Exterior (países) & 50 \\
\hline Fonte: AGROINDÚSTRIA (1999)
\end{tabular}

Tabela 4.2: Fechamento anual - 1999

\begin{tabular}{lcc}
\hline \multicolumn{3}{c}{ Mercado interno } \\
\hline \hline \multirow{2}{*}{ Categoria } & Venda valor Venda física \\
& $\mathrm{R} \$$ milhões & mil toneladas \\
Industrializado & 1373,5 & 391,3 \\
Suínos & 95,6 & 64,8 \\
Aves & 519,6 & 315,1 \\
\hline
\end{tabular}

Fonte: AGROINDÚSTRIA (1999)

\subsection{Estrutura operacional analisada}

O problema estruturado nesta análise é a movimentação de cargas frigoríficas entre as unidades industriais e os centros de distribuição. As principais fábricas estão localizadas na região sul e os centros de distribuição implantados próximos aos grandes centros consumidores, conforme mostrado na Figura 4.1.

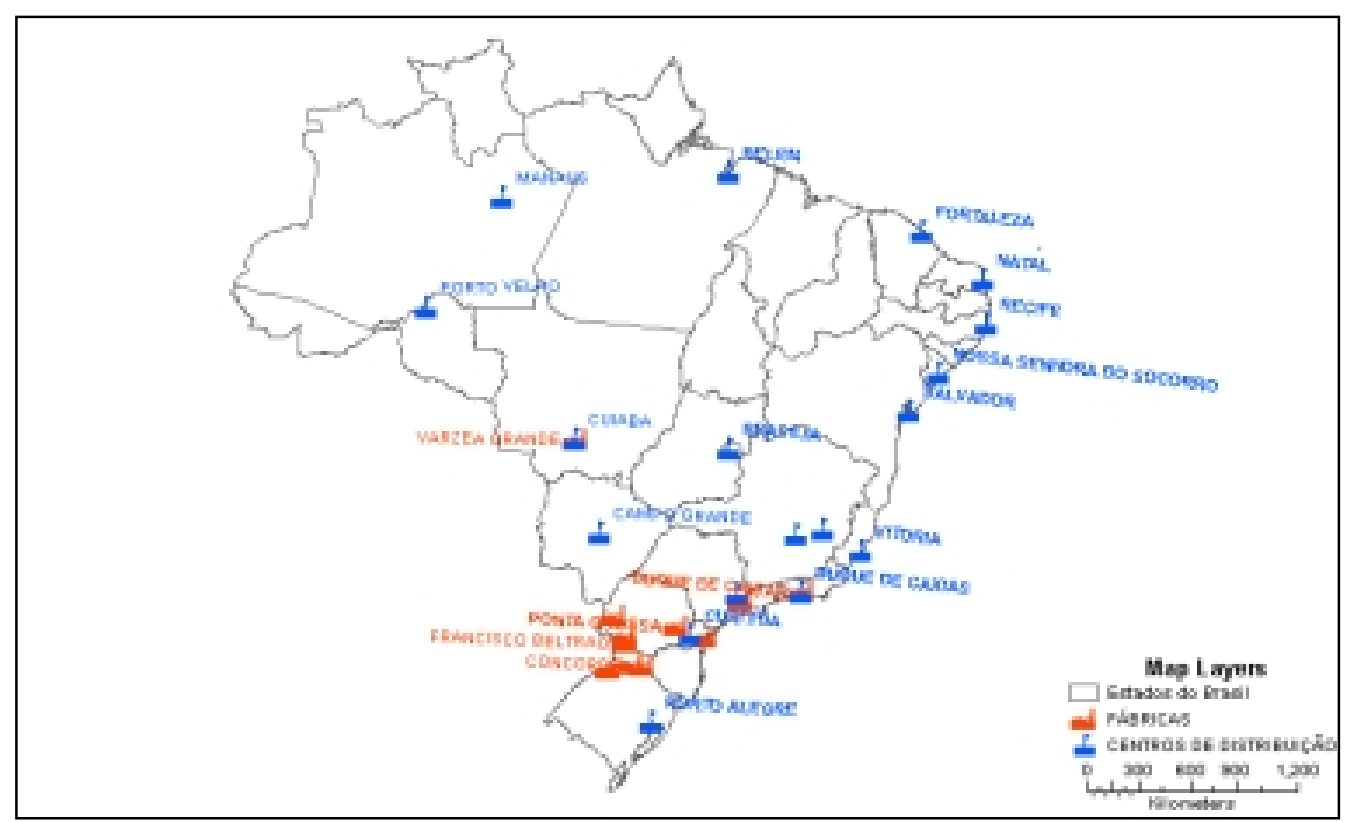

Figura 4.1: Distribuição geográfica da estrutura 
Segundo MENEGAT (2000), o montante médio de carga produzida, movimentada e armazenada entre as indústrias e os centros de distribuição, para o ano de 2000, foi de aproximadamente 56,1 mil toneladas por mês. As plantas industriais de maior expressão na produção são as fábricas de Concórdia, Chapecó, Toledo e Paranaguá, apresentando uma média mensal de carga expedida de 9 mil toneladas por mês. Os centros de distribuição de maior concentração de cargas são os armazéns de Jundiaí, Duque de Caxias e Belo Horizonte, contabilizando um volume médio aproximado de 12,2 mil toneladas por mês. Além destes valores, MENEGAT (2000) forneceu a matriz de O/D de expedição de cargas frigoríficas conforme observado no Apêndice B. Os pesos específicos médio dos produtos frigoríficos, unitizados em paletes padrão $\mathrm{PBR}$ e não unitizados, são aproximadamente $384 \mathrm{~kg} / \mathrm{m}^{3}\left(s=88 \mathrm{~kg} / \mathrm{m}^{3}\right)$ e $341 \mathrm{~kg} / \mathrm{m}^{3}\left(s=90 \mathrm{~kg} / \mathrm{m}^{3}\right)$, respectivamente. O comportamento dos pesos específicos médios dos produtos, por fábrica, é observado na Tabela 4.3.

Tabela 4.3: Peso específico por planta fabril

\begin{tabular}{lcc}
\hline \multicolumn{1}{c}{ Planta Fabril } & Não paletizada $\left(\mathrm{kg} / \mathrm{m}^{3}\right)$ & Paletizada $\left(\mathrm{kg} / \mathrm{m}^{3}\right)$ \\
\hline \hline Chapecó & 339,46 & 389,73 \\
Concórdia & 361,11 & 411,17 \\
Dois Vizinhos & 365,31 & 412,40 \\
Duque de Caxias & 431,92 & 476,56 \\
Francisco Beltrão & 445,58 & 487,33 \\
Paranaguá & 292,61 & 355,12 \\
Ponta Grossa & 138,47 & 176,12 \\
Toledo & 306,09 & 348,64 \\
Três Passos & 454,03 & 468,06 \\
São Paulo & 283,84 & 321,74 \\
Varzea Grande & 330,62 & 375,64 \\
\hline
\end{tabular}

\subsection{Cenário 1: Rodoviário 2S3}

O primeiro cenário de transporte analisado neste trabalho quantifica e dimensiona a frota para o tipo de tecnologia empregada atualmente, nas transferências entre as fábricas e os centros de distribuição ou nas entregas diretas aos compradores de grandes volumes, como por exemplo, grandes varejistas ou distribuidores autorizados. Os serviços de transporte atualmente são realizados pelo modo rodoviário, através do regime de entrega porta a porta, utilizando-se carretas equipadas com sistema de refrigeração, acoplado em implementos rodoviários com carroceria isotérmica. 
A otimização do serviço de transporte de carga necessita um conjunto de transferências de informações e documentos fiscais, entre quem oferece transporte e quem demanda a movimentação de carga. Esta otimização tem como objetivo a diminuição do tempo no processamento dos transbordos entre terminais e os veículos de carga. Na Figura 4.2 é observado o fluxo básico do processo da realização de uma viagem por um veículo rodoviário. Neste fluxograma são observados os principais documentos fiscais necessários para a liberação de um veículo para uma viagem: a Nota Fiscal do produto e o Conhecimento de Transporte Rodoviário de Carga (CTRC). Além da identificação dos processos de informação e dos processos físicos são observados os itens a terem os respectivos custos computados no modelo proposto.

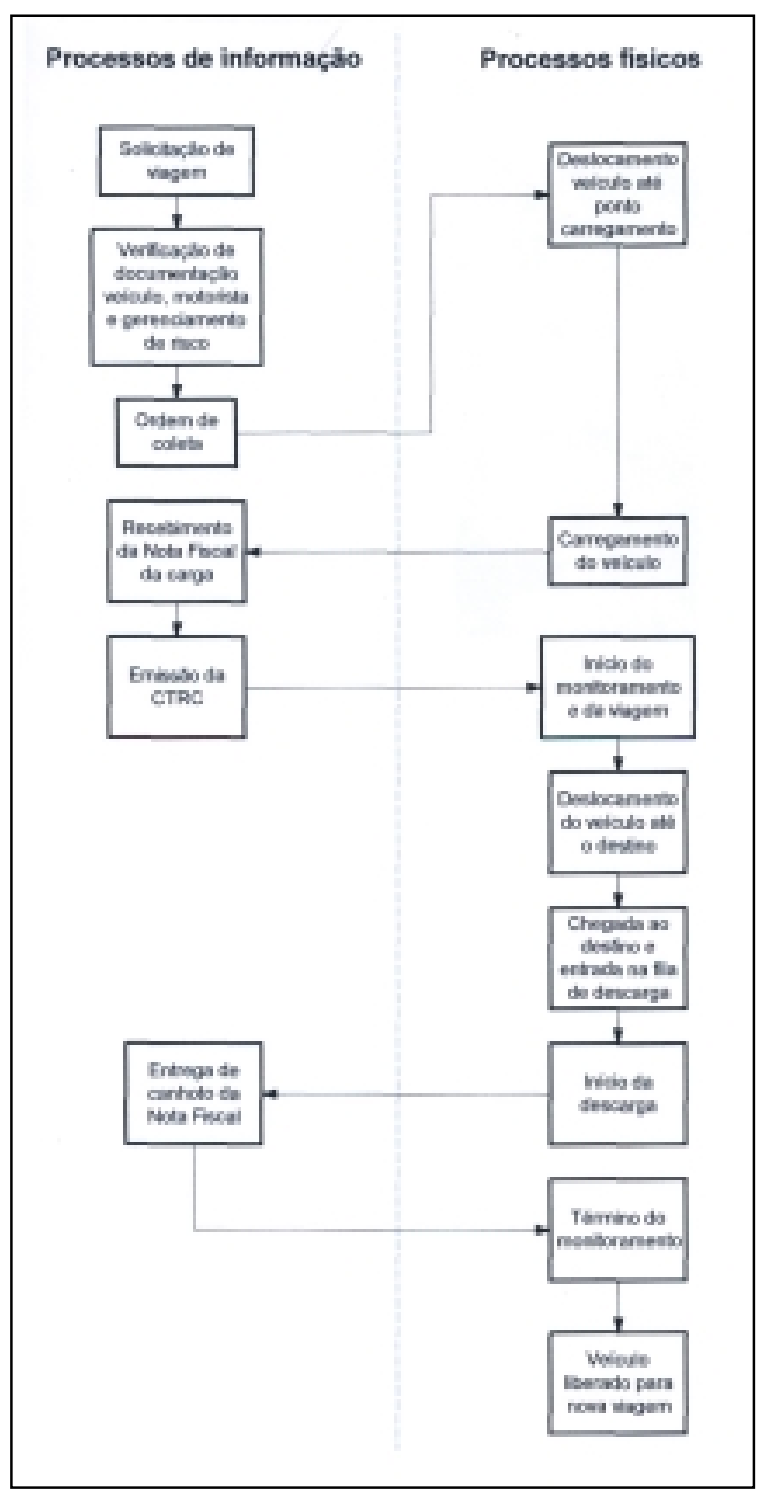

Figura 4.2: Fluxograma para viagem rodoviária - porta a porta 
Neste cenário são computados então os custos de viagem de ida, sem os pedágios, e dimensionada a frota necessária para atender a demanda descrita na matriz O/D observada no Apêndice B, para o veículo padrão proposto. Para a composição do custo do cenário 1 foi escolhido um cavalo mecânico modelo Volvo FH 12 L2H1 com potência nominal do motor de $380 \mathrm{cv}$ e tração $4 \times 2$. O implemento em análise é um baú frigorífico Recrusul com 3 eixos e capacidade de 26 paletes padrão PBR. Os custos de aquisição e as principais informações técnicas do cavalo e do implemento são observados na Tabela 4.4 e na Tabela 4.5.

Tabela 4.4: Semi-reboque frigorífico

\begin{tabular}{lc}
\hline \multicolumn{2}{c}{ Semi-reboque Recrusul frigorífico 26 paletes } \\
\hline \hline Preço do implemento novo, com pneus: & US\$ 46.928,16 \\
Peso bruto: & $9600 \mathrm{~kg}$ \\
Número de pneumáticos: & $12 \mathrm{un}$. \\
Número de motores do sistema de refrigeração: & $1 \mathrm{un}$. \\
Consumo médio de um motor de refrigeração (Recrusul TD-06): & $5 \mathrm{l} / \mathrm{h}$ \\
Custo de manutenção (balancins, lub. eixos freios, troca lonas): & US $\$ 58,66$ \\
Custo de manutenção do equipamento de refrigeração (motor): & US\$195,53/ano \\
Custo de manutenção do equipamento de refrigeração (baú): & US $\$ 156,42 / a n o$ \\
Comprimento interno baú: & $13,25 \mathrm{~m}$ \\
Largura interna baú: & $2,46 \mathrm{~m}$ \\
Altura interna baú: & $2,40 \mathrm{~m}$ \\
Capacidade volumétrica do baú: & $78,23 \mathrm{~m}^{3}$ \\
\hline Fonte:
\end{tabular}

Tabela 4.5: Cavalo mecânico 4x2

\begin{tabular}{lc}
\hline \multicolumn{2}{c}{ Volvo FH 12 L2H1 380cv, 4x2 } \\
\hline \hline Preço do chassi novo, com pneus: & US\$ 58.073,59 \\
Peso bruto: & $6.828 \mathrm{~kg}$ \\
Número de pneumáticos do eixo dianteiro: & $2 \mathrm{un}$. \\
Número de pneumáticos do eixo traseiro: & $4 \mathrm{un}$. \\
Autonomia média: & $1,5 \mathrm{Km} / \mathrm{l}$ \\
Capacidade para: & 14 I \\
Caixa de mudanças: & 31 I \\
Eixo traseiro: & 4,5 I \\
Sistema de direção: & 36 I \\
Motor: & 3 I \\
Motor - Complementação: & 9 I \\
Fluído para radiador (20 - 50\% volume radiador): & 6 I \\
Diferencial & \\
Intervalos de troca para: & $30.000 \mathrm{Km}$ \\
Caixa de mudanças: & $100.000 \mathrm{Km}$ \\
Eixo traseiro: & $100.000 \mathrm{Km}$ \\
Sistema de direção: & $15.000 \mathrm{Km}$ \\
Motor: & $5.000 \mathrm{Km}$ \\
Motor - Complementação: & $30.000 \mathrm{Km}$ \\
Fluído para radiador: & $60.000 \mathrm{Km}$ \\
\hline Óleo diferencial: &
\end{tabular}

Nos processos de coleta, nas fábricas, e de entrega, nos centros de distribuição, adotouse um tempo médio de 180 minutos, compreendendo assim os serviços de carga e 
descarga do veículo, a emissão de manifesto ou conhecimentos de carga e a liberação de veículo para viagem. Considera-se que o índice de aproveitamento da capacidade de carga do veículo seja de $100 \%$, isto é, o peso de carga transportada é igual ao peso útil máximo do conjunto. Aplicando assim a Lei da Balança e adotando o peso específico médio do produto, apresenta-se uma capacidade líquida de transporte de 25t.

O período de operação útil do veículo, sendo descontado o período de manutenção do conjunto, compreende 22 dias de operação no mês e 17 horas de trabalho diários, considerando-se dois motoristas em escala de turno.

Os demais itens adotados na planilha de custos estão descritos na Tabela 4.6.

Tabela 4.6: Dados de entrada da planilha de custo $2 \mathrm{S3}$

\begin{tabular}{|c|c|}
\hline \multicolumn{2}{|l|}{ Dados gerais } \\
\hline Período pretendido de uso do chassi e do equipamento: & $\overline{5 \text { anos }}$ \\
\hline Período pretendido de uso do equipamento: & 5 anos \\
\hline Taxa anual de juros: & $12 \%$ \\
\hline Salário mensal médio do motorista: & US\$ $\$ 400,00$ \\
\hline Encargos sociais: & $77,39 \%$ \\
\hline Horas uteis trabalhadas por dia: & $8 \mathrm{~h} / \mathrm{dia}$ \\
\hline Horas extras trabalhadas por dia: & $0,5 \mathrm{~h} / \mathrm{dia}$ \\
\hline Custo aquisição do sistema monitoramento veículos: & US $\$ 1.500,00$ \\
\hline Custo médio transmissão sitema monitoramento: & US\$ 50,84 /mês \\
\hline Perda de caminhão por ano: & 7 un. \\
\hline Período de utilização do veículo: & 12 meses \\
\hline Custo de uma apólice para frota média padrão: & US\$ 8.994,56 /ano \\
\hline Seguro obrigatório do chassi: & US\$21,67 \\
\hline IPVA: & US\$1.161,47 \\
\hline Custo de uma lavagem: & US $\$ 31,28$ \\
\hline Custo da recauchutagem: & US\$ 70,39 \\
\hline Pneumático eixo dianteiro 295/80R22,5 (Sem câmara): & US\$240,51 \\
\hline Pneumático demais eixos Z35A (Borrachudo - Sem câmara): & US\$263,97 \\
\hline Custo combustível: & US\$ $0,34 / 1$ \\
\hline \multicolumn{2}{|l|}{ Custo do óleo para: } \\
\hline Caixa de mudanças: & US $\$ 1,15 / 1$ \\
\hline Eixo traseiro, caixa de transferência: & US\$2,74/I \\
\hline Sistema de direção: & US\$2,93/I \\
\hline Motor: & US\$1,56/l \\
\hline Radiador: & US\$ $\$, 28 / 1$ \\
\hline Óleo para diferencial: & US\$1,68/l \\
\hline Vida média do pneumático novo - cavalo mecânico: & $130.000 \mathrm{Km}$ \\
\hline Vida média do pneumático recauchutado - cavalo mecânico: & $130.000 \mathrm{Km}$ \\
\hline Vida média do pneumático novo - implemento: & $85.000 \mathrm{Km}$ \\
\hline Vida média do pneumático recauchutado - implemento: & $45.000 \mathrm{Km}$ \\
\hline Intervalos para lavagem: & $2.000 \mathrm{Km}$ \\
\hline Intervalo para lubrificação e manutenção: & $4.000 \mathrm{Km}$ \\
\hline Intervalo para manutenção do sistema de refrigeração: & $30.000 \mathrm{Km}$ \\
\hline Funcionamento do sistema de refrigeração: & $24 \mathrm{~h}$ \\
\hline Autonomia do sistema de refrigeração (1 motor): & $6,6 \mathrm{~km} / \mathrm{l}$ \\
\hline Valor de revenda do cavalo-mecânico com 5 anos de uso: & US\$26.133,12 \\
\hline Valor de revenda do implemento com 5 anos de uso: & US\$ $18.097,84$ \\
\hline
\end{tabular}


As velocidades operacionais do veículo rodoviário adotado neste modelo, no carregamento dos arcos, foram de 50 e $70 \mathrm{~km} / \mathrm{h}$ para rodovias de pista simples e rodovias de pista dupla, respectivamente.

No modelo sugerido por VALENTE et al. (1997) são utilizados índices de desempenho utilizados pelo gestor de frota através de amostragem estatística. Como o trabalho é um cenário hipotético foram adotados os próprios índices aplicados por VALENTE et al. (1997). Os índices são os seguintes: $20 \%$ é a relação histórica entre custos indiretos e custos diretos; 2,3 como o índice médio de recauchutagens de pneumáticos; e 0,01 o índice de manutenção para baú e cavalo mecânico.

\subsection{Cenário 2: Rodo-hidroviário 3S3B3}

$\mathrm{Na}$ análise do cenário rodo-hidroviário, esta pesquisa estuda os custos envolvidos na utilização de uma nova tecnologia rodoviária para o transporte de contêineres: o bitrem. As atuais tecnologias de transporte rodoviário de contêineres utilizados pelo mercado são veículos do tipo $2 \mathrm{~S} 3$ e $3 \mathrm{~S} 3$ equipados com implemento porta contêiner, operacionalmente conhecidos como "prancha porta-contêiner". Os custos dos semireboques porta contêineres vigentes no mercado foram amplamente estudados no modelo de localização de terminais, conforme visto em TIAGO (2002).

Neste cenário são dimensionados a quantidade necessária de contêineres e o custo da viagem de ida para um conjunto de contêineres de 20 e 40 pés, através das informações contidas na matriz O/D do Apêndice B. Todavia os pontos de origem e destino encontram-se geograficamente separados das áreas portuárias, sendo necessária a utilização do transporte rodoviário, através do veículo 3S3B3, para a movimentação dos contêineres vazios e carregados. Assim, além do dimensionamento dos contêineres é dimensionada a frota de combinações de veículos de carga necessária para atender a demanda, encontrada nos extremos (origem e destino) da viagem hidroviária.

O fluxo dos processos de informação e dos processos físicos utilizados no transporte intermodal rodo-hidroviário é observado na Figura 4.3. 


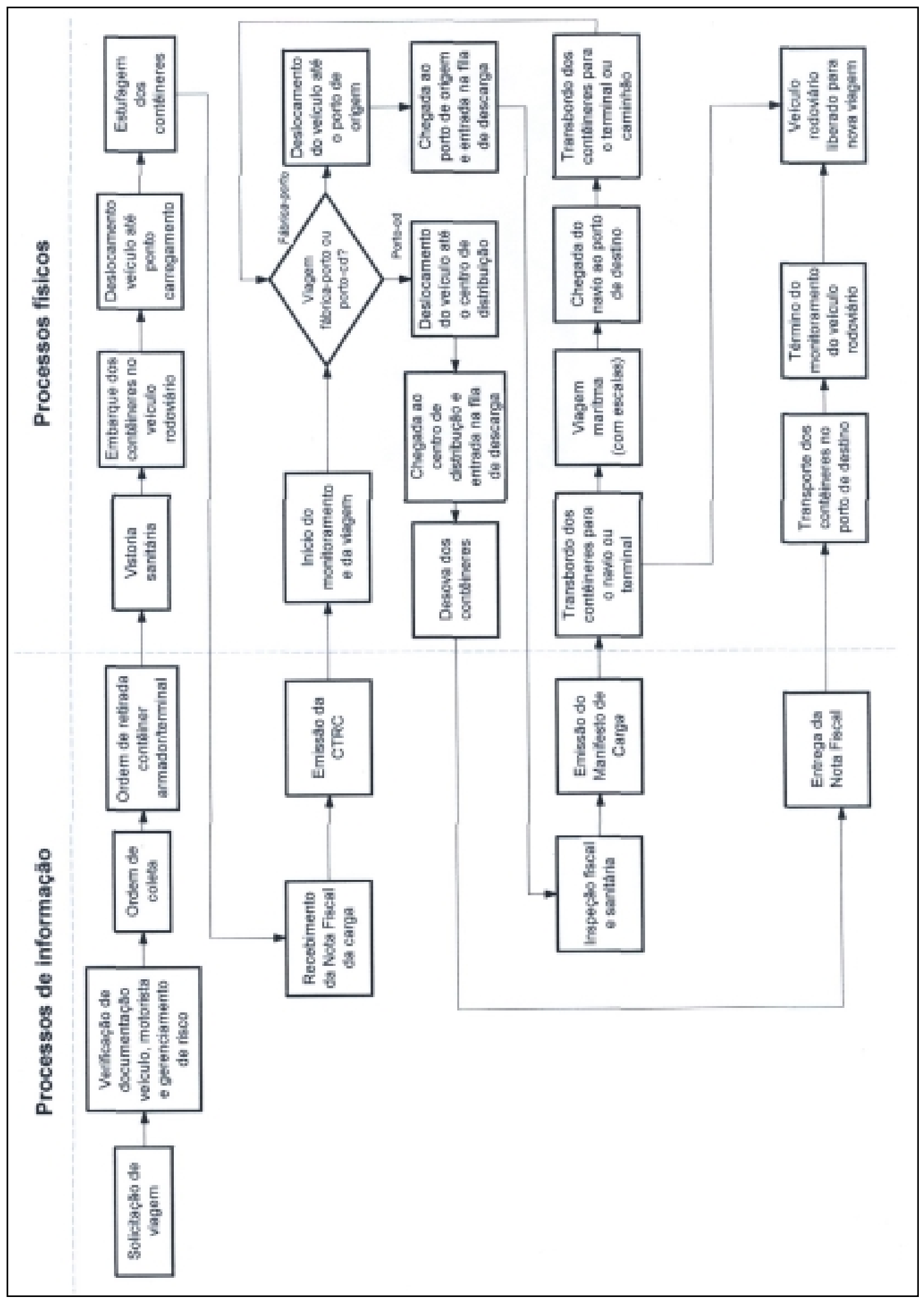

Figura 4.3: Fluxograma para viagem rodo-hidroviária - intermodal 
No fluxograma encontram-se descritos os principais processos macros que formaram a composição dos custos neste cenário.

Observando a matriz O/D do Apêndice B, verificam-se centros de distribuição próximos das unidades fabris ou muito distantes dos portos. Através de um critério de seleção, foram excluídas as viagens a centros de distribuição, via cabotagem, que se encontram a uma distância superior a $600 \mathrm{~km}$ dos portos ou a uma distância inferior a $1200 \mathrm{~km}$ das indústrias. Através desta seleção, as fábricas analisadas como origens de viagem foram: Concórdia, Chapecó, Dois Vizinhos, Duque de Caxias, Francisco Beltrão, Paranaguá, Ponta Grossa, São Paulo, Toledo e Três Passos. Os centros de distribuição escolhidos foram: Belém, Belo Horizonte, Fortaleza, Ipatinga, Manaus, Natal, Nossa Senhora do Socorro, Recife, Salvador e Vitória.

Na exclusão geográfica foram retirados os centros de distribuição de Brasília, Campo Grande, Cuiabá, Curitiba, Duque de Caxias e Jundiaí e a fábrica de Várzea Grande. Na Figura 4.4 observa-se espacialmente o critério de exclusão das instalações logísticas para o cenário 2.

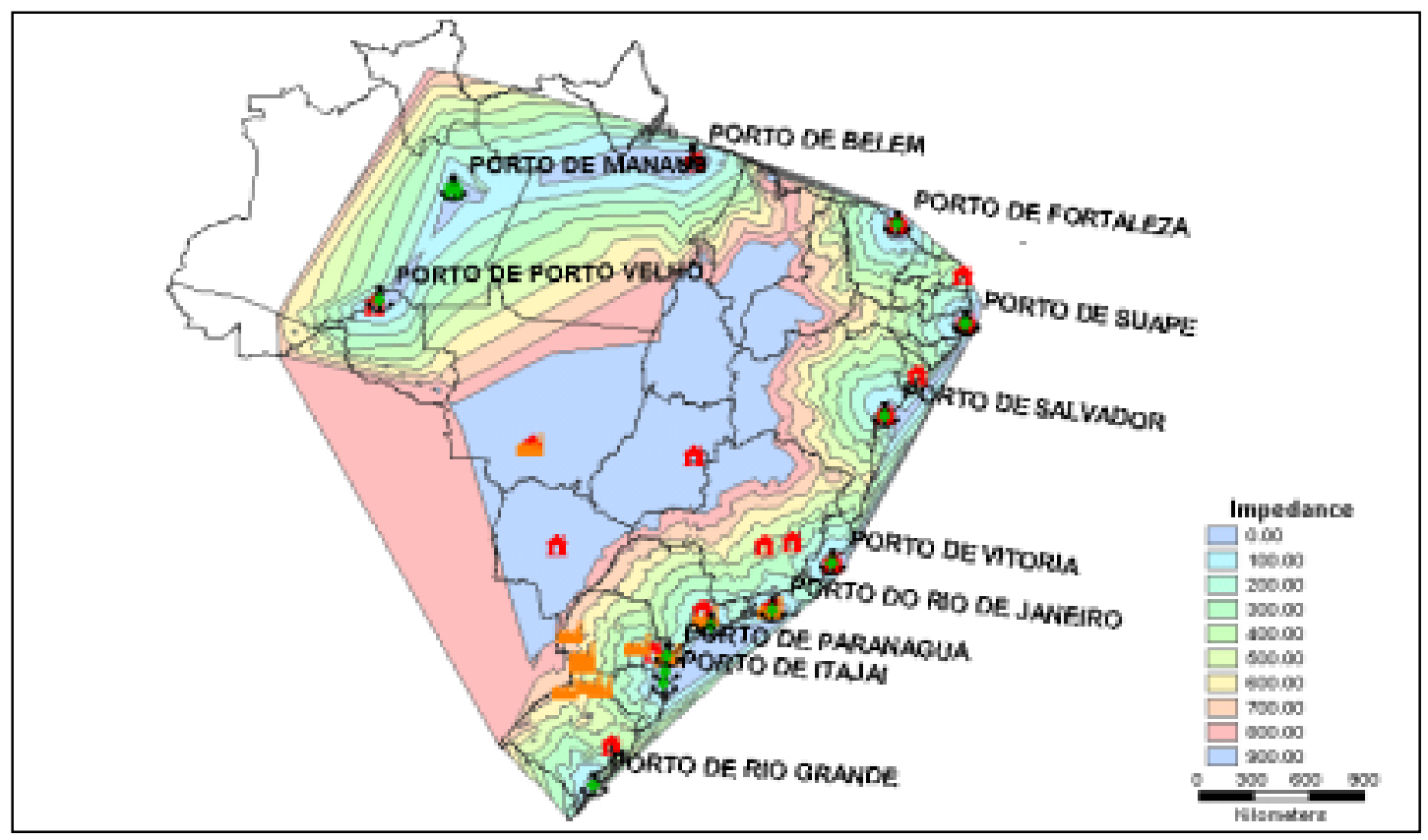

Figura 4.4: Exclusão de instalações logísticas do cenário em função do custo de transporte dos portos aos centros de distribuição 
O critério de escolha dos portos de embarque determinou-se pela minimização do custo de transporte e transbordo ocorridos entre as unidades fabris e os portos, através do comando Network/Paths $\rightarrow$ Multiple Paths $\rightarrow$ Minimize / From / To / Route System. As rotas e os respectivos portos de origem escolhidos são observados na Figura 4.5.

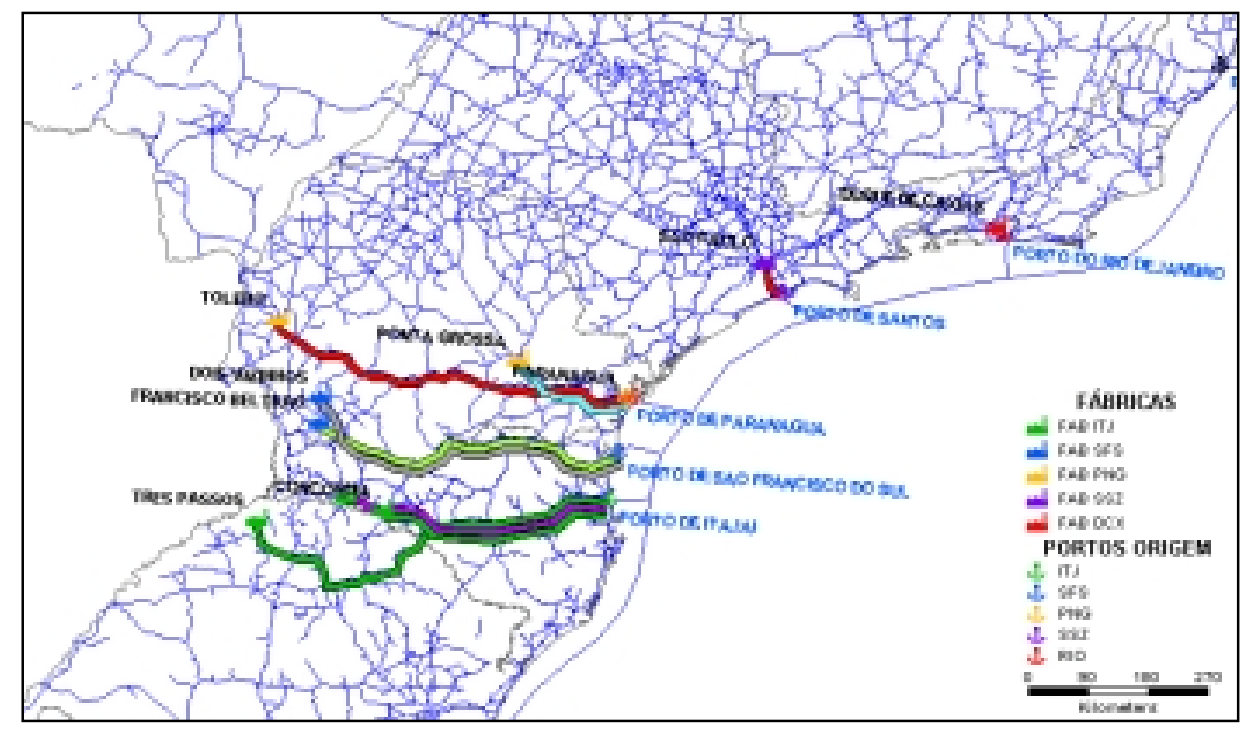

Figura 4.5: Locação de rotas das fábricas aos portos de origem

Assim, os contêineres carregados nas fábricas de Três Passos, Chapecó e Concórdia são embarcados no porto de Itajaí; os carregamentos provenientes de Francisco Beltrão e Dois Vizinhos são embarcados no porto de São Francisco do Sul; os contêineres estufados em Toledo, Ponta Grossa e Paranaguá são embarcados no porto de Paranaguá; e os contêineres provenientes de São Paulo e Duque de Caxias embarcam, respectivamente, nos portos de Santos e Rio de Janeiro.

Na navegação da embarcação geraram-se diferentes escalas nos portos antecessores aos portos de destino, com o objetivo de simular e quantificar diferentes custos de viagem. Além da viagem marítima, em algumas rotas foram simulados diferentes portos de desembarque visando quantificar os respectivos custos rodoviários. O Quadro 4.1 mostra as rotas construídas na análise do cenário 2 . 


\section{Quadro 4.1: Rotas e escalas analisadas no cenário}

\begin{tabular}{|c|c|c|c|c|}
\hline \multicolumn{5}{|c|}{ Rotas } \\
\hline & Rodoviário & & Hidroviário & Rodoviário \\
\hline \multirow{10}{*}{ Belém 01} & CDA-PITJ & & PITJ - PSSZ - PSAV - PREC - PFOT - PBEL & PBEL - BEL \\
\hline & CHP - PITJ & & PITJ - PSSZ - PSAV - PREC - PFOT - PBEL & $\mathrm{T}$ PBEL - BEL \\
\hline & TPS - PITJ & & PITJ - PSSZ - PSAV - PREC - PFOT - PBEL & \begin{tabular}{|l|l} 
& PBEL - BEL \\
\end{tabular} \\
\hline & DCX - PRIO & & PRIO - PSAV - PREC - PFOT - PBEL & a \\
\hline & DVZ-PSFS & & $\begin{array}{l}\text { PSFS - PSSZ - PSAV - PREC - PFOT - PBEL } \\
\text { PSET }\end{array}$ & $\mid \begin{array}{lll}n & \text { PEL - BEL } \\
\text { s } & \text { PBEL }\end{array}$ \\
\hline & FCB - PSFS & & PSFS - PSSZ - PSAV - PREC - PFOT - PBEL & b PBEL-BEL \\
\hline & PNG - PPNG & & PPNG - PSSZ - PSAV - PREC - PFOT - PBEL & $\circ$ PBEL - BEL \\
\hline & PGR - PPNG & & PPNG - PSSZ - PSAV - PREC - PFOT - PBEL & \begin{tabular}{|l|l|l|l} 
& PBEL - BEL \\
& PBEL
\end{tabular} \\
\hline & TLD - PPNG & & PPNG - PSSZ - PSAV - PREC - PFOT - PBEL & $\begin{array}{lll}d & \text { PBEL - BEL } \\
0\end{array}$ \\
\hline & SPL-PSSZ & & PSSZ - PSAV - PREC - PFOT - PBEL & PBEL - BEL \\
\hline \multirow{10}{*}{ Belém 02} & CDA-PITJ & & PITJ - PSSZ - PFOT & \begin{tabular}{|l|l|l|} 
& PFOT - BEL \\
\end{tabular} \\
\hline & CHP - PITJ & & PITJ - PSSZ - PFOT & T PFOT - BEL \\
\hline & TPS - PITJ & & PITJ - PSSZ - PFOT & \begin{tabular}{|l|l}
$r$ & PFOT - BEL \\
$a$ & PFT
\end{tabular} \\
\hline & DCX - PRIO & & $\begin{array}{l}\text { PRIO - PFOT } \\
\end{array}$ & \begin{tabular}{|l|l} 
a & PFOT - BEL \\
n
\end{tabular} \\
\hline & DVZ - PSFS & & PSFS - PSSZ - PFOT & \begin{tabular}{l|l}
$\mathrm{S}$ & PFOT - BEL \\
\end{tabular} \\
\hline & FCB - PSFS & & PSFS - PSSZ - PFOT & \begin{tabular}{|l|l}
$b$ & PFOT - BEL \\
\end{tabular} \\
\hline & PNG - PPNG & & PPNG - PSSZ - PFOT & O PFOT - BEL \\
\hline & PGR - PPNG & & PPNG - PSSZ - PFOT & $\begin{array}{l}r \\
d \\
d\end{array} \mid$ PFOT - BEL \\
\hline & TLD - PPNG & & PPNG - PSSZ - PFOT & \begin{tabular}{|l|l}
$d$ & PFOT - BEL \\
\end{tabular} \\
\hline & SPL - PSSZ & & PSSZ - PFOT & PFOT - BEL \\
\hline \multirow{10}{*}{ Belém 03} & CDA-PITJ & & PITJ - PSSZ - PREC - PBEL & PBEL - BEL \\
\hline & CHP - PITJ & & PIT - PSSZ - PREC - PBEL & $\mathrm{T}$ PBEL - BEL \\
\hline & TPS - PITJ & & PITJ - PSSZ - PREC - PBEL & \begin{tabular}{|l|l|l|l} 
& PBEL - BEL \\
\end{tabular} \\
\hline & DCX - PRIO & & PRIO - PREC - PBEL & \begin{tabular}{|l|l} 
a & PBEL - BEL \\
\end{tabular} \\
\hline & DVZ-PSFS & & PSFS - PSSZ - PREC - PBEL & \begin{tabular}{|l|l|l}
$n$ & \\
$s$ & PBEL - BEL
\end{tabular} \\
\hline & FCB - PSFS & & PSFS - PSSZ - PREC - PBEL & \begin{tabular}{|l|l} 
& D \\
b & PBEL - BEL \\
\end{tabular} \\
\hline & PNG - PPNG & & PPNG - PSSZ - PREC - PBEL & O PBEL - BEL \\
\hline & PGR - PPNG & & PPNG - PSSZ - PREC - PBEL & \begin{tabular}{|l|l}
$r$ & PBEL - BEL \\
\end{tabular} \\
\hline & TLD - PPNG & & PPNG - PSSZ - PREC - PBEL & $\begin{array}{lll}d & \text { PBEL - BEL } \\
0\end{array}$ \\
\hline & SPL-PSSZ & & PSSZ - PREC - PBEL & PBEL - BEL \\
\hline \multirow{10}{*}{$\begin{array}{c}\text { Belo } \\
\text { Horizonte }\end{array}$} & CDA-PITJ & & PITJ-PSSZ-PVIT & PVIT - BHO \\
\hline & CHP - PITJ & & PIT - PSSZ - PVIT & \begin{tabular}{|l|}
$T$ \\
PVIT - BHO
\end{tabular} \\
\hline & TPS - PITJ & & PIT - PSSZ - PVIT & \begin{tabular}{|l|l|}
$\mathrm{r}$ & PVIT - BHO \\
\end{tabular} \\
\hline & DCX - PRIO & & PRIO - PVIT & \begin{tabular}{|l|l|l|l}
$a$ & PVIT - BHO \\
$n$
\end{tabular} \\
\hline & DVZ - PSFS & & PSFS - PSSZ - PVIT & \begin{tabular}{|l|l|l|l}
1 & PVIT - BHO
\end{tabular} \\
\hline & FCB - PSFS & & PSFS - PSSZ - PVIT & \begin{tabular}{|l|l|l|l} 
b & PVIT - BHO
\end{tabular} \\
\hline & PNG - PPNG & & PPNG - PSSZ - PVIT & $\begin{array}{lll}0 & \text { PVIT - BHO } \\
r\end{array}$ \\
\hline & PGR - PPNG & & PPNG - PSSZ - PVIT & \begin{tabular}{|l|l|l}
$r$ & $r$ \\
$d$ & PVIT - BHO
\end{tabular} \\
\hline & TLD - PPNG & & PPNG - PSSZ - PVIT & \begin{tabular}{|l|l|l} 
& PVIT - BHO \\
& PVIT
\end{tabular} \\
\hline & SPL-PSSZ & & PSSZ - PVIT & PVIT - BHO \\
\hline \multirow{10}{*}{ Salvador } & CDA-PITJ & & PITJ - PSSZ- PSAV & PSAV-SAV \\
\hline & CHP - PITJ & & PITJ - PSSZ - PSAV & \begin{tabular}{|l|l} 
& PSAV - SAV \\
& PST
\end{tabular} \\
\hline & TPS - PITJ & & PITJ - PSSZ - PSAV & r PSAV - SAV \\
\hline & DCX - PRIO & & PRIO - PSAV & \begin{tabular}{|l|l|l}
$a$ & PSAV - SAV \\
$n$ & PSAV
\end{tabular} \\
\hline & DVZ - PSFS & & PSFS - PSSZ - PSAV & \begin{tabular}{|l|l}
11 & PSAV - SAV
\end{tabular} \\
\hline & FCB - PSFS & & PSFS - PSSZ - PSAV & \begin{tabular}{|l|l|} 
b & PSAV - SAV \\
\end{tabular} \\
\hline & PNG - PPNG & $\circ$ & PPNG - PSSZ - PSAV & $\begin{array}{ll} & \text { PSAV - SAV } \\
\end{array}$ \\
\hline & PGR - PPNG & r & PPNG - PSSZ - PSAV & \begin{tabular}{|l|l} 
& PSAV - SAV \\
& PSAV
\end{tabular} \\
\hline & TLD - PPNG & 0 & PPNG - PSSZ - PSAV & \begin{tabular}{l|l} 
d \\
0
\end{tabular} \\
\hline & SPL - PSSZ & & PSSZ - PSAV & PSAV - SAV \\
\hline
\end{tabular}

\begin{tabular}{|c|c|c|c|c|c|}
\hline \multicolumn{6}{|c|}{ Rotas } \\
\hline & Rodoviári & & Hidroviário & & Rodoviário \\
\hline \multirow{10}{*}{\begin{tabular}{|c|} 
Fortaleza \\
01
\end{tabular}} & CDA-PITJ & & PITJ - PSSZ - PSAV - REC - PFOT & & PFOT - FOT \\
\hline & CHP - PITJ & & PIT - PSSZ - PSAV - PREC - PFOT & T & PFOT - FOT \\
\hline & TPS - PITJ & & PITJ - PSSZ - PSAV - PREC - PFOT & & PFOT - FOT \\
\hline & DCX-PRIO & & PRIO - PSAV - PREC - PFOT & $\begin{array}{l}a \\
n\end{array}$ & PFOT - FOT \\
\hline & DVZ - PSFS & $\mathrm{s}$ & PSFS - PSSZ - PSAV - PREC - PFOT & $\mathrm{s}$ & PFOT - FOT \\
\hline & FCB - PSFS & & PSFS - PSSZ - PSAV - PREC - PFOT & b & PFOT - FOT \\
\hline & PNG - PPNG & o & PPNG - PSSZ - PSAV - PREC - PFOT & & PFOT - FOT \\
\hline & PGR - PPNG & 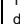 & PPNG - PSSZ - PSAV - PREC - PFOT & & PFOT - FOT \\
\hline & TLD - PPNG & & PPNG - PSSZ - PSAV - PREC - PFOT & & PFOT - FOT \\
\hline & SPL-PSSZ & & PSSZ - PSAV - PREC - PFOT & & PFOT - FOT \\
\hline \multirow{10}{*}{$\begin{array}{l}\text { Fortaleza } \\
02\end{array}$} & CDA-PITJ & & PITJ - PSSZ - PFOT & & PFOT - FOT \\
\hline & CHP - PITJ & & PITJ - PSSZ - PFOT & \begin{tabular}{|ccccc} 
\\
\end{tabular} & PFOT - FOT \\
\hline & TPS - PITJ & & PITJ - PSSZ - PFOT & & PFOT - FOT \\
\hline & DCX - PRIO & $\begin{array}{llll}a & \\
n\end{array}$ & $\begin{array}{l}\text { PRIO - PFOT } \\
\end{array}$ & & PFOT - FOT \\
\hline & DVZ - PSFS & $\mathrm{s}$ & PSFS - PSSZ - PFOT & & PFOT - FOT \\
\hline & FCB - PSFS & & PSFS - PSSZ - PFOT & & PFOT - FOT \\
\hline & PNG - PPNG & & PPNG - PSSZ - PFOT & & PFOT - FOT \\
\hline & PGR - PPNG & & PPNG - PSSZ - PFOT & & PFOT - FOT \\
\hline & TLD - PPNG & & PPNG - PSSZ - PFOT & & PFOT - FOT \\
\hline & SPL - PSSZ & & PSSZ - PFOT & & PFOT - FOT \\
\hline \multirow{10}{*}{$\begin{array}{l}\text { Fortaleza } \\
03\end{array}$} & CDA-PITJ & & PITJ - PSSZ - PREC & & PREC - FOT \\
\hline & CHP - PITJ & & PIT - PSSZ - PREC & & PREC - FOT \\
\hline & TPS - PITJ & & PITJ - PSSZ - PREC & & PREC - FOT \\
\hline & DCX - PRIO & a & PRIO - PREC & & PREC - FOT \\
\hline & DVZ - PSFS & $\mathrm{s}$ & PSFS - PSSZ - PREC & & PREC - FOT \\
\hline & FCB - PSFS & & PSFS - PSSZ - PREC & & PREC - FOT \\
\hline & PNG - PPNG & & PPNG - PSSZ - PREC & & PREC - FOT \\
\hline & PGR - PPNG & & PPNG - PSSZ - PREC & & PREC - FOT \\
\hline & TLD - PPNG & $a_{0}^{0}$ & PPNG - PSSZ - PREC & & PREC - FOT \\
\hline & SPL - PSSZ & & PSSZ - PREC & & PREC - FOT \\
\hline \multirow{10}{*}{ Ipatinga } & CDA-PITJ & & PITJ - PSSZ - PVIT & & PVIT - IPT \\
\hline & CHP - PITJ & $\mathrm{T}$ & PIT - PSSZ - PVIT & & PVIT - IPT \\
\hline & TPS - PITJ & r & PIT - PSSZ - PVIT & & PVIT - IPT \\
\hline & DCX-PRIO & $\frac{a}{n}$ & PRIO - PVIT & & PVIT - IPT \\
\hline & DVZ - PSFS & s & PSFS - PSSZ - PVIT & & PVIT - IPT \\
\hline & FCB - PSFS & b & PSFS - PSSZ - PVIT & & PVIT - IPT \\
\hline & PNG - PPNG & & PPNG - PSSZ - PVIT & & PVIT - IPT \\
\hline & PGR - PPNG & $\begin{aligned} 9 \\
r\end{aligned}$ & PPNG - PSSZ - PVIT & & PVIT - IPT \\
\hline & TLD - PPNG & 0 & PPNG - PSSZ - PVIT & & PVIT - IPT \\
\hline & SPL-PSSZ & & PSSZ - PVIT & & PVIT - IPT \\
\hline \multirow{10}{*}{ Vitória } & CDA-PITJ & & PITJ - PSSZ - PVIT & & PVIT - VIT \\
\hline & CHP - PITJ & \begin{tabular}{|ccc}
$T$ \\
\end{tabular} & PIT - PSSZ - PVIT & & PVIT - VIT \\
\hline & TPS - PIT & $a^{2}$ & PIT - PSSZ - PVIT & & PVIT - VIT \\
\hline & DCX-PRIO & $\mathrm{a}$ & PRIO - PVIT & & PVIT - VIT \\
\hline & DVZ - PSFS & $\mathrm{s}$ & PSFS - PSSZ - PVIT & & PVIT - VIT \\
\hline & FCB - PSFS & b & PSFS - PSSZ - PVIT & b & PVIT - VIT \\
\hline & PNG - PPNG & & PPNG - PSSZ - PVIT & & PVIT - VIT \\
\hline & PGR - PPNG & $d a$ & PPNG - PSSZ - PVIT & r & PVIT - VIT \\
\hline & TLD - PPNG & 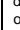 & PPNG - PSSZ - PVIT & a & PVIT - VIT \\
\hline & SPL - PSSZ & & PSSZ-PVIT & & PVIT - VIT \\
\hline
\end{tabular}

\begin{tabular}{|c|c|c|c|}
\hline $\begin{array}{c}\text { Manaus } \\
01\end{array}$ & $\begin{array}{l}\text { CDA - PITJ } \\
\text { CHP }- \text { PITJ } \\
\text { TPS }- \text { PITJ } \\
\text { DCX }- \text { PRIO } \\
\text { DVZ } \text { PSFS } \\
\text { FCB }- \text { PSFS } \\
\text { PNG }- \text { PPNG } \\
\text { PGR }- \text { PPNG } \\
\text { TLD }- \text { PPNG } \\
\text { SPL }- \text { PSSZ }\end{array}$ & \begin{tabular}{|l|l|} 
T & PIT - PSSZ - PSAV - PREC - PFOT - PMAN \\
r & PIT - PSSZ - PSAV - PREC - PFOT - PMAN \\
a & PIT - PSSZ - PSAV - PREC - PFOT - PMAN \\
n & PRIO - PSAV - PREC - PFOT - PMAN \\
s & PSFS - PSSZ - PSAV - PREC - PFOT - PMAN \\
b & PSFS - PSSZ - PSAV - PREC - PFOT - PMAN \\
o & PPNG - PSSZ - PSAV - PREC - PFOT - PMAN \\
r & PPNG - PSSZ - PSAV - PREC - PFOT - PMAN \\
d & PPNG PSA \\
o PPNG - PSSZ - PSAV - PREC - PFOT - PMAN & PSSZ PSAV - PREC - PFOT - PMAN \\
\end{tabular} & \begin{tabular}{l|l} 
& PMAN - MAN \\
r & PMAN - MAN \\
a & PMAN - MAN \\
n & PMAN - MAN \\
s & PMAN - MAN \\
b & PMAN - MAN \\
0 & PMAN - MAN \\
r & PMAN - MAN \\
d & PMAN - MAN \\
0 & PMAN \\
& PMAN - MAN
\end{tabular} \\
\hline $\begin{array}{c}\text { Manaus } \\
02\end{array}$ & $\begin{array}{l}\text { CDA - PITJ } \\
\text { CHP }- \text { PITJ } \\
\text { TPS }- \text { PITJ } \\
\text { DCX - PRIO } \\
\text { DVZ }- \text { PSFS } \\
\text { FCB } \text { PSFS } \\
\text { PNG }- \text { PPNG } \\
\text { PGR }- \text { PPNG } \\
\text { TLD } \text { PPNG } \\
\text { SPL }- \text { PSSZ } \\
\end{array}$ & \begin{tabular}{|l|l|} 
T & PITJ - PSSZ - PREC - PMAN \\
r & PITJ - PSSZ - PREC - PMAN \\
a & PITJ - PSSZ - PREC - PMAN \\
n & PRIO - PREC - PMAN \\
s & PSFS - PSSZ - PREC - PMAN \\
b & PSFS - PSSZ - PREC - PMAN \\
o & PPNG - PSSZ - PREC - PMAN \\
r & PPNG - PSSZ - PREC - PMAN \\
d & PPN \\
o & PPNG - PSSZ - PREC - PMAN \\
& PSSZ - PREC - PMAN \\
\end{tabular} & \begin{tabular}{|l|l} 
T & PMAN - MAN \\
r & PMAN - MAN \\
a & PMAN - MAN \\
n & PMAN - MAN \\
s & PMAN - MAN \\
b & PMAN - MAN \\
0 & PMAN - MAN \\
r & PMAN - MAN \\
d & PMAN MAN \\
0 & PMAN - MAN \\
& PMAN - MAN \\
\end{tabular} \\
\hline
\end{tabular}

\begin{tabular}{|c|c|c|c|}
\hline $\begin{array}{c}\text { Nossa } \\
\text { Senhora } \\
\text { do Socorro } \\
01\end{array}$ & \begin{tabular}{|l} 
CDA - PITJ \\
CHP - PITJ \\
TPS PIT \\
DCX - PRIO \\
DVZ - PSFS \\
FCB - PSFS \\
PNG - PPNG \\
PGR - PPNG \\
TLD - PPNG \\
SPL - PSSZ
\end{tabular} & \begin{tabular}{|l|l} 
T & PIT - PSSZ - PSAV \\
r & PIT J PSSZ - PSAV \\
a & PIT - PSSZ PSAV \\
n & PRIO - PSAV \\
s & PSFS - PSSZ - PSAV \\
b & PSFS - PSSZ - PSAV \\
o & PPNG - PSSZ - PSAV \\
r & PPNG - PSSZ - PSAV \\
o & PPNG - PSSZ - PSAV \\
PSSZ - PSAV
\end{tabular} & \begin{tabular}{l|l} 
T & PSAV - NSS \\
r & PSAV - NSS \\
a & PSAV - NSS \\
$n$ & PSAV - NSS \\
s & PSAV - NSS \\
$b$ & PSAV - NSS \\
o & PSAV - NSS \\
r & PSAV - NSS \\
d & PSAV - NSS \\
& PSAV - NSS
\end{tabular} \\
\hline $\begin{array}{c}\text { Nossa } \\
\text { Senhora } \\
\text { do Socorro } \\
02\end{array}$ & \begin{tabular}{|l|} 
CDA - PITJ \\
CHP - PITJ \\
TPS - PITJ \\
DCX - PRIO \\
DVZ - PSFS \\
FCB - PSFS \\
PNG - PPNG \\
PGR - PPNG \\
TLD - PPNG \\
SPL - PSSZ \\
\end{tabular} & \begin{tabular}{|l|l|} 
& PIT - PSSZ - PREC \\
T & PIT - PSSZ - PREC \\
a & PIT - PSSZ - PREC \\
n & PRIO - PREC \\
s & PSFS - PSSZ - PREC \\
b & PSFS - PSSZ - PREC \\
o & PRNG - PSSZ - PREC \\
r & PPNG - PSSZ - PREC \\
0 & PPNG - PSSZ - PREC \\
PSSZ - PREC
\end{tabular} & 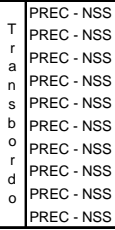 \\
\hline
\end{tabular}

\begin{tabular}{|c|c|c|c|}
\hline Natal 01 & \begin{tabular}{|l|} 
CDA - PITJ \\
CHP - ITI \\
TPS - PITJ \\
DCX - PRIO \\
DVZ - PSFS \\
FCB - PSFS \\
PNG - PPNG \\
PGR - PPNG \\
TLD - PPNG \\
SPL - PSSZ
\end{tabular} & \begin{tabular}{l|l} 
& PIT - PSSZ - PREC \\
T & PITJ - PSZ - PREC \\
a & PIT - PSSZ - PREC \\
n & PRIO - PREC \\
s & PSFS - PSSZ - PREC \\
b & PSFS - PSSZ - PREC \\
r & PPNG - PSSZ - PREC \\
d & PPNG - PSSZ - PREC \\
0 & PPNG - PSSZ - PREC \\
& PSSZ - PREC \\
\end{tabular} & \begin{tabular}{|l|l} 
& PREC - NAT \\
t & PREC - NAT \\
a & PREC - NAT \\
n & PREC - NAT \\
s & PREC - NAT \\
b & PREC - NAT \\
o & PREC - NAT \\
$r$ & PREC - NAT \\
d & PREC - NAT \\
0 & PREC - NAT \\
\end{tabular} \\
\hline Natal 02 & \begin{tabular}{|l|} 
CDA - PITJ \\
CHP - PITJ \\
TPS - PITJ \\
DCX - PRIO \\
DVZ - PSFS \\
FCB - PSFS \\
PNG - PPNG \\
PGR - PPNG \\
TLD - PPNG \\
SPL - PSSZ
\end{tabular} & 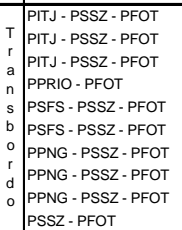 & \begin{tabular}{l|l} 
& PFOT - NAT \\
r & PFOT - NAT \\
a & PFOT - NAT \\
n & PFOT - NAT \\
s & PFOT - NAT \\
b & PFOT - NAT \\
o & PFOT - NAT \\
$r$ & PFOT - NAT \\
d & PFOT - NAT \\
o & PFOT - NAT
\end{tabular} \\
\hline
\end{tabular}

\begin{tabular}{|c|c|c|c|}
\hline Recife 01 & \begin{tabular}{|l} 
CDA - PITJ \\
CHP - PITJ \\
TPS - PITJ \\
DCX - PRIO \\
DVZ - PSFS \\
FCB - PSFS \\
PNG - PPNG \\
PGR - PPNG \\
TLD - PPNG \\
SPL - PSSZ
\end{tabular} & 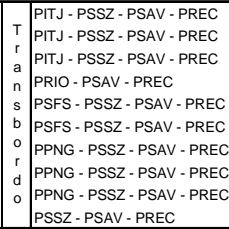 & \begin{tabular}{|l|l} 
& PREC - REC \\
t & PREC - REC \\
a & PREC - REC \\
n & PREC - REC \\
s & PREC - REC \\
b & PREC - REC \\
o & PREC - REC \\
$\mathrm{r}$ & PREC - REC \\
d & PREC - REC \\
o & PREC - REC \\
\end{tabular} \\
\hline \begin{tabular}{|l|l} 
Recife 02 \\
\end{tabular} & $\begin{array}{l}\text { CDA - PITJ } \\
\text { CHP - PITJ } \\
\text { TPS - PITJ } \\
\text { DCX - PRIO } \\
\text { DVZ - PSFS } \\
\text { FCB - PSFS } \\
\text { PNG - PPNG } \\
\text { PGR - PPNG } \\
\text { TLD - PPNG } \\
\text { SPL - PSSZ }\end{array}$ & \begin{tabular}{|l|l|} 
t & PITJ - PSSZ - PREC \\
r & PIT - PSSZ - PREC \\
a & PITJ - PSSZ - PREC \\
n & PRIO - PREC \\
s & PSFS - PSSZ - PREC \\
b & PSFS - PSSZ - PREC \\
o & PPNG - PSSZ - PREC \\
r & PPNG - PSSZ - PREC \\
d & PNA \\
o & PPNG - PSSZ - PREC \\
& PSSZ - PREC \\
\end{tabular} & \begin{tabular}{|l|l} 
t & PREC - REC \\
$\mathrm{r}$ & PREC - REC \\
$\mathrm{a}$ & PREC - REC \\
$\mathrm{n}$ & PREC - REC \\
$\mathrm{s}$ & PREC - REC \\
$\mathrm{b}$ & PREC - REC \\
$\mathrm{o}$ & PREC - REC \\
$\mathrm{r}$ & PREC - REC \\
$\mathrm{d}$ & PREC \\
$\mathrm{o}$ & PREC - REC \\
& PREC - REC \\
\end{tabular} \\
\hline
\end{tabular}


Sendo,

$\quad$ Fábricas
CDA: Concórdia
CHP: Chapecó
FCB: Francisco Beltrão
PNG: Paranaguá
DVZ: Dois Vizinhos
PGR: Ponta Grossa
TLD: Toledo
TPS: Três Passos
SPL: São Paulo
DCX: Duque de Caxias

$\quad$ Centros de distribuição
BEL: Belém (PA)
BHO: Belo Horizonte (MG)
FOT: Fortaleza (CE)
IPT: Ipatinga (MG)
MAN: Manaus (AM)
NAT: Natal (RN)
NSS: Nossa Senhora do Socorro (SE)
REC: Recife (PE)
SAV: Salvador (BA)
VIT: Vitória (ES)

$\quad$ Portos
PITJ: Porto de Itajaí
PSFS: Porto de São F. do Sul
PPNG: Porto de Paranaguá
PSSZ: Porto de Santos
PRIO: Porto do Rio de Janeiro
PVIT: Porto de Vitória
PSAV: Porto de Salvador
PREC: Porto de Recife
PFOT: Porto de Fortaleza
PBEL: Porto de Belém

Como exemplo, analisaram-se diferentes rotas com destino a Belém. Na primeira rota, Belém 01, a embarcação realiza escalas nos portos de Santos, Salvador, Recife, Fortaleza e transborda os contêineres em Belém. Na segunda rota, Belém 02, a embarcação realiza escalas em Santos e desembarca os contêineres em Fortaleza, sendo a carga transportada pelo veículo 3S3B3 porta contêineres até Belém. Na terceira rota, as escalas do navio são nos portos de Santos, Recife e carga transbordadas para o veículo rodoviário no porto de Belém. Outro exemplo de estudo de rotas encontra-se no abastecimento do centro de distribuição de Nossa Senhora do Socorro. São variados os portos de desembarque: uma rota desembarca em Salvador e na outra rota o navio desembarca os contêineres no porto de Recife.

Neste cenário rodo-hidroviário adotou-se como cavalo mecânico padrão o modelo Volvo FH 12 L2H1 com potência nominal do motor de 420cv, distância entre eixos de $3600 \mathrm{~mm}$ e sistema de tração $6 \times 4$. O implemento em análise é o bitrem porta-contêiner da Recrusul com 6 eixos e capacidade de transporte de um contêiner de 20' e um contêiner de 40', respectivamente, no primeiro e no segundo reboque. O navio é um modelo porta contêineres com calado máximo de 11,3m e com motor principal MAN 5L80 GBE apresentando potência de serviço de 15400BHP.

As velocidades operacionais adotadas no carregamento dos $\operatorname{arcos}$ rodoviários e hidroviários foram de 50 e $70 \mathrm{~km} / \mathrm{h}$ para rodovias de pista simples e rodovias de pista dupla e $34,8 \mathrm{~km} / \mathrm{h}(18,8 \mathrm{kn})$ para as hidrovias. 
As principais informações técnicas e custos adotados neste cenário, para o veículo rodoviário, para a embarcação e para os contêineres, são observados na Tabela 4.7, Tabela 4.8, Tabela 4.9 e Tabela 4.10 .

Tabela 4.7: Navio porta contêineres

\begin{tabular}{lc}
\hline \multicolumn{2}{c}{ Navio 1400 TEU - Motor MAN 5L80 GBE } \\
\hline \hline Valor estimado da embarcação & US\$ 20.000.000,00 \\
Custo de manutenção e pequenos reparos: & US $\$ 300.000,00 /$ ano \\
Custo de docagem: & US $\$ 260.000,00 /$ ano \\
Custo de seguro: & US $\$ 600.000,00 /$ ano \\
Consumo de óleo: & $50 t / d i a$ \\
Consumo específico de combustível $\left(\alpha_{c}\right):$ & $0,17 \mathrm{~kg} /(\mathrm{BHPxh})$ \\
Preço óleo diesel marítimo (1): & US $\$ 139,00 / \mathrm{t}$ \\
Preço óleo pesado marítimo (2): & US $\$ 91,5 / \mathrm{t}$ \\
Proporção da mistura de óleo (1): & $17 \%$ \\
Proporção da mistura de óleo (2): & $83 \%$ \\
Fator médio de utilização $(\phi):$ & 0,75 \\
Horas de operação do navio por dia: & $24 \mathrm{~h}$ \\
Carga de estiva por viagem & $1.050 \mathrm{TEU}$ \\
\hline
\end{tabular}

(1) MDO: Maritime Diesel Oil

(2) HFO: High Fuel Oil

Fonte: DREWRY (1999); CAMELLO (2001); CUNHA (2000); NOVAES (1976).

Tabela 4.8: Bitrem porta contêineres

\begin{tabular}{lc}
\hline \multicolumn{2}{c}{ Bitrem Recrusul Porta-contêineres (20" + 40") } \\
\hline \hline Preço do implemento novo, com pneus: & US $\$ 25.390,00$ \\
Peso bruto: & $11.000 \mathrm{~kg}$ \\
Número de pneumáticos: & $24 \mathrm{un}$. \\
Custo de manutenção (balancins, lub. eixos freios, troca lonas): & US $\$ 58,66$ \\
\hline Fonte: GOMES (2001).
\end{tabular}

Tabela 4.9: Contêineres frigoríficos

\begin{tabular}{lr}
\hline \multicolumn{2}{c}{ Contêineres refrigerados 20" e 40" } \\
\hline \hline Preço de um contêiner 20" refrigerado: & US\$ 13.150,00 \\
Preço de um contêiner 40" refrigerado: & US $\$ 14.992,00$ \\
Peso bruto contêiner 20": & $2.990 \mathrm{~kg}$ \\
Peso bruto contêiner 40": & $4.530 \mathrm{~kg}$ \\
Capacidade máxima de carga do contêiner 20" refrigerado: & $21.010 \mathrm{~kg}$ \\
Capacidade máxima de carga do contêiner 40" refrigerado: & $25.950 \mathrm{~kg}$ \\
Comprimento interno contêiner 20": & $5,558 \mathrm{~m}$ \\
Largura interna baú contêiner 20": & $2,300 \mathrm{~m}$ \\
Altura interna baú contêiner 20": & $2,345 \mathrm{~m}$ \\
Comprimento interno contêiner 40": & $11,580 \mathrm{~m}$ \\
Largura interna baú contêiner 40": & $2,288 \mathrm{~m}$ \\
Altura interna baú contêiner 40": & $2,249 \mathrm{~m}$ \\
Capacidade volumétrica do conjunto de contêineres 20"+40": & $89,56 \mathrm{~m}$ \\
Autonomia média do sistema refrigeração - 20": & $120 \mathrm{l} / \mathrm{dia}$ \\
Autonomia média do sistema refrigeração - 40": & $120 \mathrm{l} / \mathrm{dia}$ \\
Custo de manutenção e pequenos reparos - 20": & US\$ 2.070,00/ano \\
Custo de manutenção e pequenos reparos - 40": & US $\$ 2.501,60 / \mathrm{ano}$ \\
\hline Fonte: CAMELLO (2001); TIAGO (2002). &
\end{tabular}


Tabela 4.10: Cavalo mecânico 6x4

\begin{tabular}{lc}
\hline \multicolumn{2}{c}{ Volvo FH 12 L2H1 420cv, 6x4 } \\
\hline \hline Preço do chassi novo, com pneus: & US\$ 70.392,24 \\
Peso bruto: & $9.160 \mathrm{~kg}$ \\
Número de pneumáticos do eixo dianteiro: & $2 \mathrm{un}$. \\
Número de pneumáticos dos eixos traseiros: & $8 \mathrm{un}$. \\
Autonomia média: & $1,8 \mathrm{Km} / \mathrm{l}$ \\
Capacidade para: & \\
$\quad$ Caixa de mudanças: & 14 I \\
Eixo traseiro: & 64 I \\
Sistema de direção: & 4,5 I \\
Motor: & 36 I \\
Motor - Complementação: & 3 I \\
Fluído para radiador (20 - 50\% volume radiador): & 9 I \\
Diferencial & 6 I \\
Intervalos de troca para: & \\
Caixa de mudanças: & $30.000 \mathrm{Km}$ \\
Eixo traseiro: & $100.000 \mathrm{Km}$ \\
Sistema de direção: & $100.000 \mathrm{Km}$ \\
Motor: & $15.000 \mathrm{Km}$ \\
Motor - Complementação: & $5.000 \mathrm{Km}$ \\
Fluído para radiador: & $30.000 \mathrm{Km}$ \\
Óleo diferencial: & $60.000 \mathrm{Km}$ \\
\hline Fonte: CECCHET (2001).
\end{tabular}

Também se adotou um tempo médio de 180 minutos para a carga e descarga dos contêineres nos pontos de coleta e de entrega. O índice de aproveitamento da capacidade de carga do veículo considerado neste cenário é de $100 \%$. Os demais índices de manutenção e recauchutagens propostos por VALENTE et al. (1997) foram adotados para o cavalo mecânico e implemento rodoviário. O período de operação útil da CVC compreende 22 dias de operação no mês e 17 horas de trabalho diários, também operando com dois motoristas em escala de turno. Neste cenário considera-se que a CVC é liberada para o tráfego diurno e para o tráfego noturno. Os demais itens operacionais e custos adotados e aplicados no modelo proposto são observados na Tabela 4.11.

Tabela 4.11: Dados de entrada da planilha de custo 3S3B3 / PC1050TEU

\begin{tabular}{lc}
\hline \multicolumn{2}{c}{ Dados gerais } \\
\hline \hline Período pretendido de uso da embarcação: \\
Período pretendido de uso dos contêineres: & 25 anos \\
Taxa anual de juros (hidroviário): & 5 anos \\
Taxa anual de juros (contêineres): & $20 \%$ \\
Dias em manutenção (estaleiro): & $6 \%$ \\
Dias de operação: & 15 dias/ano \\
Encargos sociais (tripulação): & 350 dias/ano \\
Custo de uma apólice para frota média padrão (rodoviário): & $95,86 \%$ \\
IPVA: & US $\$ 7.821,36$ /ano \\
Intervalos para lavagem: & US $\$ 1.407,84$ \\
Intervalo para lubrificação e manutenção: & $6.000 \mathrm{Km}$ \\
Valor de revenda do cavalo-mecânico com 5 anos de uso: & $10.000 \mathrm{Km}$ \\
Valor de revenda do implemento com 5 anos de uso: & US $\$ 31.676,51$ \\
Valor de revenda da embarcação com 25 anos de uso: & US $\$ 10.156,00$ \\
Valor de revenda do contêiner de 20' com 5 anos de uso: & US $\$ 7.000 .000,00$ \\
Valor de revenda do contêiner de 40' com 5 anos de uso: & US $\$ 8.995,20$ \\
\hline
\end{tabular}




\subsection{Cenário 3: Rodoviário 3S3B3}

No terceiro e último cenário é dimensionada a frota e computado o custo da composição de veículo de carga bitrem 3S3B3 para a transferência porta-a-porta entre as fábricas e centros de distribuição. O fluxo dos processos para este cenário é idêntico ao processo do cenário 1, descrito na Figura 4.2.

As diferenças entre os cenários 1 e 3 encontram-se na capacidade de carga do veículo, no valor de pedágio cobrado na viagem (diferentes quantidades de eixos) e nos valores econômico-financeiro utilizados na composição dos custos envolvidos no transporte.

O cavalo mecânico utilizado neste cenário também foi um modelo Volvo FH 12 L2H1 com potência de $420 \mathrm{cv}$, equipado com. implemento baú frigorífico de 6 eixos e dois sistemas de refrigeração independentes. Os parâmetros operacionais deste cenário são idênticos aos proposto no cenário do semi-reboque. Também é considerado o tráfego diurno e noturno da CVC, sendo utilizados assim dois motoristas. Os demais itens adotados no modelo de custo são observados na Tabela 4.13. Também se considerou velocidade operacional do veículo rodoviário de 50 e $70 \mathrm{~km} / \mathrm{h}$ para rodovias de pista simples e rodovias de pista dupla, respectivamente.

\section{Tabela 4.12: Bitrem baú frigorífico}

\begin{tabular}{lr}
\hline \multicolumn{2}{c}{ Bitrem Recrusul Baú Frigoríico } \\
\hline \hline Preço do implemento novo, com pneus: & US\$ 89.800,00 \\
Peso bruto: & $16.700 \mathrm{~kg}$ \\
Número de pneumáticos: & $24 \mathrm{un}$. \\
Número de motores do sistema de refrigeração: & $2 \mathrm{un}$. \\
Consumo médio de um motor de refrigeração (Recrusul TD-06): & $5 \mathrm{l} / \mathrm{h}$ \\
Custo de manutenção (balancins, lub. eixos freios, troca lonas): & US\$ 58,66 \\
Custo de manutenção do equipamento de refrigeração (motor): & US\$ 195,53/ano \\
Custo de manutenção do equipamento de refrigeração (baú): & US\$ 156,42/ano \\
Comprimento interno baú - reboque 01: & $7,25 \mathrm{~m}$ \\
Largura interna baú - reboque 01: & $2,46 \mathrm{~m}$ \\
Altura interna baú - reboque 01: & $2,40 \mathrm{~m}$ \\
Comprimento interno baú - reboque 02: & $13,25 \mathrm{~m}$ \\
Largura interna baú - reboque 02: & $2,46 \mathrm{~m}$ \\
Altura interna baú - reboque 02: & $2,40 \mathrm{~m}$ \\
Capacidade volumétrica do conjunto: & $121,03 \mathrm{~m}$ \\
\hline Fonte: GOMES (2001).
\end{tabular}


Tabela 4.13: Dados de entrada da planilha de custo 3S3B3

\begin{tabular}{lc}
\hline & Dados gerais \\
\hline \hline Período pretendido de uso do chassi e do equipamento: & 5 anos \\
Taxa anual de juros: & $12 \%$ \\
Salário mensal médio do motorista: & US $\$ 400,00$ \\
Encargos sociais: & $77,39 \%$ \\
Horas uteis trabalhadas por dia: & $8 \mathrm{~h} / \mathrm{dia}$ \\
Horas extras trabalhadas por dia: & $0,5 \mathrm{~h} / \mathrm{dia}$ \\
Custo aquisição do sistema monitoramento veículos: & US $\$ 1.500,00$ \\
Custo médio transmissão sitema monitoramento: & US $\$ 50,84 / \mathrm{mês}$ \\
Perda de caminhão por ano: & 7 un. \\
Período de utilização do veículo: & 12 meses \\
Custo de uma apólice para frota média padrão: & US $\$ 11.732,04 / \mathrm{ano}$ \\
Seguro obrigatório do chassi: & $\mathrm{US} \$ 21,67$ \\
IPVA: & $\mathrm{US} \$ 1.161,47$ \\
Funcionamento do sistema de refrigeração: & $24 \mathrm{~h}$ \\
Autonomia do sistema de refrigeração (1 motor): & $6,6 \mathrm{~km} / \mathrm{l}$ \\
Valor de revenda do cavalo-mecânico com 5 anos de uso: & US\$ 31.676,51 \\
Valor de revenda do implemento com 5 anos de uso: & US $\$ 35.920,00$ \\
\hline
\end{tabular}

\subsection{Dimensionamento e custo operacional dos cenários}

Aqui são apresentados os primeiros resultados propostos nesta pesquisa, por cenário: o dimensionamento da frota de veículos e contêineres, os custos médios por quilômetro rodado e os custos por dia de operação.

O dimensionamento da frota de contêineres de 20 e 40 pés, das combinações dos veículos de carga, do tipo $2 \mathrm{~S} 3,3 \mathrm{~S} 3 \mathrm{~B} 3$ porta contêiner e $3 \mathrm{~S} 3 \mathrm{~B} 3$ baú frigorífico e a quilometragem média mensal dos veículos rodoviários, envolvidos nos cenários previamente estabelecidos, são observados no Apêndice $\mathrm{C}$ (cenário 1), Apêndice $\mathrm{E}$ (cenário 2) e Apêndice F (cenário 3).

Os valores dos custos médios por quilômetro e por dia de operação, gerados através de planilhas eletrônica, serviram como principal informação para a criação das redes de custos gerados no SIG-T. As planilhas de composição dos custos operacionais dos veículos rodoviários do tipo $2 \mathrm{~S} 3,3 \mathrm{~S} 3 \mathrm{~B} 3$ porta contêiner e $3 \mathrm{~S} 3 \mathrm{~B} 3$ baú frigorífico são observadas no Apêndice D e Apêndice G, respectivamente. A composição dos custos diários dos contêineres, dos custos $C M D$ e $C P D$ das embarcações de 1400TEU e 800TEU são observados no Apêndice H, Apêndice I e Apêndice J, respectivamente.

Os valores obtidos no dimensionamento e no cálculo dos custos operacionais, para cada cenário analisado, estão descritos na Tabela 4.14. Assim, para a movimentação de carga 
frigorífica entre os 11 pontos de origem para os 18 pontos de destino, são necessários 253 caminhões do tipo 2S3. No transporte dos contêineres são utilizadas 25 e 20 combinações de veículos de carga do tipo 3S3B3 porta contêiner, nos trechos rodoviários entre porto-fábrica-porto e porto-cd-porto, respectivamente. No transporte porta a porta através do bitrem 3S3B3 baú frigorífico encontrou-se a necessidade de 164 composições para o atendimento da demanda de transporte de toda a matriz O/D.

Tabela 4.14: Dimensionamento e custo operacional para os veículos rodoviários

\begin{tabular}{llccc}
\hline & Item & & Cenário 01 & Cenário 02 Cenário 03 \\
\hline \hline \multirow{2}{*}{ Número de veículos (NV): } & Fábrica - CD & 253 & 0 & 164 \\
& Fábrica - Porto Origem & 0 & 25 & 0 \\
& Porto Destino - CD & 0 & 20 & 0 \\
& Total & 253 & 45 & 164 \\
\hline \multirow{2}{*}{ Número de contêineres: } & $20 "$ & 0 & 255 & 0 \\
& $40 "$ & 0 & 255 & 0 \\
\hline Quilometragem média mensal $(\mathrm{QMM}):$ & $\mathrm{km}$ & 0 & 510 & 0 \\
\hline Custo operacional por quilômetro $(\mathrm{COQ}):$ & US\$/km & 17.417 & 12.672 & 17.417 \\
\hline
\end{tabular}

Os valores dos custos diários para os contêineres frigoríficos e a embarcação marítima de 1400TEU, determinados através do modelo proposto, são observados na Tabela 4.15.

Tabela 4.15: Resumo dos custos operacionais para o cenário 2

\begin{tabular}{ll}
\hline \multicolumn{1}{c}{ Cenário 02 } \\
\hline \hline Custo diário do contêiner frigorífico 20': & US\$14,71 \\
Custo diário do contêiner frigorífico 40': & US\$16,97 \\
Custo diário da embarcação em trânsito: & US\$16.847,49 \\
Custo diário da embarcação atracada: & US\$11.142,19 \\
\hline
\end{tabular}

$\mathrm{Na}$ geração das rotas de mínimo custo para os cenários foram computados os seguintes itens:

- Custo total final por quilômetro, somando-se os custos de pedágios, transbordos e modos de transporte;

- Custo total final da viagem;

- Custo total final por tonelada transportada;

- Tempo de viagem, em dias; 
- Custo rodoviário entre fábricas e portos de origem;

- Custo rodoviário entre portos de destino e centros de distribuição;

- Custo portuário na origem da viagem marítima;

- Custo portuário no destino da viagem marítima;

- Custo da viagem marítima.

Os principais resultados obtidos nas análises dos cenários são mostrados na forma de mapas temáticos e gráficos de barras. Os mapas temáticos apresentam curvas de isocustos com o intervalo da impedância total final para uma viagem com destino a um ponto $x$ de um segmento de área. Estas áreas são diferenciadas através de uma escala cromática e limitadas por um intervalo de valores, em US\$. Além das curvas de isocustos são apresentadas as rotas de mínimo custo, criadas através do comando Multiple Shortest Path. Os histogramas foram criados através do custo total final por tonelada transportada (US\$/t) obtido através do comando de caminho mínimo.

A Figura 4.6 e o gráfico da Figura 4.7 apresentam, respectivamente, o mapa de isocusto para impedância total (US\$) e os custos (US\$/t), por rota, das viagens com origem na fábrica de Concórdia para o cenário 1.

Os valores dos custos por tonelada transportada para os semi-reboques frigoríficos $2 \mathrm{~S} 3$ situaram-se nas seguintes faixas: distâncias menores que $500 \mathrm{~km}$ - custos por tonelada menores que US $\$ 20,00$; distâncias no intervalo de $1000 \mathrm{~km}$ a $1500 \mathrm{~km}$ - custos por tonelada variando entre US\$34,00 a US\$51,50; na faixa de distâncias entre 2500 e $3000 \mathrm{~km}$ - custos entre US $\$ 85,90$ a US $\$ 103,00$ por tonelada transportada; distâncias entre 3500 a $4000 \mathrm{~km}$ - custos de US\$120,20 a US\$137,40 por tonelada transportada.

$\mathrm{O}$ índice médio US\$/t km, nas viagens com origem em Concórdia, foi de aproximadamente US\$0,034/tkm. A única exceção foi na rota Concórdia - Manaus, onde o custo por tonelada quilômetro foi menor devido ao deslocamento da composição, via balsa, entre Belém e Manaus, atingindo o valor de US\$0,023/t km.

As rotas de caminho mínimo, os mapas temáticos e os custos de viagem referentes às outras origens do cenário 1, podem ser observados no Apêndice L. 
A Figura 4.8 e a Figura 4.9 mostram, respectivamente, o mapa temático para a rota Concórdia - Fortaleza e os custos por tonelada por rota das viagens rodo-hidroviárias do cenário 2, com origem em Concórdia. Os mapas temáticos e os custos por tonelada para as demais rotas podem ser observados no Apêndice $M$.

Através das rotas factíveis descritas no Quadro 4.1, simularam-se e escolheram-se as rotas com as escalas e transporte rodoviário de mínimo custo para os $j$ destinos. Assim, através da construção dos mapas temáticos e das rotas de mínimo custo, foram obtidos os resultados operacionais para as respectivas rotas: Belém 03, Belo Horizonte, Fortaleza 02, Ipatinga, Manaus 02, Natal 01, Nossa Senhora do Socorro 01, Salvador, Vitória e Recife 02.

A Figura 4.10 e Figura 4.11 apresentam, respectivamente, o mapa temático e os custos por tonelada para o cenário 3, com embarque na fábrica de Concórdia. Os valores dos custos, por tonelada transportada, com o veículo 3S3B3 comportaram-se nas seguintes faixas: distâncias menores de $500 \mathrm{~km}$ - custos por tonelada transportada menores que US\$10,20; distâncias no intervalo superior de $1000 \mathrm{~km}$ e inferior a $1500 \mathrm{~km}$ - custos por tonelada entre US\$20,60 a US\$30,50; distâncias entre 2500 e 3000km - custos entre US\$50,90 a US\$61,00 por tonelada transportada; distâncias entre 3500 a 4000km custos por tonelada transportada de US\$71,30 a US\$79,40.

Os mapas temáticos e os custos por tonelada para as demais rotas podem ser observados no Apêndice N. 


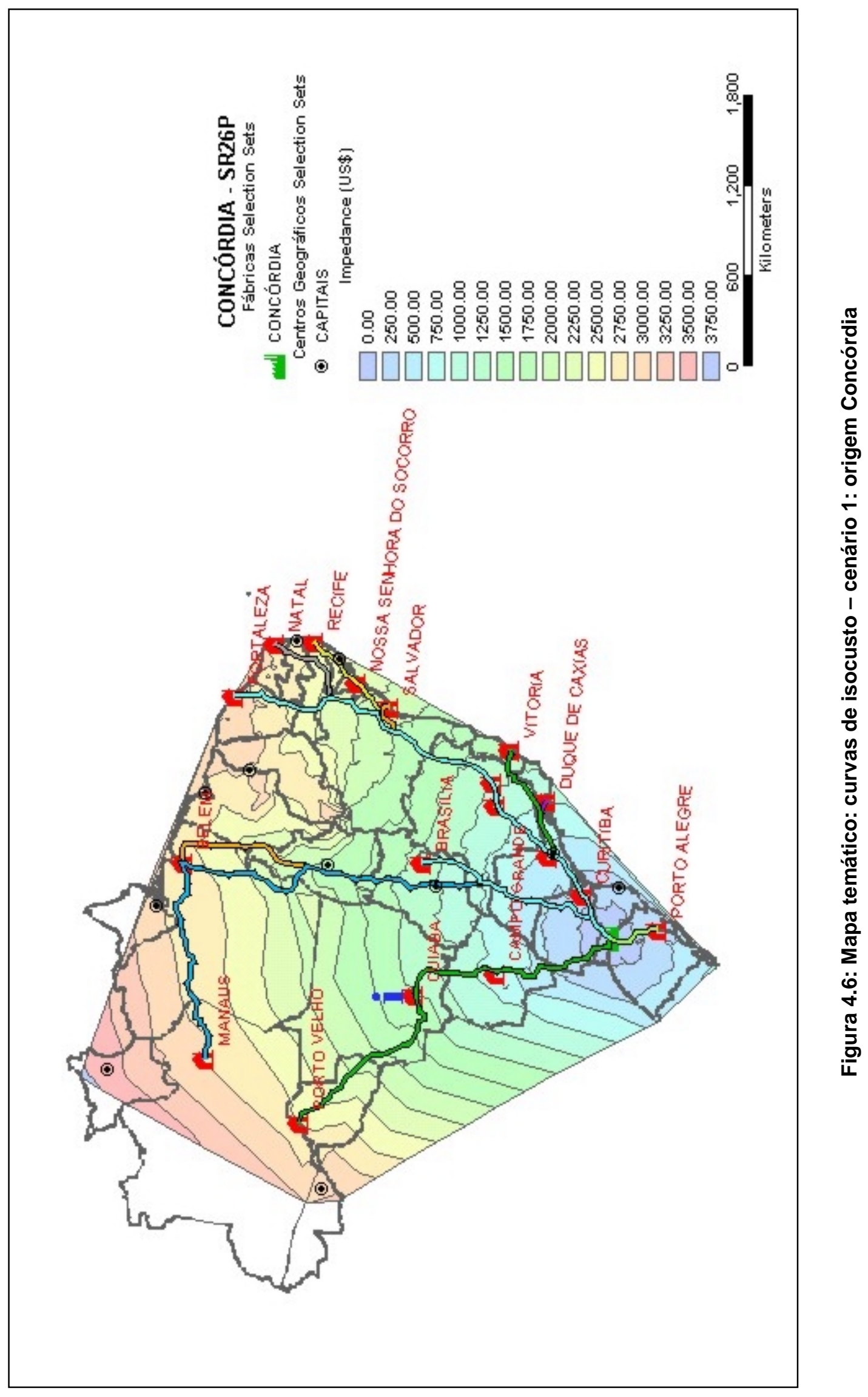




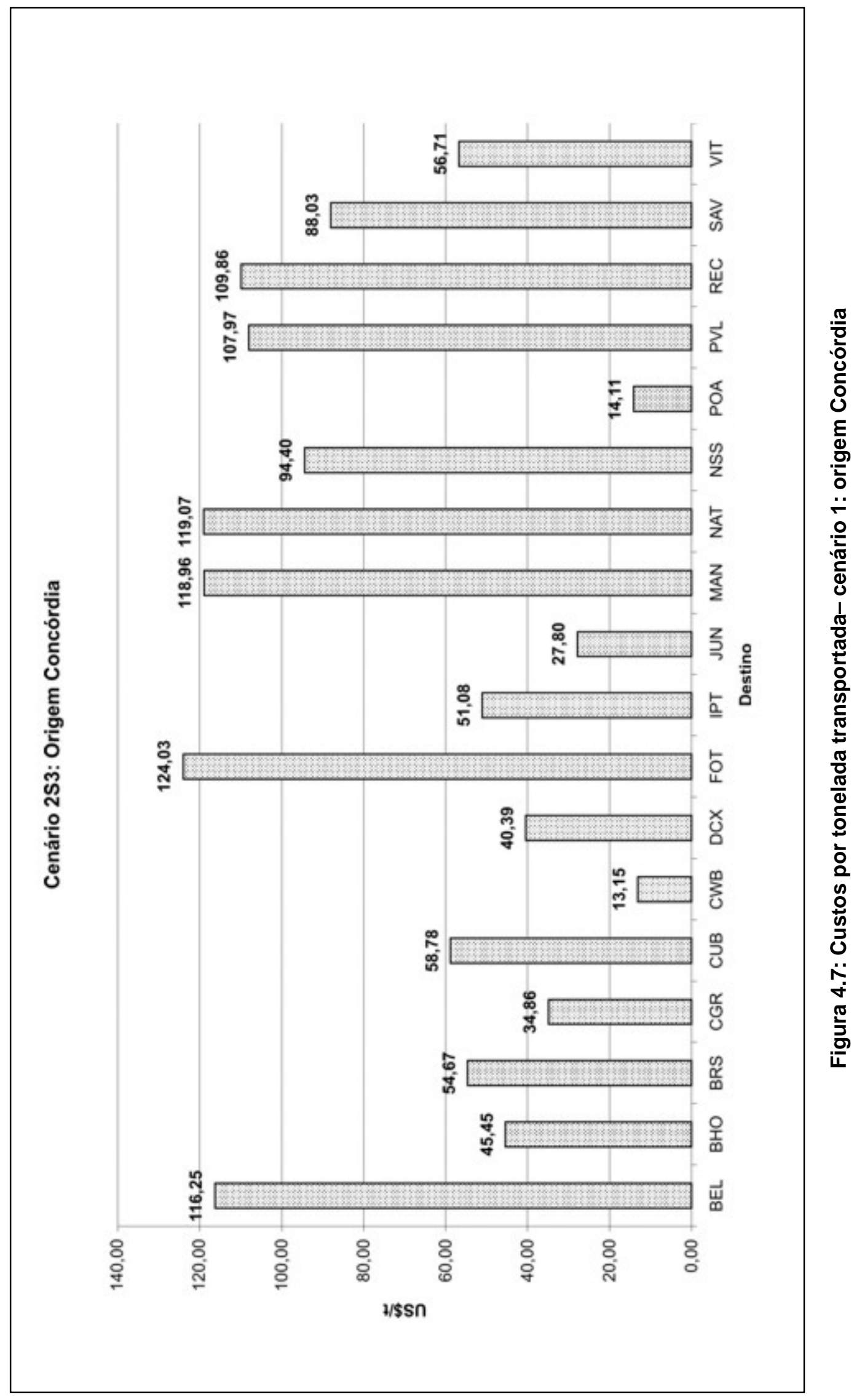



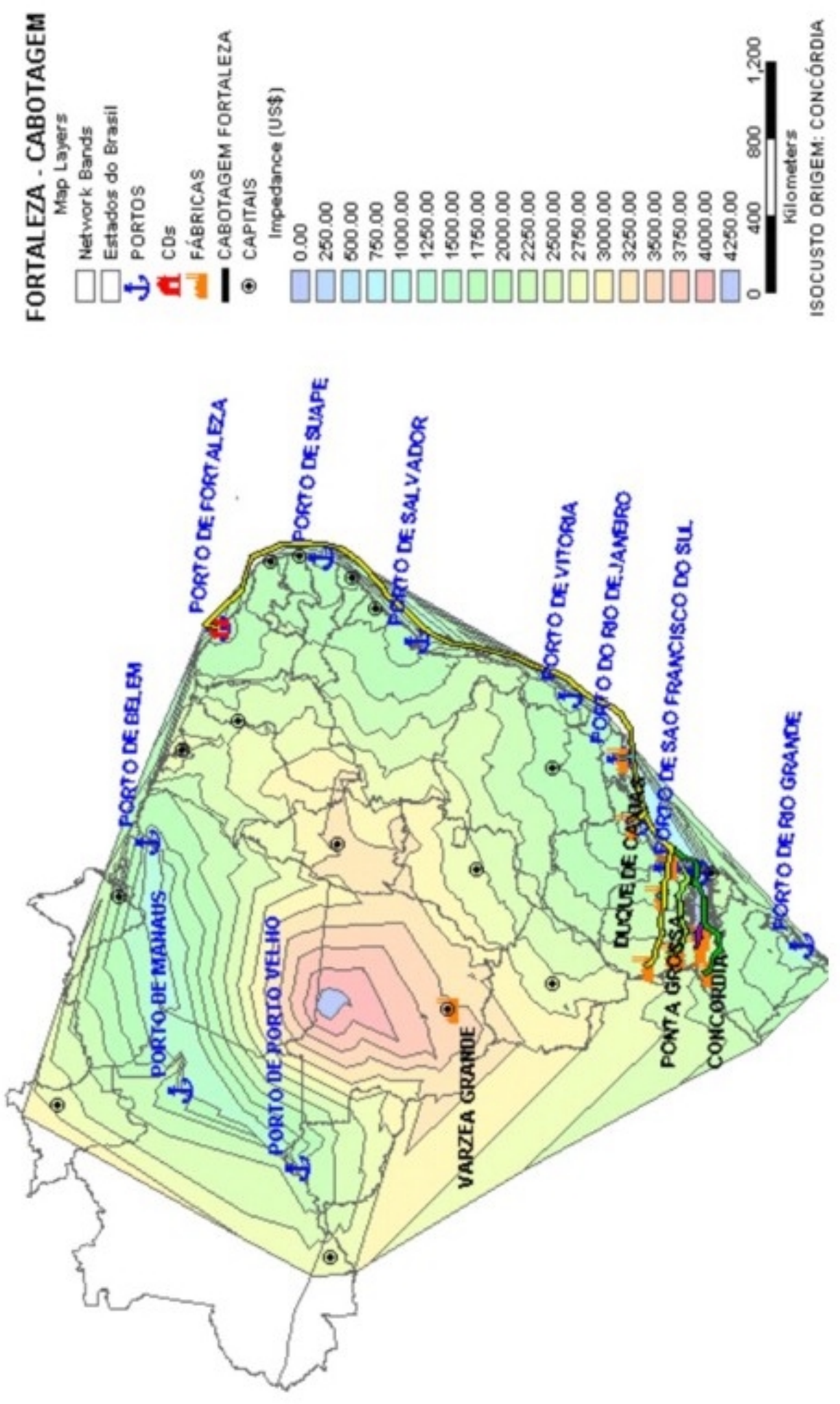


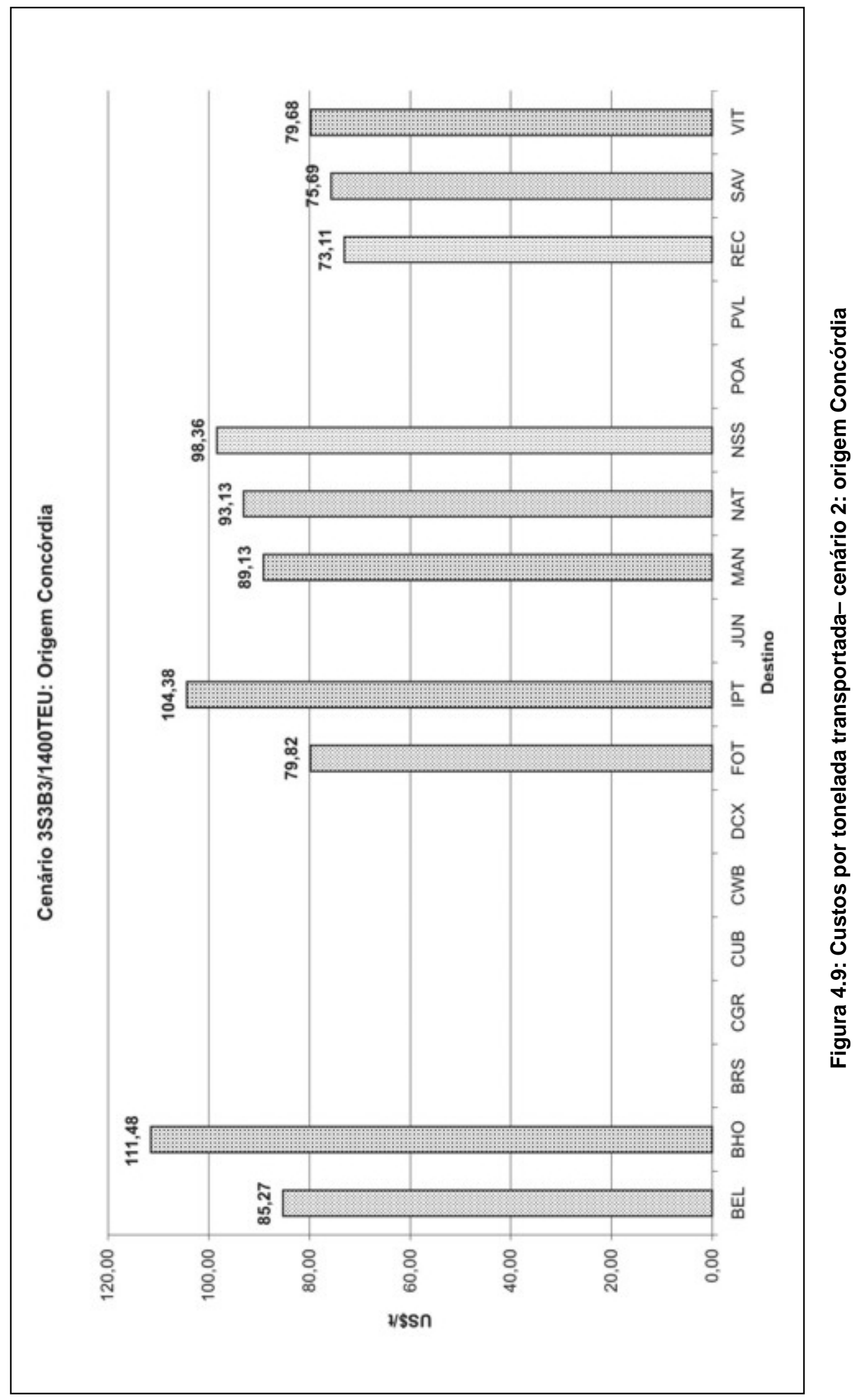



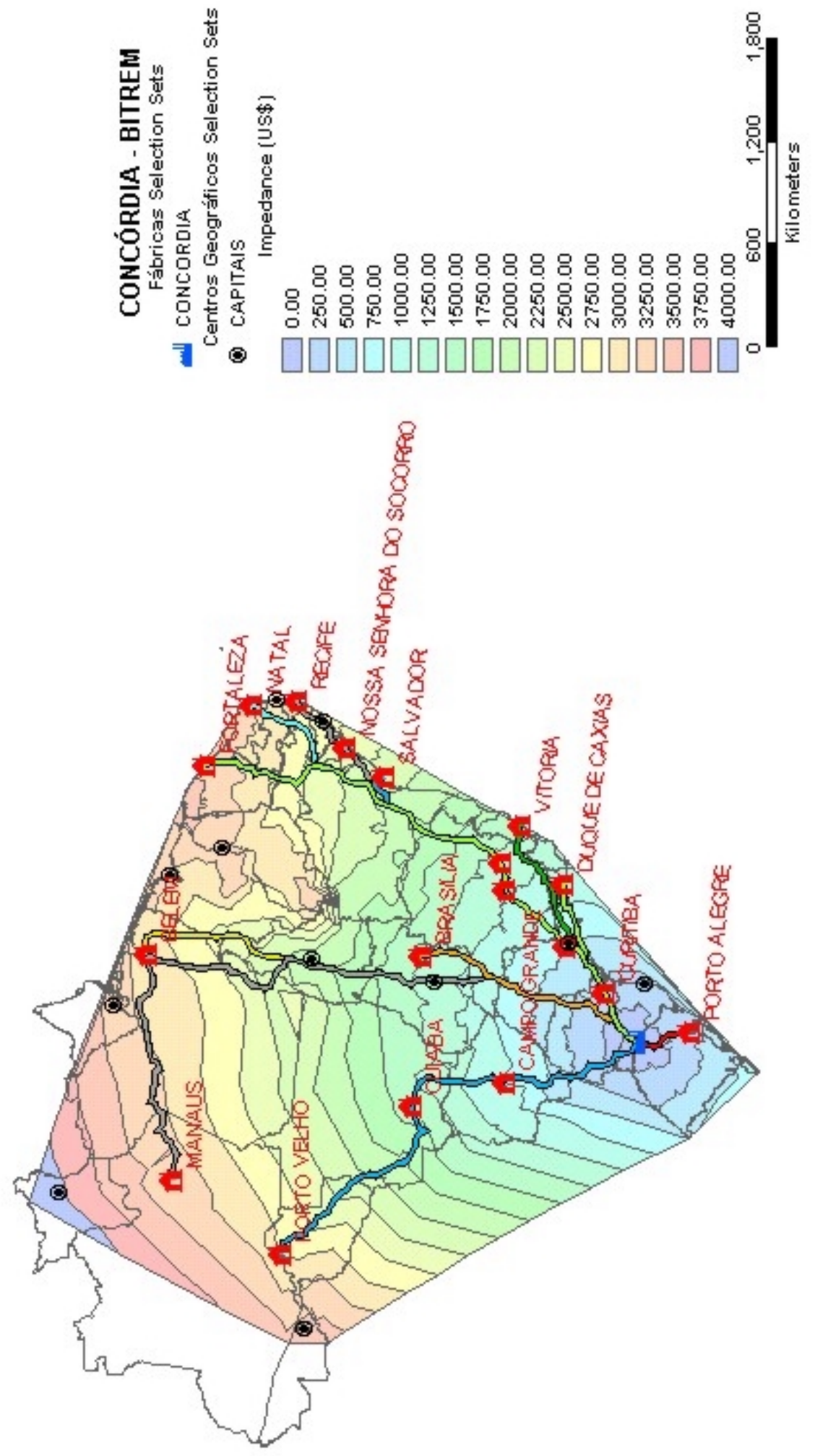

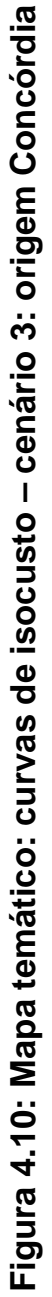




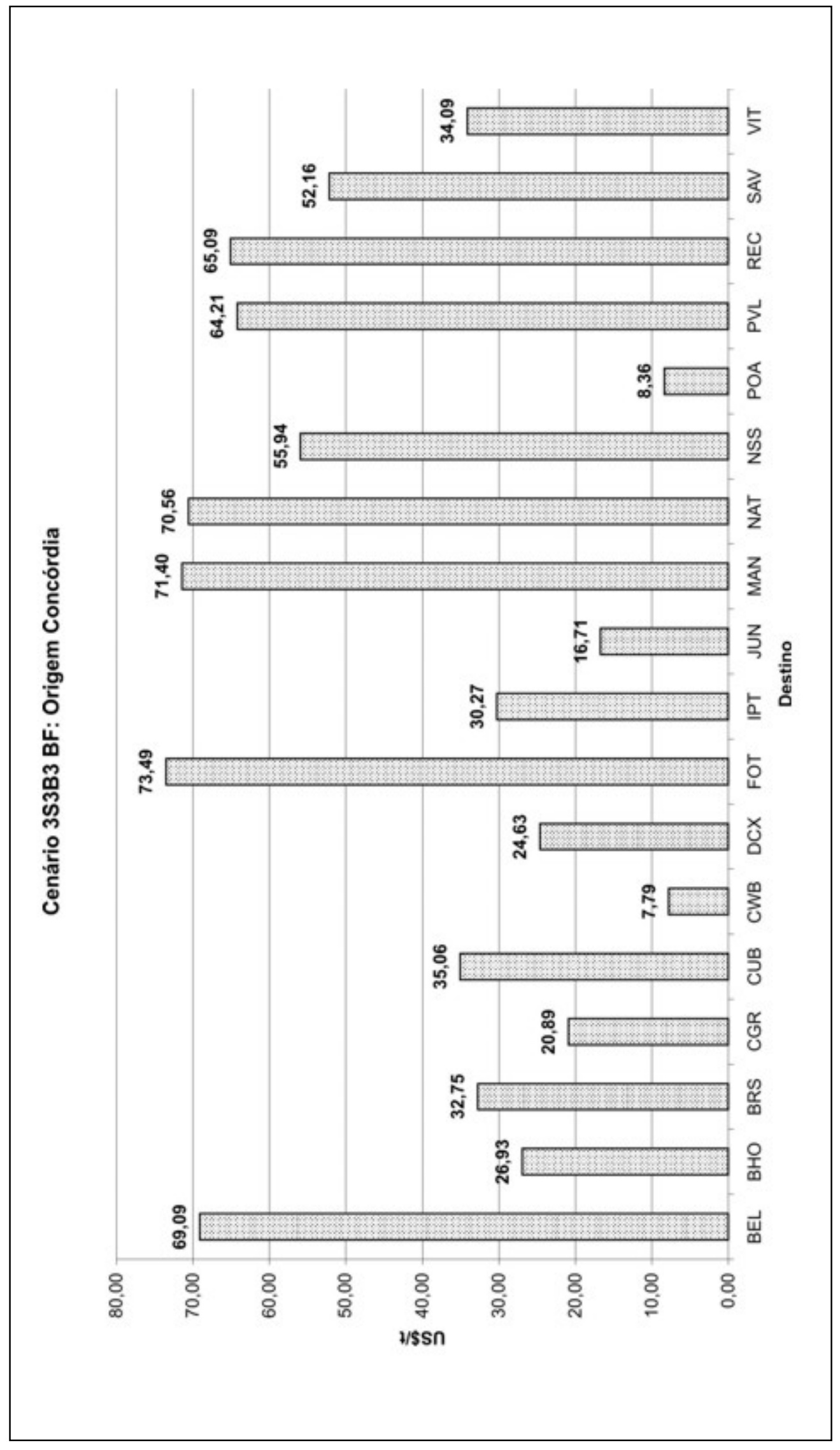

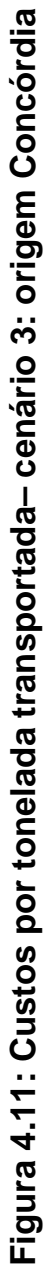


Os gráficos observados nas Figuras 4.12 a 4.23, apresentam a comparação dos custos por tonelada transportada para as três diferentes tecnologias estudadas nos cenários 1,2 e 3. Além do custo total do cenário 2, são mostrados os custos relativos ao transporte marítimo (somando-se os transbordos dos contêineres e as escalas da embarcação) e os custos do transporte rodoviário dos contêineres carregados e vazios (entre fábricas, centros de distribuição e portos). Esta comparação gráfica apresenta somente os custos das viagens, conforme os destinos escolhidos segundo os critérios restritivos para o cenário rodo-hidroviário. Os valores dos custos por tonelada transportada plotados nos gráficos são observados nas tabelas do Apêndice L, do Apêndice M e do Apêndice N.
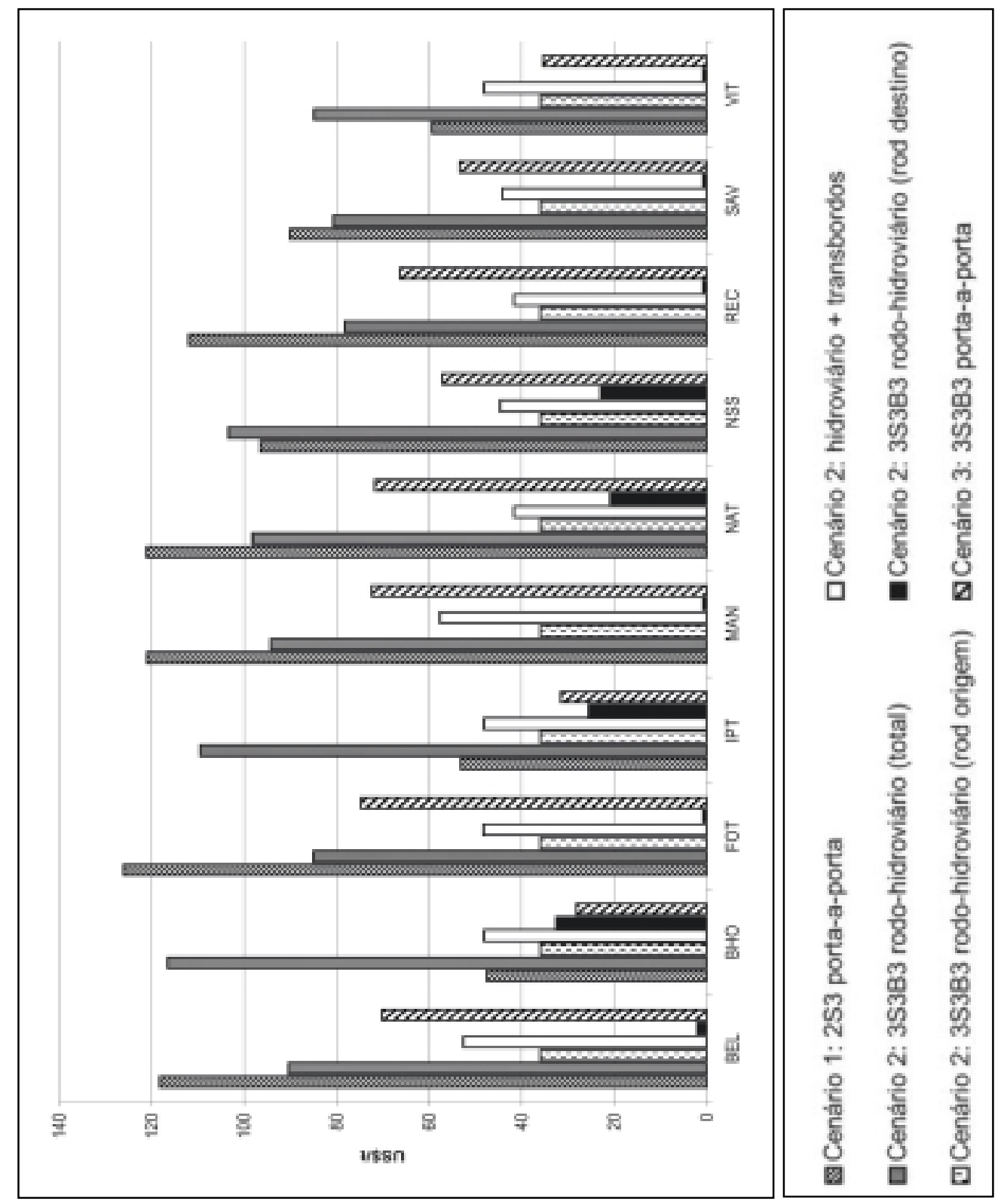

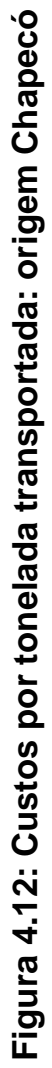




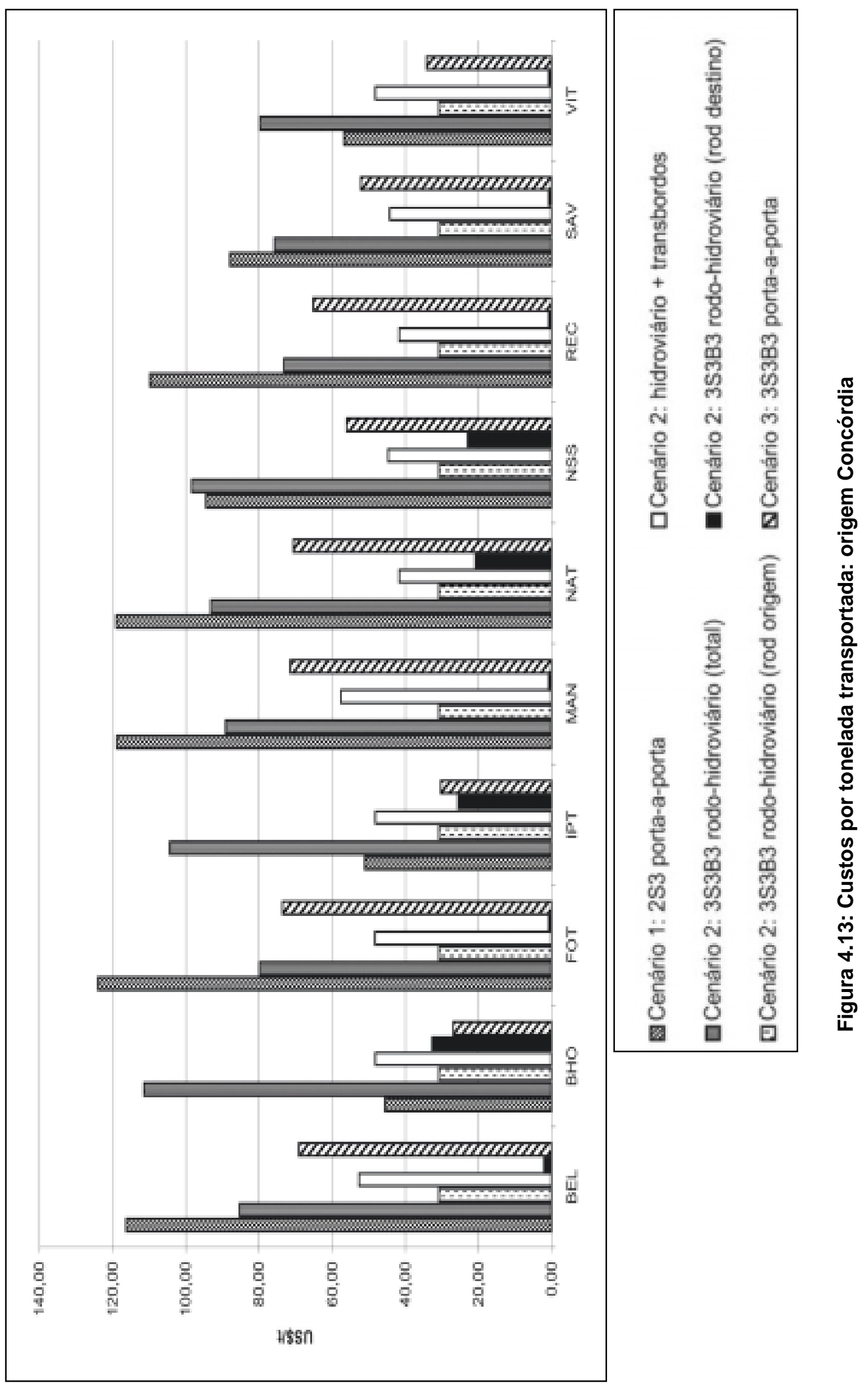




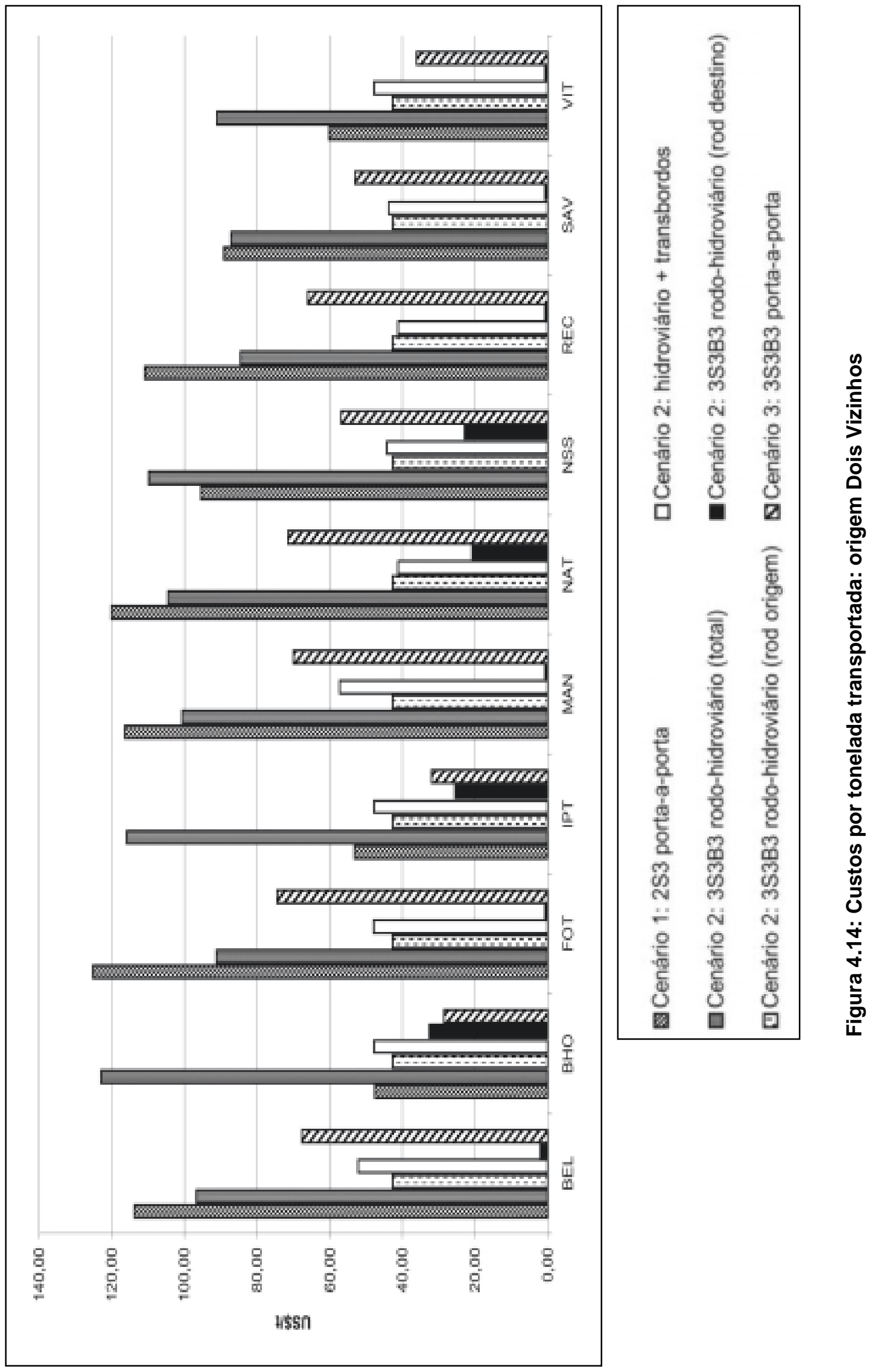




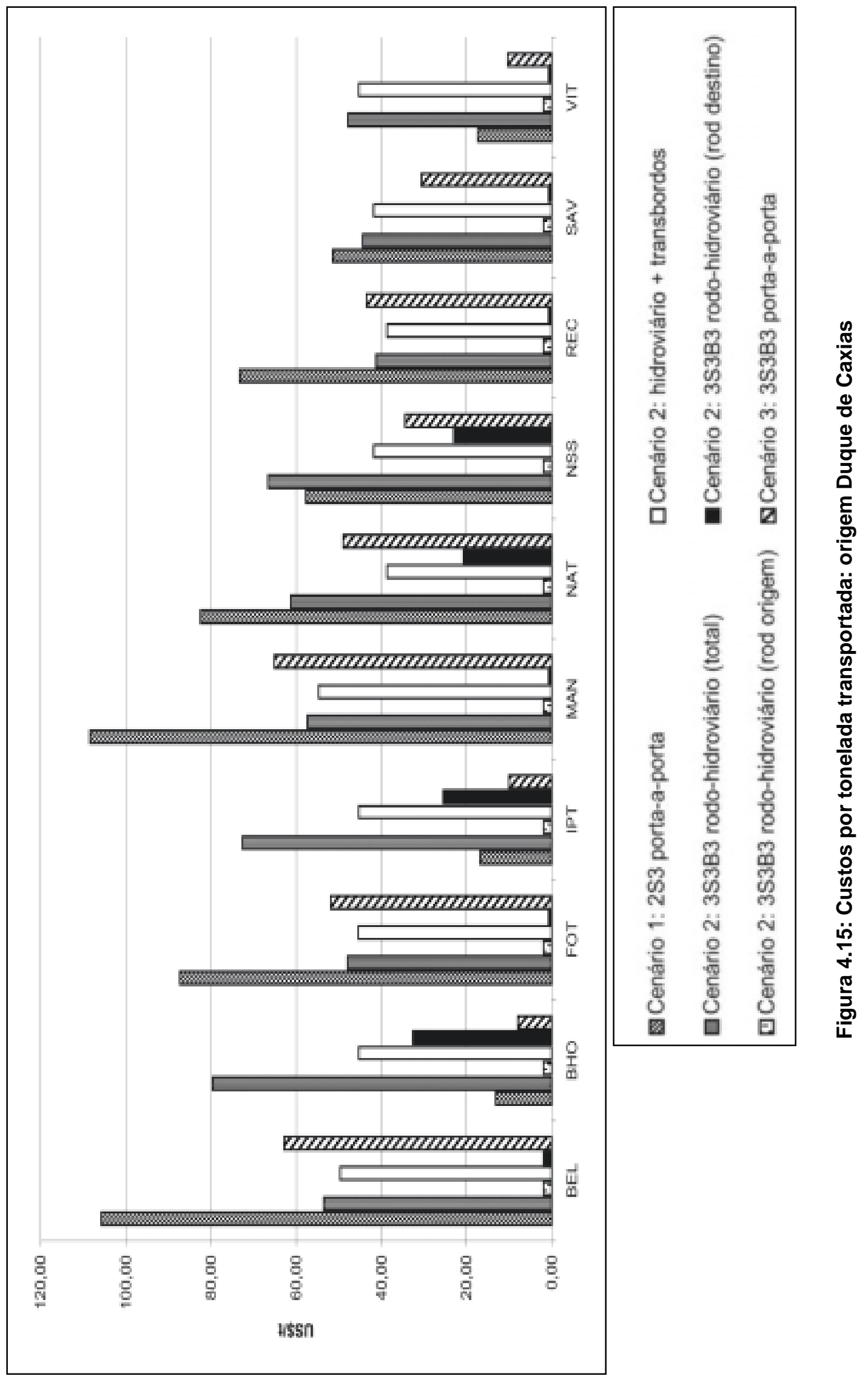




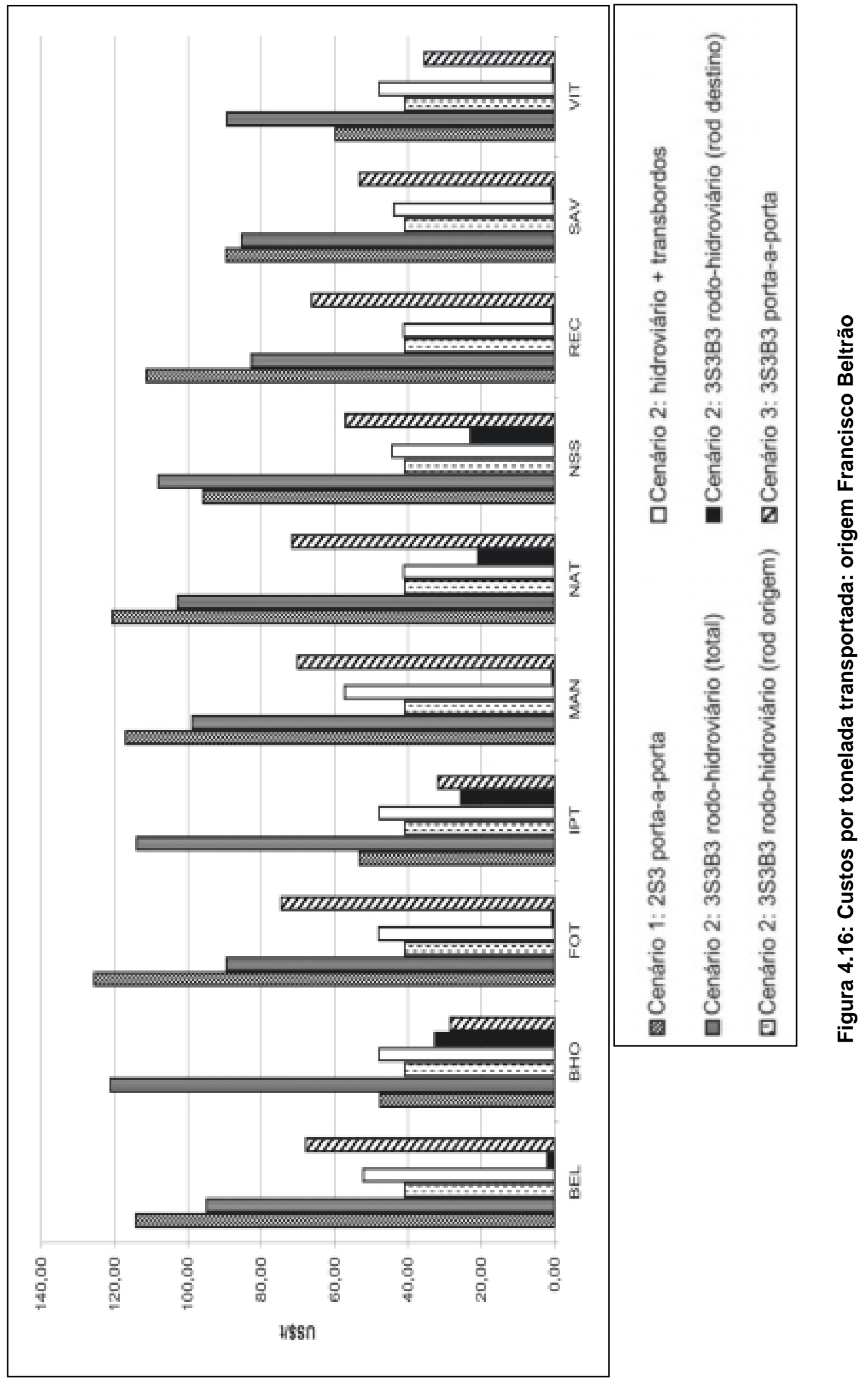




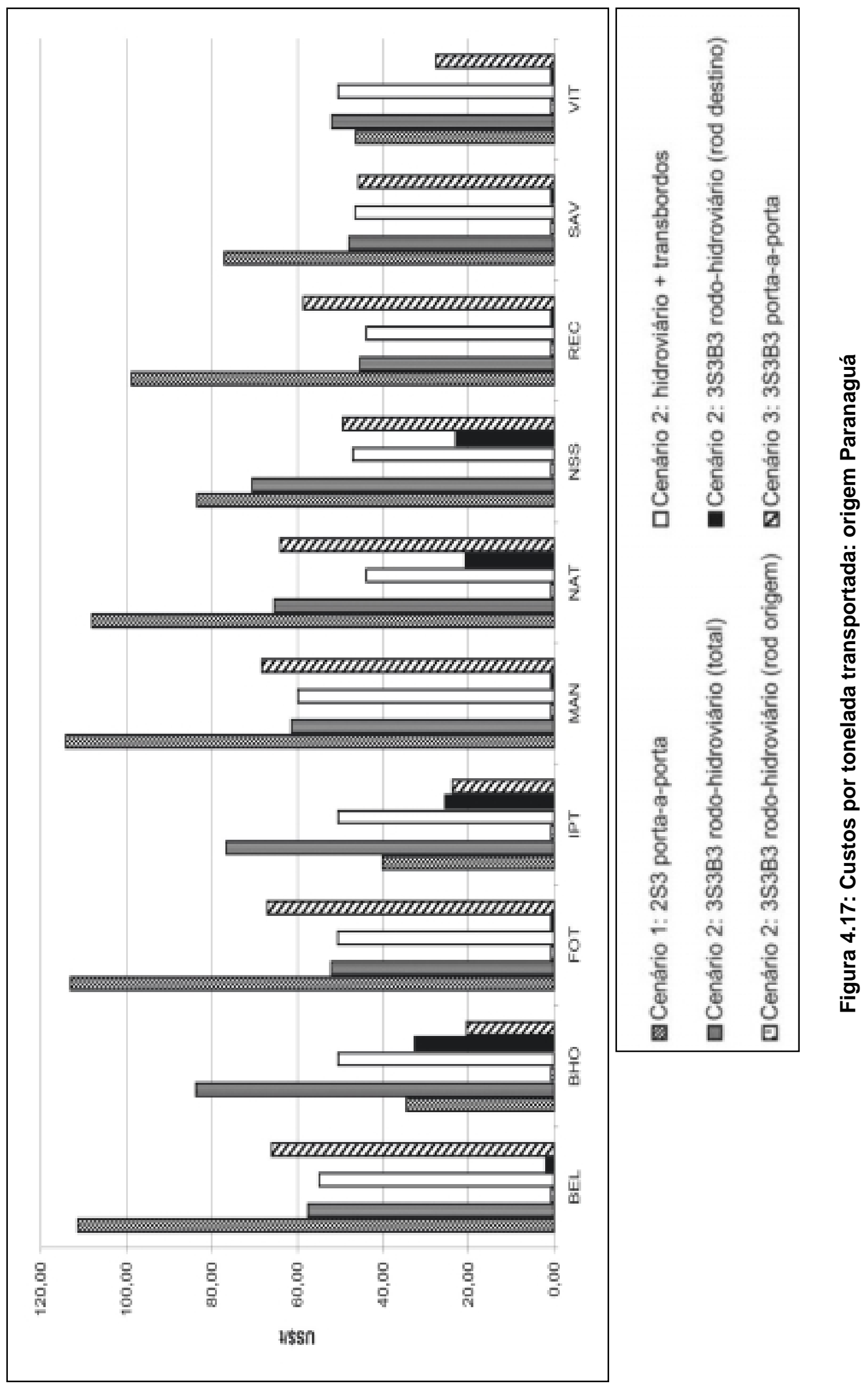




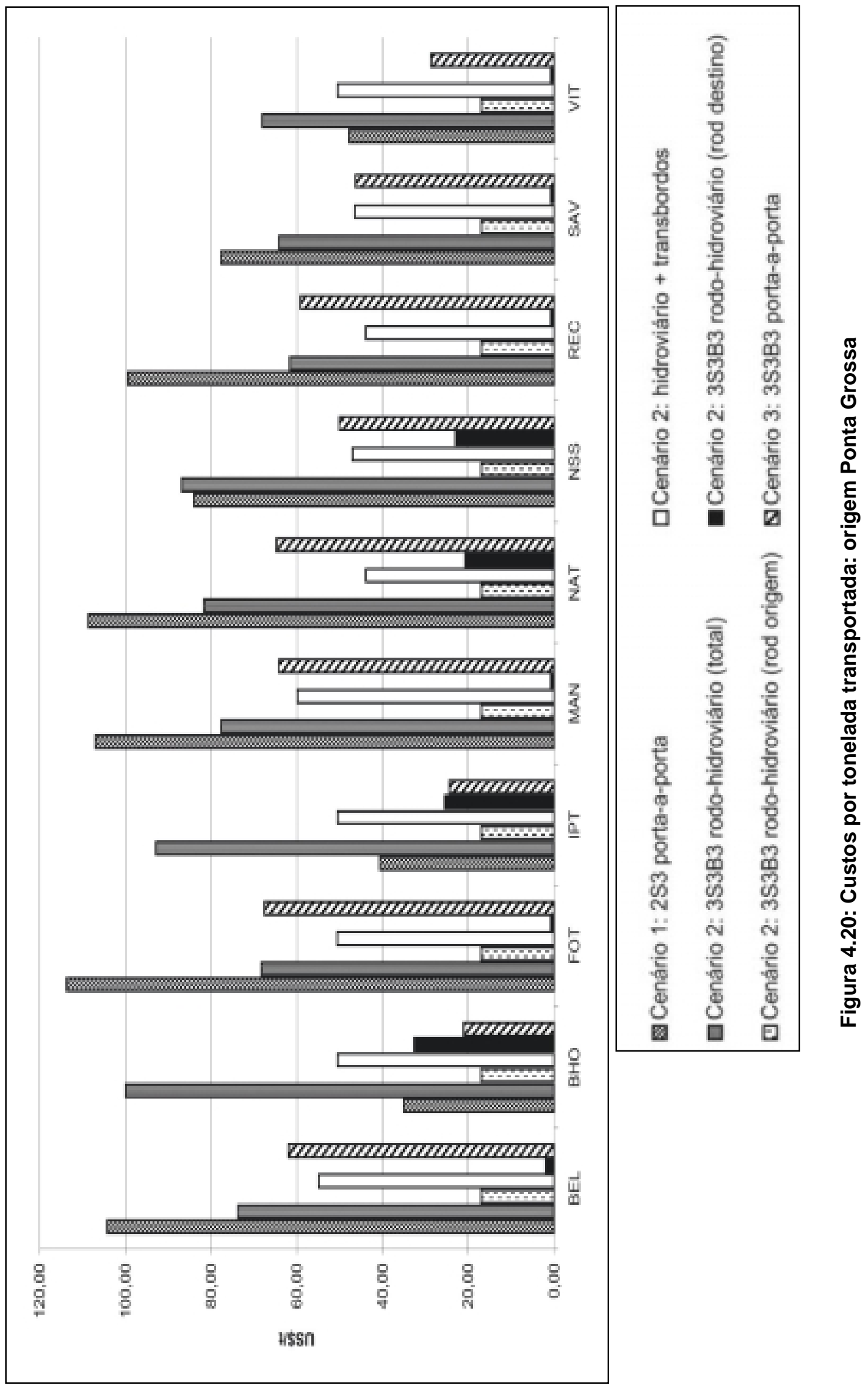




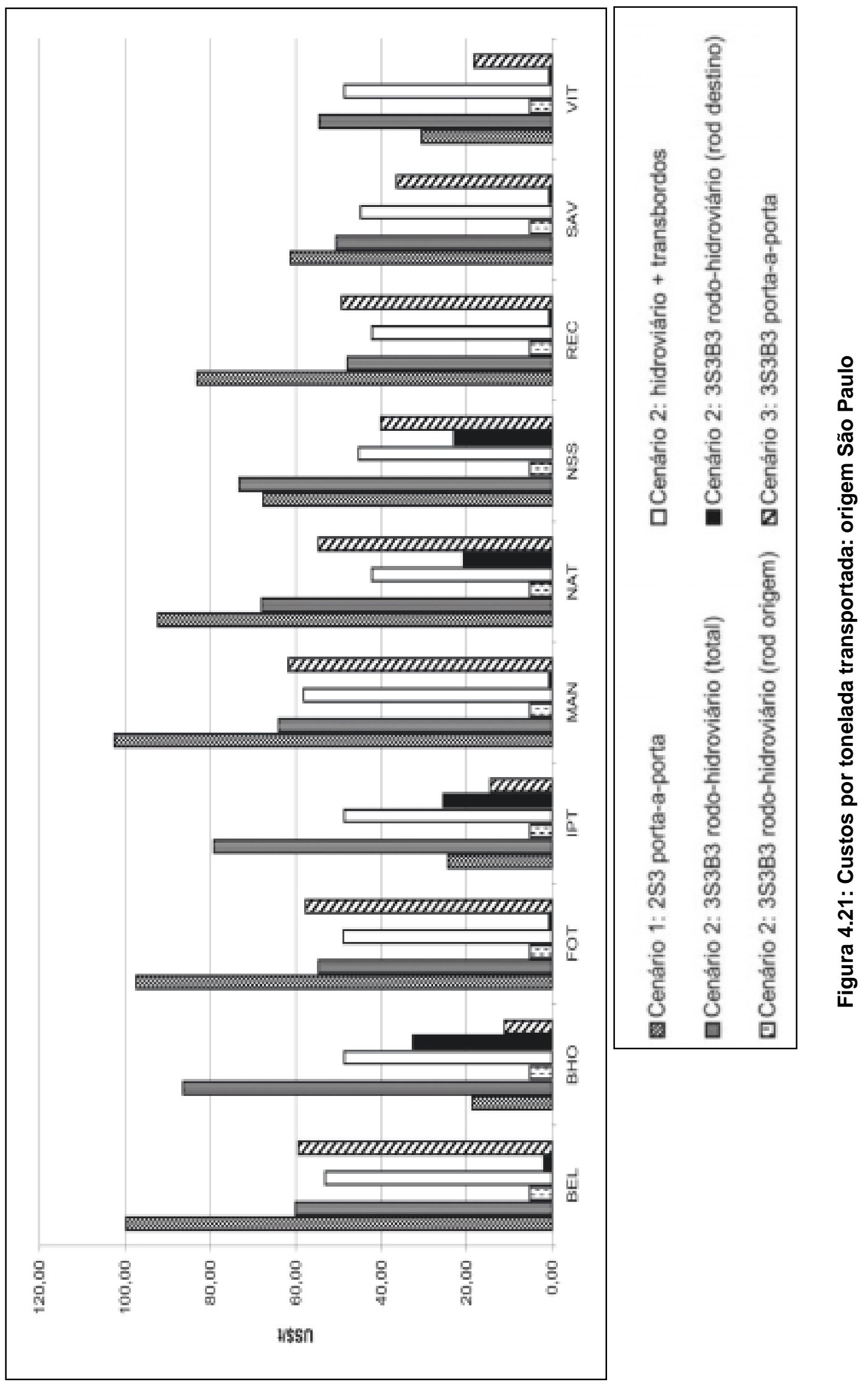




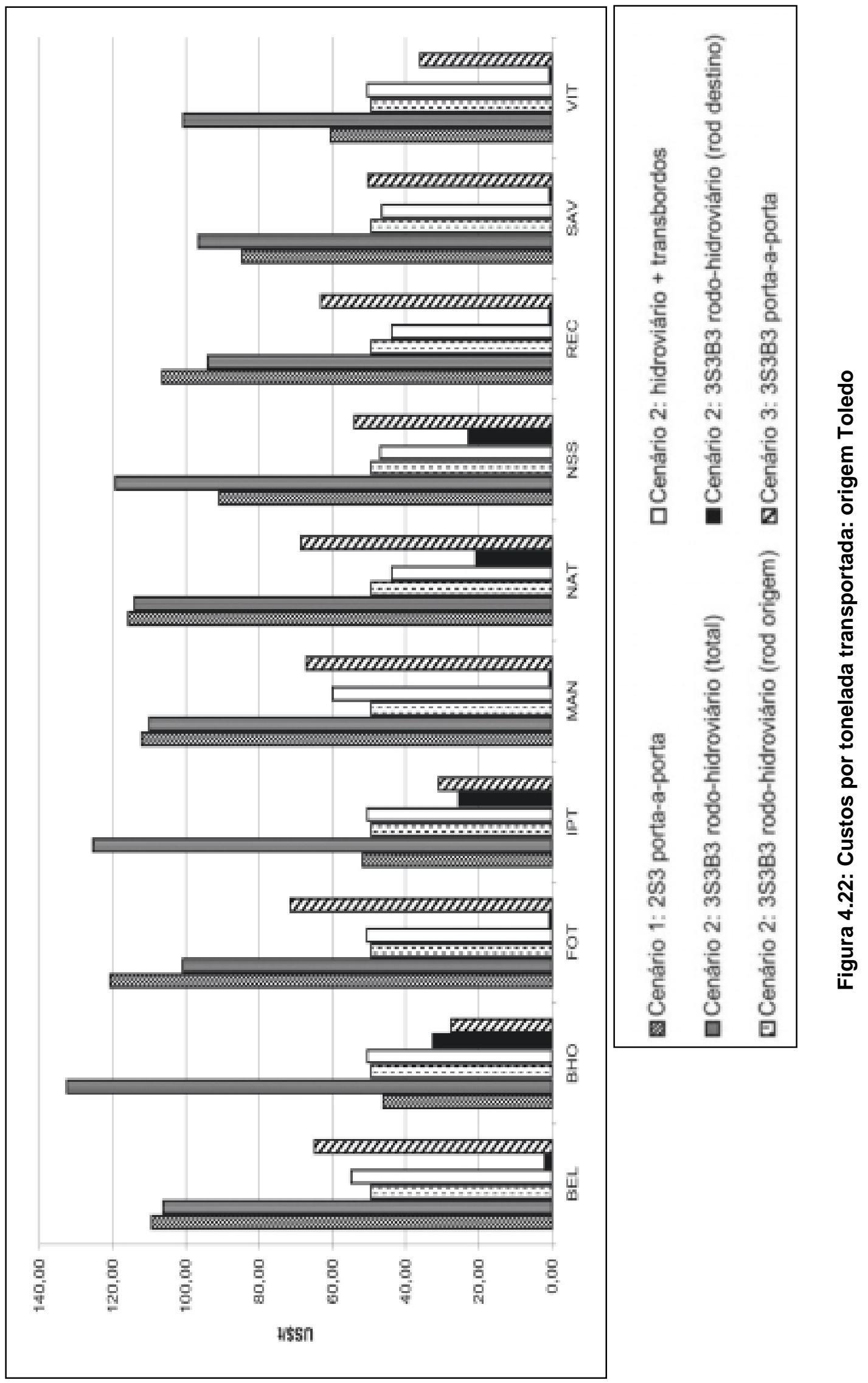




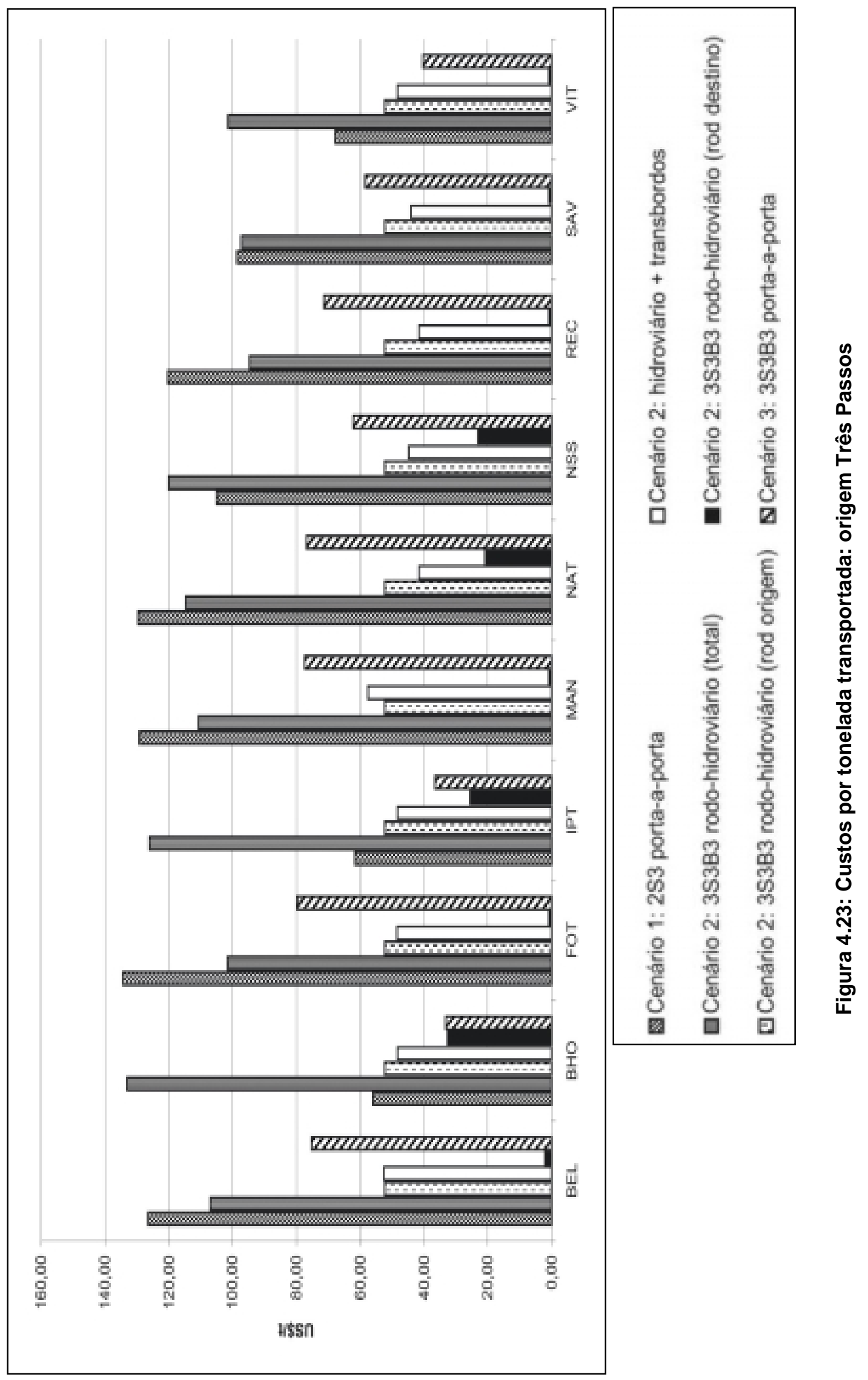


Uma outra variável de decisão importante na escolha tecnológica operacional no transporte é o tempo de viagem. Neste trabalho, os tempos de viagem calculados na análise da rede de custo são referentes aos tempos de trânsito entre as fábricas e os centros de distribuição, no caso do cenário 1 e do cenário 3. Esses valores, entretanto, não contemplam os tempos das escalas dos navios nos portos antecessores ao porto de destino e os tempos de transbordo dos contêineres, no caso do cenário 2. Assim, para o tempo de ciclo das rotas para o dimensionamento da frota de contêineres, somaram-se os tempos de trânsito dos veículos rodoviários entre os terminais, os tempos de transbordo dos contêineres e os tempos das escalas da embarcação nos portos.

A Figura 4.24 mostra os tempos de trânsito para as viagens rodoviárias e as viagens marítimas com origem na fábrica de Chapecó e com destino aos centros de distribuição. Neste gráfico não foram adicionados os tempos de retorno da viagem dos veículos e dos contêineres vazios. Conforme exposto nos itens 4.2 e 4.4, consideraram-se velocidades operacionais teóricas idênticas para os veículos $2 \mathrm{~S} 3$ e 3S3B3 dos cenários 1 e 3, acarretando assim resultados idênticos de tempos de viagem.

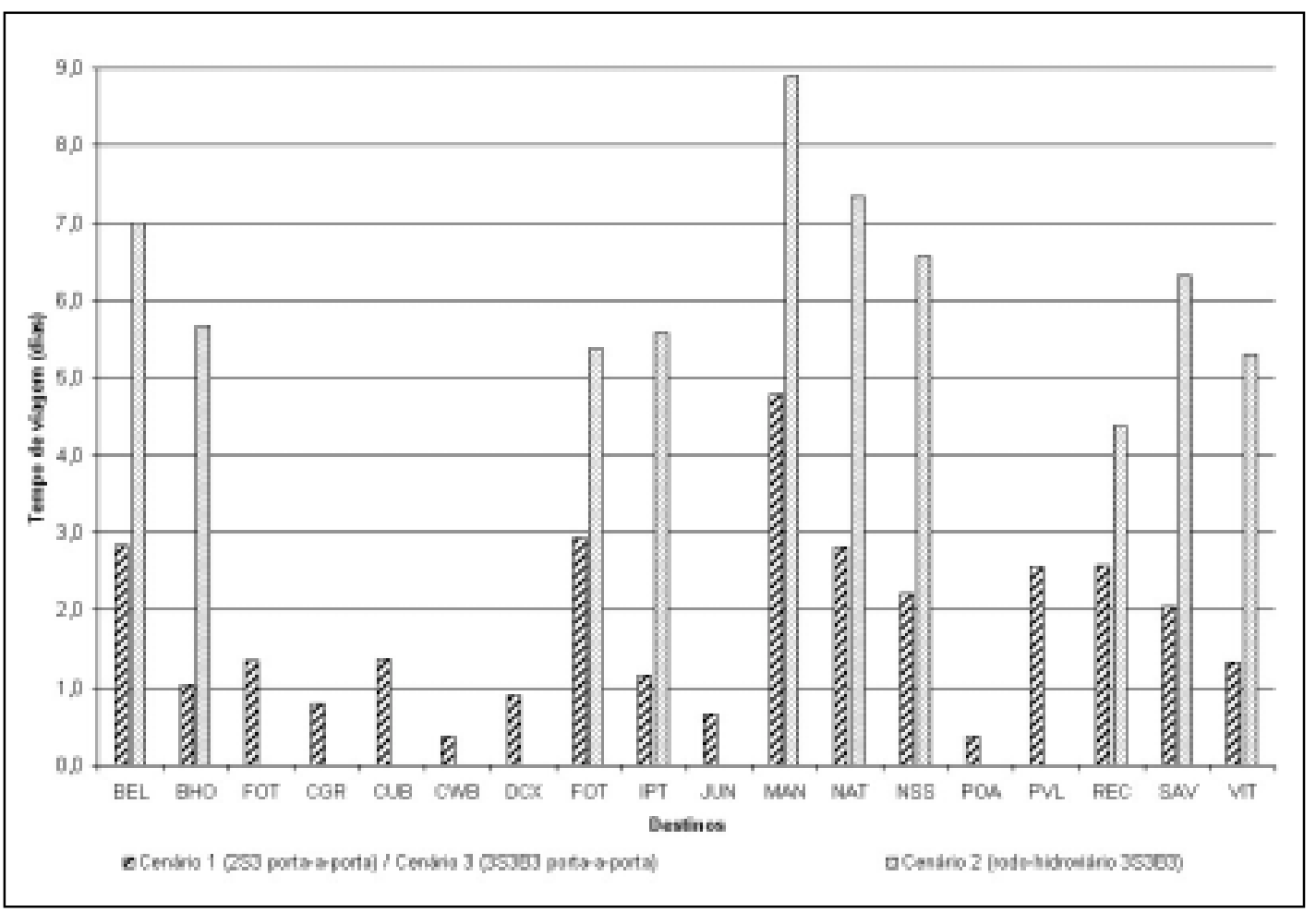

Figura 4.24: Tempo de trânsito: cenários rodoviários e rodo-hidoviário - Origem Chapecó 


\section{ANÁLISE DOS RESULTADOS}

\subsection{Competitividade econômica dos cenários}

Do ponto de vista das vantagens competitivas em cada uma das rotas selecionadas, nos cenários, são três as análises comparativas das economias. Uma compara os custos do transporte rodo-hidroviário, com o bitrem 3S3B3 nas pontas, versus o transporte rodoviário porta-a-porta com o veículo $2 \mathrm{~S} 3$ com baú frigorífico. A segunda analisa os custos do transporte rodo-hidroviário, com o bitrem 3S3B3 nas pontas versus os custos do transporte porta-a-porta com o bitrem 3S3B3, com baú frigorífico. A última análise compara os custos entre os cenários do transporte rodoviário porta-a-porta com os veículos $2 \mathrm{~S} 3$ e 3S3B3 equipados com baú frigorífico. Nas análises foram escolhidas as rotas factíveis com destino aos centros de distribuição de Belém, Belo Horizonte, Fortaleza, Ipatinga, Manaus, Natal, Nossa Senhora do Socorro, Recife, Salvador e Vitória, conforme as restrições descritas em 4.3.

O método de comparação é baseado no índice percentual $g$, calculado através da eq. (5.1), onde $c_{i} / c_{2}$ são as razões entre os custos por tonelada obtidos nas rotas para o cenário 1 ou o cenário 3 e os custos do cenário 2. Conforme a variação do sinal de $g$, positivo ou negativo, encontrou-se o ganho ou a perda econômica na rota em relação ao cenário 2.

$$
g=\left(1-\frac{c_{i}}{c_{2}}\right) \times 100
$$

O principais valores de $g$ obtidos na comparação dos cenários 1 e 3, com o cenário 2, são observados no Quadro 5.1 


\section{Quadro 5.1: Economia relativa dos cenários 1 e 3 frente à alternativa rodo-marítima}

\begin{tabular}{|c|c|c|c|c|}
\hline \multirow{3}{*}{$\begin{array}{l}\text { Rota: } \\
\text { Manaus }\end{array}$} & \multicolumn{4}{|c|}{ Custo por tonelada (US $\$ / \mathrm{t}$ ) } \\
\hline & \multirow{2}{*}{$\begin{array}{l}\text { Razão dos custos } \\
\text { cenários 01/02 (\%) }\end{array}$} & \multirow{2}{*}{$\begin{array}{l}\text { Razão dos custos } \\
\text { cenários } 03 / 02(\%)\end{array}$} & \multicolumn{2}{|c|}{ Economia Relativa (\%) } \\
\hline & & & $01 / 02$ & $03 / 02$ \\
\hline CDA - MAN & $133,46 \%$ & $80,10 \%$ & $-33,46 \%$ & $19,90 \%$ \\
\hline CHP - MAN & $128,30 \%$ & $76,87 \%$ & $-28,30 \%$ & $23,13 \%$ \\
\hline DCX - MAN & $189,23 \%$ & $113,55 \%$ & $-89,23 \%$ & $-13,55 \%$ \\
\hline DVZ - MAN & $115,81 \%$ & $69,51 \%$ & $-15,81 \%$ & $30,49 \%$ \\
\hline FCB - MAN & $118,36 \%$ & $70,98 \%$ & $-18,36 \%$ & $29,02 \%$ \\
\hline PNG - MAN & $185,92 \%$ & $111,24 \%$ & $-85,92 \%$ & $-11,24 \%$ \\
\hline PGR - MAN & $137,85 \%$ & $82,68 \%$ & $-37,85 \%$ & $17,32 \%$ \\
\hline SPL - MAN & $160,22 \%$ & $96,47 \%$ & $-60,22 \%$ & $3,53 \%$ \\
\hline TLD - MAN & $101,77 \%$ & $60,94 \%$ & $-1,77 \%$ & $39,06 \%$ \\
\hline TPS - MAN & $116,59 \%$ & $69,95 \%$ & $-16,59 \%$ & $30,05 \%$ \\
\hline \multirow{3}{*}{$\begin{array}{l}\text { Rota: } \\
\text { Belém }\end{array}$} & \multicolumn{4}{|c|}{ Custo por tonelada (US\$/t) } \\
\hline & \multirow{2}{*}{$\begin{array}{l}\text { Razão dos custos } \\
\text { cenários 01/02 (\%) }\end{array}$} & \multirow{2}{*}{$\begin{array}{c}\text { Razão dos custos } \\
\text { cenários 03/02 (\%) }\end{array}$} & \multicolumn{2}{|c|}{ Economia Relativa (\%) } \\
\hline & & & $01 / 02$ & $03 / 02$ \\
\hline CDA - BEL & $137,92 \%$ & $81,97 \%$ & $-37,92 \%$ & $18,03 \%$ \\
\hline CHP - BEL & $132,16 \%$ & $78,46 \%$ & $-32,16 \%$ & $21,54 \%$ \\
\hline DCX - BEL & $201,54 \%$ & $119,65 \%$ & $-101,54 \%$ & $-19,65 \%$ \\
\hline DVZ - BEL & $118,78 \%$ & $70,68 \%$ & $-18,78 \%$ & $29,32 \%$ \\
\hline FCB - BEL & $121,58 \%$ & $72,18 \%$ & $-21,58 \%$ & $27,82 \%$ \\
\hline PNG - BEL & $196,96 \%$ & $116,71 \%$ & $-96,96 \%$ & $-16,71 \%$ \\
\hline PGR - BEL & $143,30 \%$ & $85,02 \%$ & $-43,30 \%$ & $14,98 \%$ \\
\hline SPL - BEL & $168,18 \%$ & $100,13 \%$ & $-68,18 \%$ & $-0,13 \%$ \\
\hline TLD - BEL & $103,88 \%$ & $61,55 \%$ & $-3,88 \%$ & $38,45 \%$ \\
\hline TPS - BEL & $119,37 \%$ & $70,97 \%$ & $-19,37 \%$ & $29,03 \%$ \\
\hline \multirow{3}{*}{$\begin{array}{c}\text { Rota: } \\
\text { Fortaleza }\end{array}$} & \multicolumn{4}{|c|}{ Custo por tonelada (US\$/t) } \\
\hline & \multirow{2}{*}{$\begin{array}{l}\text { Razão dos custos } \\
\text { cenários 01/02 (\%) }\end{array}$} & \multirow{2}{*}{$\begin{array}{c}\text { Razão dos custos } \\
\text { cenários 03/02 (\%) }\end{array}$} & \multicolumn{2}{|c|}{ Economia Relativa (\%) } \\
\hline & & & $01 / 02$ & $03 / 02$ \\
\hline CDA - FOT & $155,39 \%$ & $92,07 \%$ & $-55,39 \%$ & $7,93 \%$ \\
\hline CHP - FOT & $148,39 \%$ & $87,93 \%$ & $-48,39 \%$ & $12,07 \%$ \\
\hline DCX - FOT & $182,00 \%$ & $108,09 \%$ & $-82,00 \%$ & $-8,09 \%$ \\
\hline DVZ - FOT & $137,02 \%$ & $81,50 \%$ & $-37,02 \%$ & $18,50 \%$ \\
\hline FCB - FOT & $140,32 \%$ & $83,29 \%$ & $-40,32 \%$ & $16,71 \%$ \\
\hline PNG - FOT & $217,03 \%$ & $128,59 \%$ & $-117,03 \%$ & $-28,59 \%$ \\
\hline PGR - FOT & $166,42 \%$ & $99,00 \%$ & $-66,42 \%$ & $1,00 \%$ \\
\hline SPL - FOT & $177,35 \%$ & $105,08 \%$ & $-77,35 \%$ & $-5,08 \%$ \\
\hline TLD - FOT & $119,74 \%$ & $70,95 \%$ & $-19,74 \%$ & $29,05 \%$ \\
\hline TPS - FOT & $132,61 \%$ & $78,57 \%$ & $-32,61 \%$ & $21,43 \%$ \\
\hline & & Custo por tonelada (L & $S \$ / t)$ & \\
\hline Rota: & Razão dos custos & Razão dos custos & Economia $\mathrm{P}$ & tiva (\%) \\
\hline Natal & cenários 01/02 (\%) & cenários 03/02 (\%) & $01 / 02$ & $03 / 02$ \\
\hline CDA - NAT & $127,86 \%$ & $75,77 \%$ & $-27,86 \%$ & $24,23 \%$ \\
\hline CHP - NAT & $123,26 \%$ & $73,03 \%$ & $-23,26 \%$ & $26,97 \%$ \\
\hline DCX - NAT & $134,41 \%$ & $79,84 \%$ & $-34,41 \%$ & $20,16 \%$ \\
\hline \begin{tabular}{|l|} 
DVZ - NAT \\
\end{tabular} & $114,85 \%$ & $68,33 \%$ & $-14,85 \%$ & $31,67 \%$ \\
\hline FCB - NAT & $117,34 \%$ & $69,66 \%$ & $-17,34 \%$ & $30,34 \%$ \\
\hline PNG - NAT & $165,28 \%$ & $97,94 \%$ & $-65,28 \%$ & $2,06 \%$ \\
\hline \begin{tabular}{|l|} 
PGR - NAT \\
\end{tabular} & $133,21 \%$ & $79,25 \%$ & $-33,21 \%$ & $20,75 \%$ \\
\hline SPL - NAT & $135,47 \%$ & $80,27 \%$ & $-35,47 \%$ & $19,73 \%$ \\
\hline TLD - NAT & $101,43 \%$ & $60,10 \%$ & $-1,43 \%$ & $39,90 \%$ \\
\hline TPS - NAT & $112,91 \%$ & $66,90 \%$ & $-12,91 \%$ & $33,10 \%$ \\
\hline & & Custo por tonelada (L & $S \$ / t)$ & \\
\hline Rota: & Razão dos custos & Razão dos custos & Economia $\mathrm{P}$ & tiva (\%) \\
\hline Recife & cenários 01/02 (\%) & cenários 03/02 (\%) & $01 / 02$ & $03 / 02$ \\
\hline CDA - REC & $150,26 \%$ & $89,03 \%$ & $-50,26 \%$ & $10,97 \%$ \\
\hline CHP - REC & $142,99 \%$ & $84,73 \%$ & $-42,99 \%$ & $15,27 \%$ \\
\hline DCX - REC & $177,24 \%$ & $105,30 \%$ & $-77,24 \%$ & $-5,30 \%$ \\
\hline DVZ - REC & $131,12 \%$ & $78,04 \%$ & $-31,12 \%$ & $21,96 \%$ \\
\hline FCB - REC & $134,58 \%$ & $79,90 \%$ & $-34,58 \%$ & $20,10 \%$ \\
\hline PNG - REC & $217,87 \%$ & $129,11 \%$ & $-117,87 \%$ & $-29,11 \%$ \\
\hline PGR - REC & $161,53 \%$ & $96,14 \%$ & $-61,53 \%$ & $3,86 \%$ \\
\hline SPL - REC & $172,62 \%$ & $102,27 \%$ & $-72,62 \%$ & $-2,27 \%$ \\
\hline
\end{tabular}




\section{Quadro 5.1: Economia relativa dos cenários 1 e 3 frente à alternativa rodo-marítima (continuação)}

\begin{tabular}{|c|c|c|c|c|}
\hline \multirow{3}{*}{$\begin{array}{c}\text { Rota: } \\
\text { Nossa Senhora } \\
\text { do Socorro }\end{array}$} & \multicolumn{4}{|c|}{ Custo por tonelada (US $\$ / \mathrm{t}$ ) } \\
\hline & \multirow{2}{*}{$\begin{array}{l}\text { Razão dos custos } \\
\text { cenários 01/02 (\%) }\end{array}$} & \multirow{2}{*}{$\begin{array}{c}\text { Razão dos custos } \\
\text { cenários } 03 / 02(\%)\end{array}$} & \multicolumn{2}{|c|}{ Economia Relativa (\%) } \\
\hline & & & $01 / 02$ & $03 / 02$ \\
\hline CDA - NSS & $95,98 \%$ & $56,87 \%$ & $4,02 \%$ & $43,13 \%$ \\
\hline CHP - NSS & $93,19 \%$ & $55,22 \%$ & $6,81 \%$ & $44,78 \%$ \\
\hline DCX - NSS & $86,77 \%$ & $51,60 \%$ & $13,23 \%$ & $48,40 \%$ \\
\hline DVZ - NSS & $86,92 \%$ & $51,75 \%$ & $13,08 \%$ & $48,25 \%$ \\
\hline FCB - NSS & $88,81 \%$ & $52,75 \%$ & $11,19 \%$ & $47,25 \%$ \\
\hline PNG - NSS & $118,11 \%$ & $69,98 \%$ & $-18,11 \%$ & $30,02 \%$ \\
\hline PGR - NSS & $96,76 \%$ & $57,63 \%$ & $3,24 \%$ & $42,37 \%$ \\
\hline SPL - NSS & $92,19 \%$ & $54,63 \%$ & $7,81 \%$ & $45,37 \%$ \\
\hline TLD - NSS & $76,31 \%$ & $45,21 \%$ & $23,69 \%$ & $54,79 \%$ \\
\hline TPS - NSS & $87,42 \%$ & $51,80 \%$ & $12,58 \%$ & $48,20 \%$ \\
\hline \multirow{3}{*}{$\begin{array}{l}\text { Rota: } \\
\text { Salvador }\end{array}$} & \multicolumn{4}{|c|}{ Custo por tonelada (US\$/t) } \\
\hline & \multirow{2}{*}{$\begin{array}{c}\text { Razão dos custos } \\
\text { cenários } 01 / 02(\%)\end{array}$} & \multirow{2}{*}{$\begin{array}{l}\text { Razão dos custos } \\
\text { cenários } 03 / 02(\%)\end{array}$} & \multicolumn{2}{|c|}{ Economia Relativa (\%) } \\
\hline & & & $01 / 02$ & $03 / 02$ \\
\hline CDA - SAL & $116,31 \%$ & $68,91 \%$ & $-16,31 \%$ & $31,09 \%$ \\
\hline CHP - SAL & $111,45 \%$ & $66,04 \%$ & $-11,45 \%$ & $33,96 \%$ \\
\hline DCX - SAL & $115,74 \%$ & $68,84 \%$ & $-15,74 \%$ & $31,16 \%$ \\
\hline DVZ - SAL & $102,22 \%$ & $60,88 \%$ & $-2,22 \%$ & $39,12 \%$ \\
\hline FCB - SAL & $104,95 \%$ & $62,34 \%$ & $-4,95 \%$ & $37,66 \%$ \\
\hline PNG - SAL & $160,66 \%$ & $95,20 \%$ & $-60,66 \%$ & $4,80 \%$ \\
\hline PGR - SAL & $121,04 \%$ & $72,13 \%$ & $-21,04 \%$ & $27,87 \%$ \\
\hline SPL-SAL & $120,85 \%$ & $71,62 \%$ & $-20,85 \%$ & $28,38 \%$ \\
\hline TLD - SAL & $87,62 \%$ & $51,92 \%$ & $12,38 \%$ & $48,08 \%$ \\
\hline TPS - SAL & $101,25 \%$ & $59,99 \%$ & $-1,25 \%$ & $40,01 \%$ \\
\hline \multirow{3}{*}{$\begin{array}{c}\text { Rota: } \\
\text { Vitória }\end{array}$} & \multicolumn{4}{|c|}{ Custo por tonelada (US\$/t) } \\
\hline & \multirow{2}{*}{$\begin{array}{l}\text { Razão dos custos } \\
\text { cenários 01/02 (\%) }\end{array}$} & \multirow{2}{*}{$\begin{array}{l}\text { Razão dos custos } \\
\text { cenários 03/02 (\%) }\end{array}$} & \multicolumn{2}{|c|}{ Economia Relativa (\%) } \\
\hline & & & $01 / 02$ & $03 / 02$ \\
\hline CDA - VIT & $71,17 \%$ & $42,78 \%$ & $28,83 \%$ & $57,22 \%$ \\
\hline CHP - VIT & $70,00 \%$ & $41,64 \%$ & $30,00 \%$ & $58,36 \%$ \\
\hline $\mathrm{DCX}-\mathrm{VIT}$ & $36,16 \%$ & $21,56 \%$ & $63,84 \%$ & $78,44 \%$ \\
\hline DVZ - VIT & $66,02 \%$ & $39,56 \%$ & $33,98 \%$ & $60,44 \%$ \\
\hline FCB - VIT & $66,95 \%$ & $39,81 \%$ & $33,05 \%$ & $60,19 \%$ \\
\hline PNG - VIT & $89,18 \%$ & $53,09 \%$ & $10,82 \%$ & $46,91 \%$ \\
\hline PGR - VIT & $70,31 \%$ & $42,05 \%$ & $29,69 \%$ & $57,95 \%$ \\
\hline SPL - VIT & $55,90 \%$ & $33,36 \%$ & $44,10 \%$ & $66,64 \%$ \\
\hline TLD - VIT & $60,14 \%$ & $35,92 \%$ & $39,86 \%$ & $64,08 \%$ \\
\hline TPS - VIT & $66,94 \%$ & $39,79 \%$ & $33,06 \%$ & $60,21 \%$ \\
\hline & & usto por tonelada (U & $\$ / \mathrm{t})$ & \\
\hline Rota: & Razão dos custos & Razão dos custos & Economia $\mathrm{Re}$ & ativa (\%) \\
\hline Belo Horizonte & cenários 01/02 (\%) & cenários 03/02 (\%) & $01 / 02$ & $03 / 02$ \\
\hline $\mathrm{CDA}-\mathrm{BH}$ & $40,77 \%$ & $24,16 \%$ & $59,23 \%$ & $75,84 \%$ \\
\hline $\mathrm{CHP}-\mathrm{BH}$ & $40,75 \%$ & $24,15 \%$ & $59,25 \%$ & $75,85 \%$ \\
\hline $\mathrm{DCX}-\mathrm{BH}$ & $16,52 \%$ & $9,94 \%$ & $83,48 \%$ & $90,06 \%$ \\
\hline DVZ - BH & $38,64 \%$ & $23,21 \%$ & $61,36 \%$ & $76,79 \%$ \\
\hline FCB - BH & $39,25 \%$ & $23,45 \%$ & $60,75 \%$ & $76,55 \%$ \\
\hline PNG - BH & $41,15 \%$ & $24,38 \%$ & $58,85 \%$ & $75,62 \%$ \\
\hline PGR - BH & $35,09 \%$ & $21,05 \%$ & $64,91 \%$ & $78,95 \%$ \\
\hline SPL-BH & $21,65 \%$ & $12,83 \%$ & $78,35 \%$ & $87,17 \%$ \\
\hline TLD - BH & $34,82 \%$ & $20,85 \%$ & $65,18 \%$ & $79,15 \%$ \\
\hline TPS - BH & $42,03 \%$ & $24,91 \%$ & $57,97 \%$ & $75,09 \%$ \\
\hline & & usto por tonelada (U & $\$ / \mathrm{t})$ & \\
\hline Rota: & Razão dos custos & Razão dos custos & Economia $\mathrm{Re}$ & ativa (\%) \\
\hline Ipatinga & cenários 01/02 (\%) & cenários 03/02 (\%) & $01 / 02$ & $03 / 02$ \\
\hline CDA - IPT & $48,94 \%$ & $29,00 \%$ & $51,06 \%$ & $71,00 \%$ \\
\hline CHP - IPT & $48,53 \%$ & $28,75 \%$ & $51,47 \%$ & $71,25 \%$ \\
\hline DCX - IPT & $23,04 \%$ & $13,82 \%$ & $76,96 \%$ & $86,18 \%$ \\
\hline DVZ - IPT & $45,87 \%$ & $27,51 \%$ & $54,13 \%$ & $72,49 \%$ \\
\hline FCB - IPT & $46,63 \%$ & $27,84 \%$ & $53,37 \%$ & $72,16 \%$ \\
\hline PNG - IPT & $52,31 \%$ & $31,00 \%$ & $47,69 \%$ & $69,00 \%$ \\
\hline PGR - IPT & $43,84 \%$ & $26,25 \%$ & $56,16 \%$ & $73,75 \%$ \\
\hline SPL - IPT & $30,67 \%$ & $18,18 \%$ & $69,33 \%$ & $81,82 \%$ \\
\hline
\end{tabular}


Os textos em negrito, no Quadro 5.1, representam as rotas onde a alternativa hidrorodoviária mostrou-se mais econômica que as alternativas rodoviárias porta-a-porta do cenário 1 e do cenário 3.

Comparado ao transporte porta-a-porta realizado através do veículo rodoviário $2 \mathrm{~S} 3$, nota-se que a cabotagem apresentou uma expressiva economia no custo por tonelada transportada para as viagens de longo curso. Nas rotas com destino a Manaus e Belém os ganhos médios no custo por tonelada transportada foram de aproximadamente $38 \% \mathrm{e}$ 44\%, respectivamente. As rotas com destinos aos centros de distribuição de Fortaleza, Natal, Recife e Salvador apresentaram um ganho médio no custo por tonelada transportada de $58 \%, 27 \%, 53 \%$ e $17 \%$, respectivamente.

As viagens intermodais com destino aos centros de distribuição de Nossa Senhora do Socorro, no Sergipe, e de Natal, no Rio Grande do Norte que processam o transbordo intermodal dos contêineres nos portos de Salvador e Recife, respectivamente, tiveram comportamento diferenciado. Enquanto todas as rotas para Natal são viáveis, no caso Nossa Senhora do Socorro apenas uma rota mostrou ganhos econômicos em relação ao transporte porta-a-porta com o 2S3. Dois fatores contribuem para esse resultado. De um lado as distâncias rodoviárias que separam os portos de Salvador e Recife dos respectivos destinos são de aproximadamente 610 e $550 \mathrm{~km}$, o que provoca um custo adicional de US\$2,14/t, mas o motivo principal, que responde por $71 \%$ da diferença, é que o custo do processamento dos contêineres no Porto de Salvador adiciona US\$ 5,21/t em relação à operação no Porto do Recife, ou seja, os custos de processamento portuário têm um impacto significativo sobre os resultados em algumas rotas.

Nas viagens hidroviárias curtas, como é o caso das rotas de Ipatinga, Belo Horizonte e Vitória, o transporte rodo-hidroviário não apresenta nenhuma vantagem perante $o$ transporte rodoviário porta-a-porta. Para esses destinos a cabotagem chega a aumentar 0 custo da tonelada transportada, comparados ao veículo 2S3, em 43, 35 e 65\%, respectivamente. 
Observando a comparação do cenário 2 e o cenário 3 nota-se que o veículo bitrem 3S3B3, no geral, apresenta uma significativa economia no custo por tonelada transportada. Somente em poucas viagens, com origem em unidades fabris e destinos a centros de distribuição próximos aos portos, a cabotagem tornou-se mais competitiva que o bitrem com baú frigorífico.

No caso das duas alternativas rodoviárias porta-a-porta o Quadro 5.2 mostra a economia da utilização do bitrem 3S3B3 perante o semi-reboque 2S3. Nota-se que para todas as rotas o comportamento do custo por tonelada transportada e o custo total da viagem foram semelhantes. Verifica-se que o custo de uma viagem com um veículo frigorífico do tipo 3S3B3 é aproximadamente $10 \%$ mais cara que um veículo $2 \mathrm{~S} 3$, mas devido à maior capacidade de carga do 3S3B3 o custo final por tonelada transportada é de aproximadamente $40 \%$ menor que o veículo $2 \mathrm{~S} 3$.

Cabe salientar que este resultado numérico é sensível à escolha da configuração dos veículos e a carga líquida máxima decorrente dessa configuração para o peso específico da carga transportada. Neste estudo de caso o $2 \mathrm{~S} 3$ tem uma capacidade volumétrica de $78 \mathrm{~m}^{3}$, a qual, multiplicada pelo peso específico médio da carga paletizada de $384 \mathrm{~kg} / \mathrm{m}^{3}$ conduz a uma carga líquida de 30t, é incompatível com a restrição legal de PBTC da composição de 41,5t. A restrição de PBTC associada ao fato de que o baú frigorífico com a unidade de refrigeração pesa da ordem de 9,6t impõe um limite em peso à carga líquida de 25t. No caso do 3S3B3, que tem uma capacidade volumétrica de $121 \mathrm{~m}^{3}$, obtem-se uma carga líquida para o total de capacidade de 46,5t, a qual neste caso não sofre restrição pela 'Lei da Balança'. Para uma CVC do tipo 3S3, semi-reboque de 6 eixos, o qual também é utilizado neste segmento e tem uma capacidade de carga líquida maior que o $2 \mathrm{~S} 3$ com pequena variação de custo operacional, o diferencial de ganho seria da ordem de $25 \%$.

Comparando-se os cenários de transporte rodoviário porta-a-porta, pode-se observar que ocorre uma significativa redução no número de veículos necessários quando se aumenta a capacidade de carga unitária da tecnologia de transporte. Este aumento na capacidade 
provoca, no caso estudado, uma redução de 89 equipamentos rodoviários, o que implica uma redução expressiva do custo fixo da operação.

\section{Quadro 5.2: Economia relativa entre os cenários rodoviários}
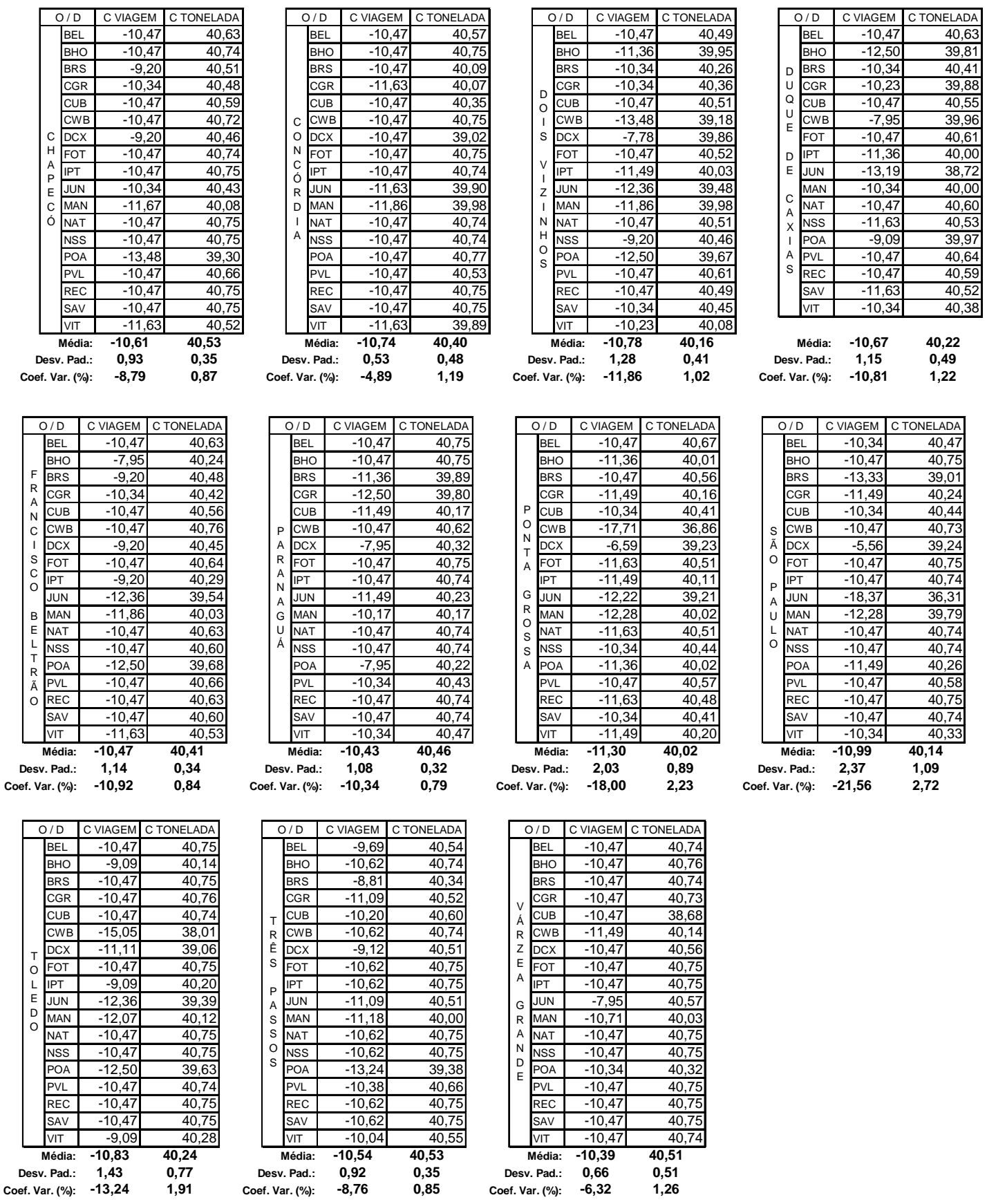

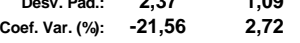


Observando as informações geradas na criação dos mapas temáticos não é constatada uma divergência do itinerário no grafo de caminho mínimo para as rotas envolvendo as mesmas origens e destinos, comparando o cenário 1 e o cenário 3. Isso nos sugere que o acréscimo do custo de pedágios no veículo 3S3B3, devido ao maior número de eixos, não ocasiona a escolha de novas rotas para o desvio dos custos de pedágios.

Comparando as duas tecnologias rodoviárias do tipo bitrem 3S3B3, na versão baú frigorífico e na versão porta-contêineres, verifica-se que ambos apresentam uma tara aproximada de 27,5t e um mesmo valor de PBTC. Porém, as restrições estruturais e volumétricas dos contêineres, as restrições de segurança na alocação dos contêineres na estiva do navio e o peso específico médio dos produtos frigoríficos estudados, acarretam uma redução na capacidade de carga líquida transportada pelo conjunto porta contêineres de aproximadamente 34\% comparado ao bitrem baú frigorífico.

\subsection{Análise de sensibilidade}

Dado que os resultados da pesquisa mostraram-se pouco favoráveis às integrações rodohidroviárias, comparados ao transporte rodoviário porta-a-porta com o veículo 3S3B3, decidiu-se complementar o estudo com uma análise de sensibilidade dos resultados à variação dos dados de entrada do modelo proposto. Assim, para os cenários rodohidroviários, realizou-se uma análise de sensibilidade com variação linear dos principais itens que influenciam no custo final do modelo. Os principais itens escolhidos para a análise de sensibilidade foram:

- Cenário 1:

- Salário do motorista; custo de aquisição do cavalo mecânico; custo de aquisição do implemento rodoviário; custo do pneumático; e custo do óleo diesel.

- Cenário 2:

- Custo da viagem marítima; custo rodoviário na origem; custo rodoviário no destino; custos portuários na origem e no destino;

- Variação dos custos portuários adotados no modelo proposto. 
- Cenário 3:

- Salário motorista; custo de aquisição do cavalo mecânico; custo de aquisição do implemento rodoviário; custo do pneumático; e custo do óleo diesel.

A Figura 5.1 e a Figura 5.2 mostram os gráficos das análises de sensibilidade para a variação dos custos do cenário 1, em duas viagens com origem na fábrica de Chapecó e com os seguintes destinos: Fortaleza (rota longa) e Porto Alegre (rota curta). Nota-se que os principais itens que afetam o valor final no custo da tonelada, para o transporte com o semi-reboque frigorífico 2S3, são: o custo do óleo diesel e o custo de aquisição do cavalo-mecânico, nesta mesma ordem.

Da mesma forma, a Figura 5.3 e a Figura 5.4 mostram a variação dos custos para o cenário 3, também para uma viagem longa e uma viagem curta, com origem em Chapecó e destinos à Fortaleza e Porto Alegre, respectivamente. Inversamente ao constatado no cenário 1 , o item de maior impacto na variação dos custos foi o valor de aquisição do cavalo mecânico, seguido do valor do óleo diesel.

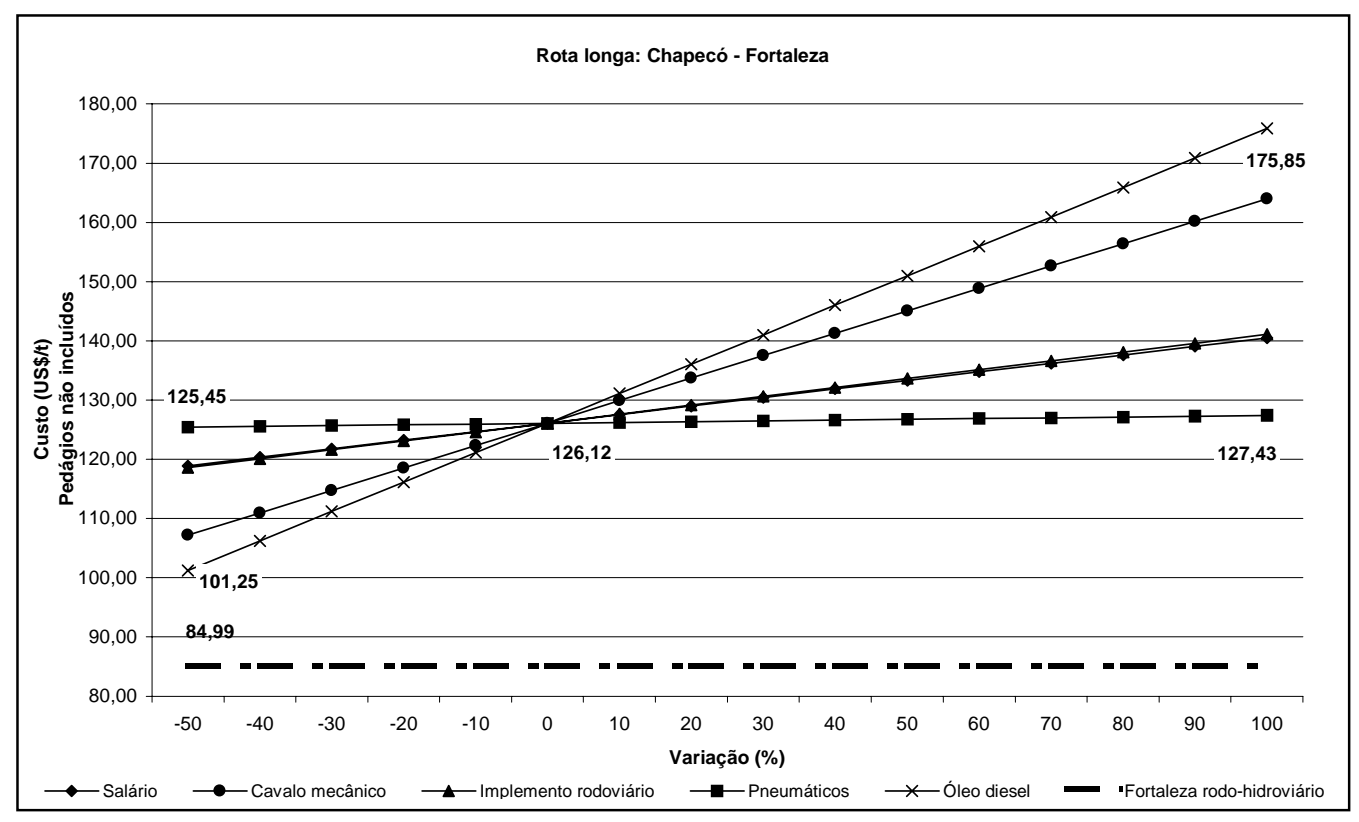

Figura 5.1: Análise de sensibilidade - cenário 1: Chapecó - Fortaleza 


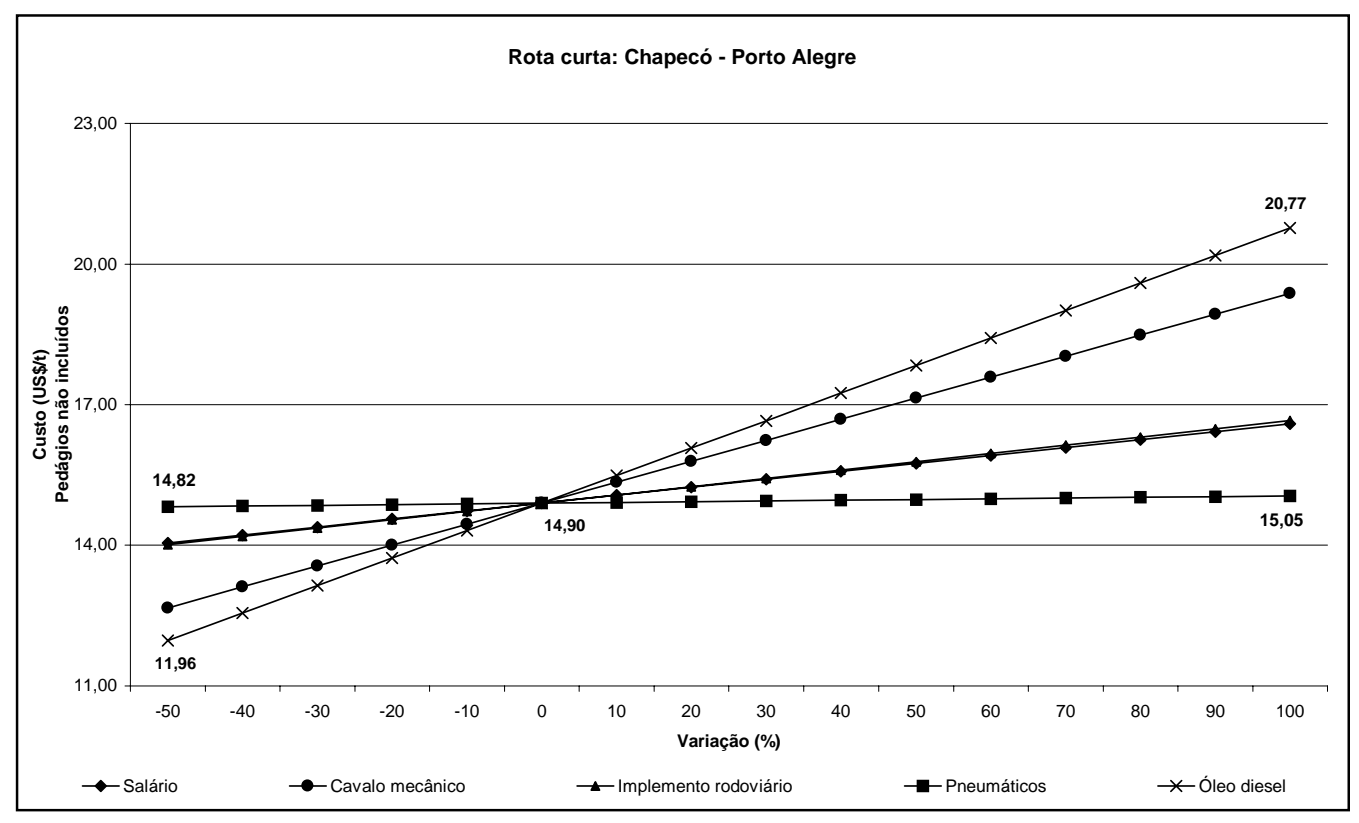

Figura 5.2: Análise de sensibilidade - cenário 1: Chapecó - Porto Alegre

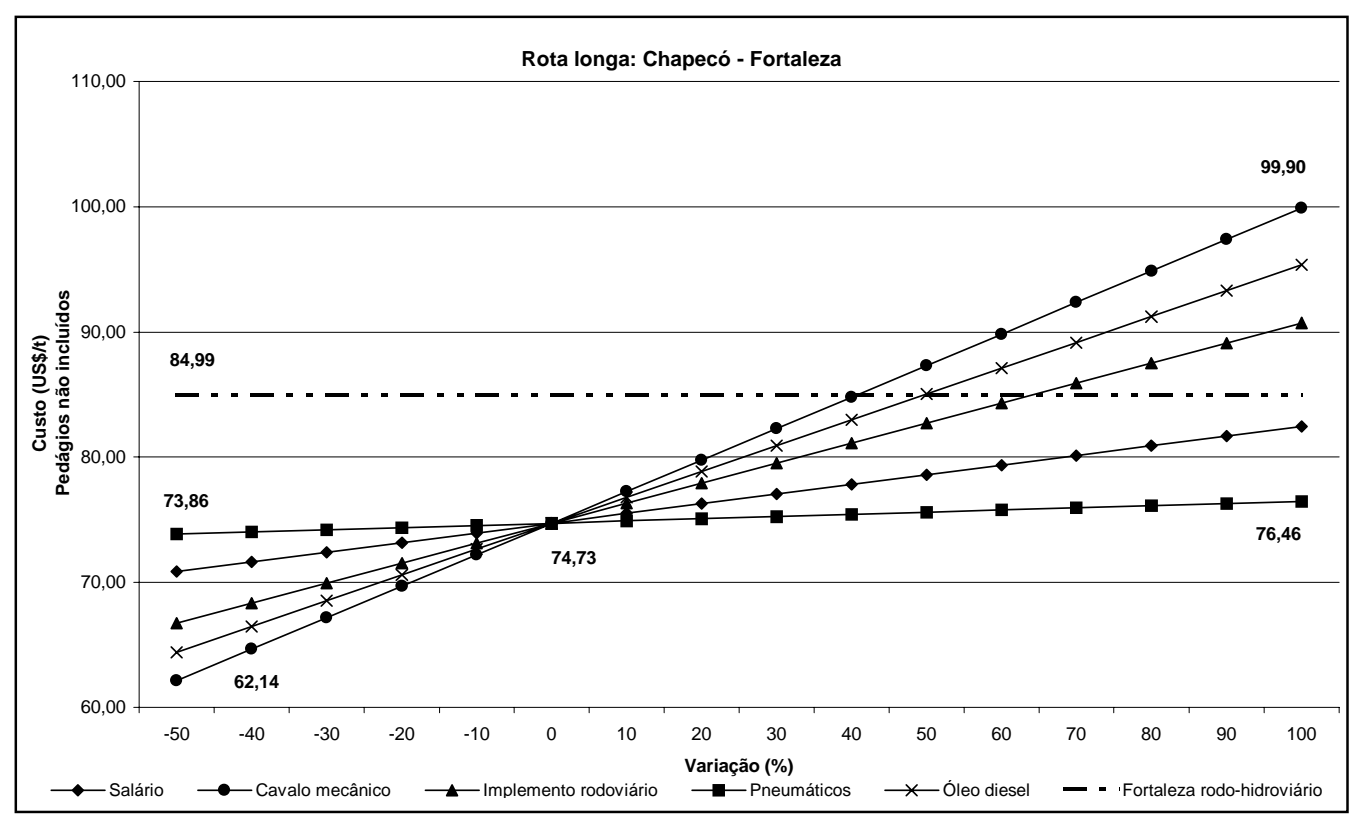

Figura 5.3: Análise de sensibilidade - cenário 3: Chapecó - Fortaleza 


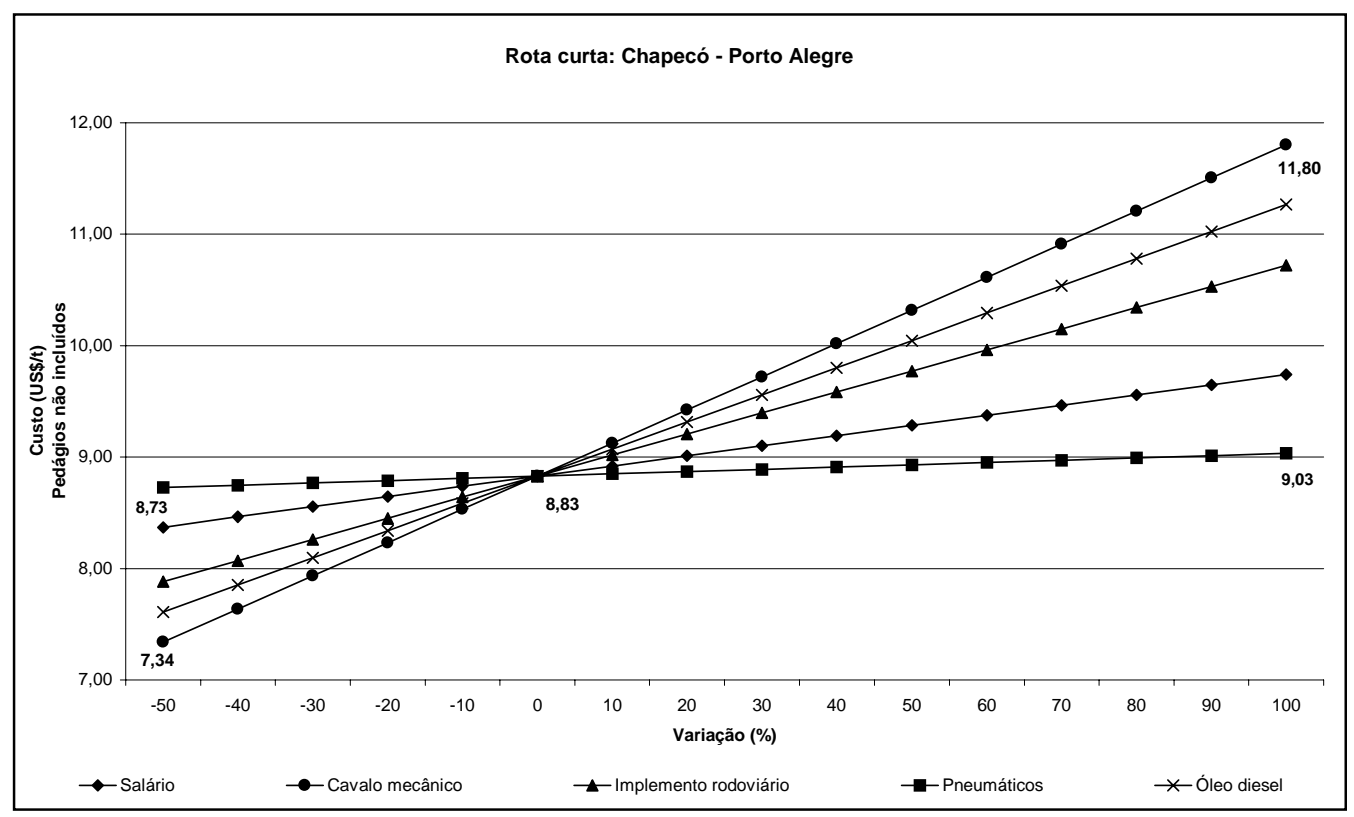

Figura 5.4: Análise de sensibilidade - cenário 3: Chapecó - Porto Alegre

O impacto da variação de $100 \%$ no custo do óleo diesel para o cenário 1 acarretou um acréscimo de 37,3\% no valor da tonelada transportada para a rota de Chapecó Fortaleza. A mesma variação para a rota Chapecó - Porto Alegre acresceu em 39,4\% o custo final por tonelada transportada pelo veículo $2 \mathrm{~S} 3$.

A variação de $100 \%$ no valor de aquisição do cavalo mecânico, para o bitrem 3S3B3, acarretou um acréscimo de aproximadamente $33,6 \%$ no custo por tonelada transportada para as rotas de Chapecó - Fortaleza e Chapecó - Porto Alegre.

A Figura 5.5 mostra que para a viagem rodo-hidroviária com origem em Chapecó e destino Fortaleza, com transbordo de embarque no porto de Itajaí, escala no porto de Santos e transbordo de desembarque no porto de Fortaleza, o principal item que afetou o custo total foi o custo rodoviário do transporte dos contêineres vazios do porto de origem à planta fabril e o retorno dos mesmos carregados até o porto de embarque. $\mathrm{O}$ segundo item foi o custo de transbordo, movimentação e taxas portuárias do porto de Fortaleza. 
Além da variação no conjunto dos custos envolvidos no modelo parametrizado do cenário rodo-hidroviário, esta análise de sensibilidade também estuda o comportamento de 6 diferentes rotas com variação dos custos praticados nos portos de origem e nos portos de destino das viagens rodo-hidroviárias para o cenário 2.

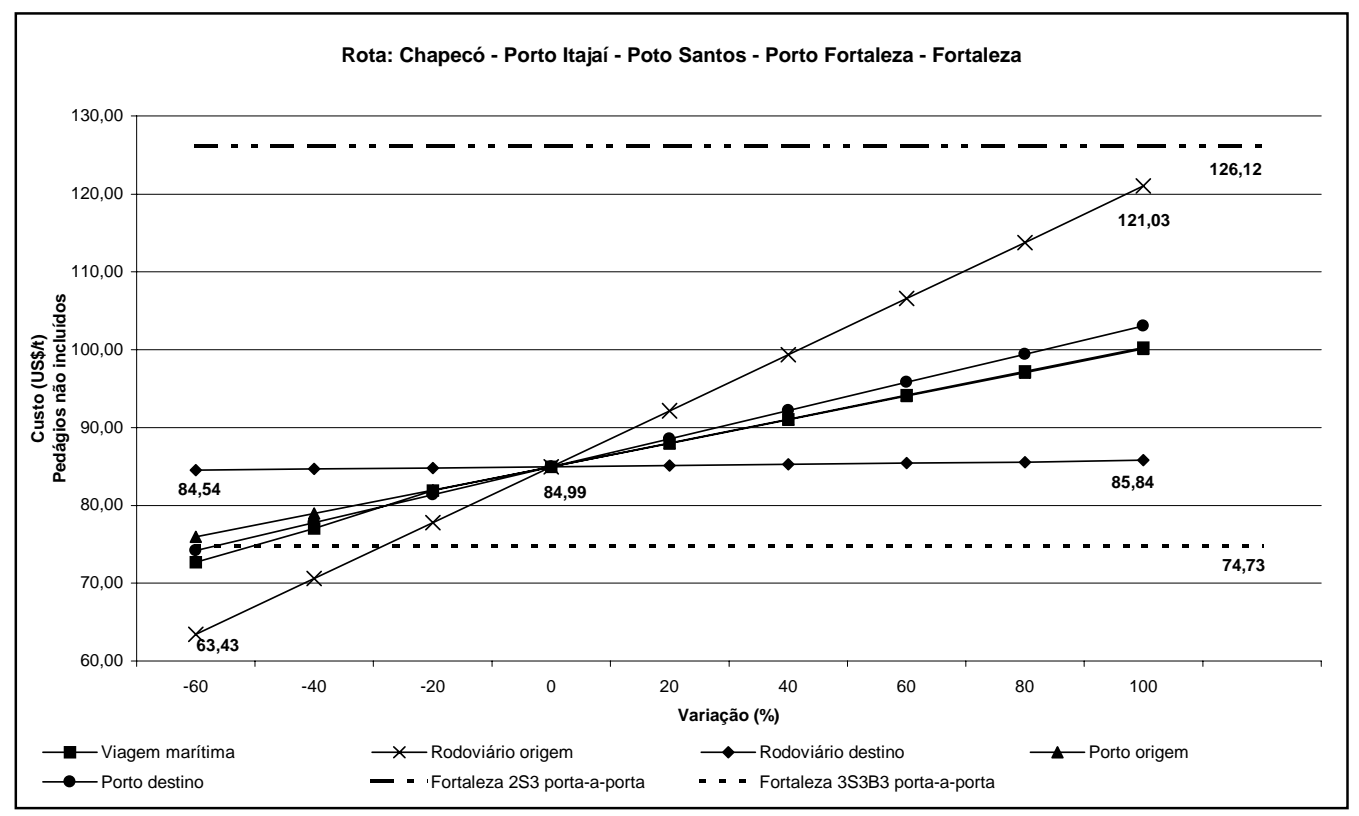

Figura 5.5: Análise de sensibilidade - cenário 2: Chapecó - Fortaleza

As rotas analisadas são: Chapecó - Belém, Paranaguá - Belo Horizonte, Dois Vizinhos - Ipatinga, Três Passos - Manaus, Concórdia - Salvador e Ponta Grossa - Recife. Nessa análise foram mantidos os mesmos valores de custos operacionais dos veículos rodoviários e da embarcação marítima. Foram variadas apenas as somatórias dos custos totais portuários envolvidos em cada rota e verificado o comportamento final do custo por tonelada transportada.

Na rota Chapecó - Belém, segundo a Figura 5.6, caso ocorra um acréscimo de $10 \%$ no custo portuário final, acarretará o equilíbrio do valor do custo por tonelada transportada entre o transporte rodo-hidroviário, com o veículo 3S3B3 nas pontas e o transporte rodoviário 2S3 porta-a-porta. No caso da rota Três Passos - Manaus (Figura 5.7) o acréscimo no custo final portuário deverá ser de aproximadamente $60 \%$ para ocorrer um equilíbrio entre o transporte intermodal e o rodoviário com o semi-reboque. Similarmente, na rota Concórdia - Salvador (Figura 5.8), o acréscimo do custo portuário deverá ser de aproximadamente $40 \%$. Na rota Ponta Grossa - Recife (Figura 
5.9), o acréscimo para que o custo da cabotagem torne-se igual ao do semi-reboque deverá ser superior a $100 \%$.

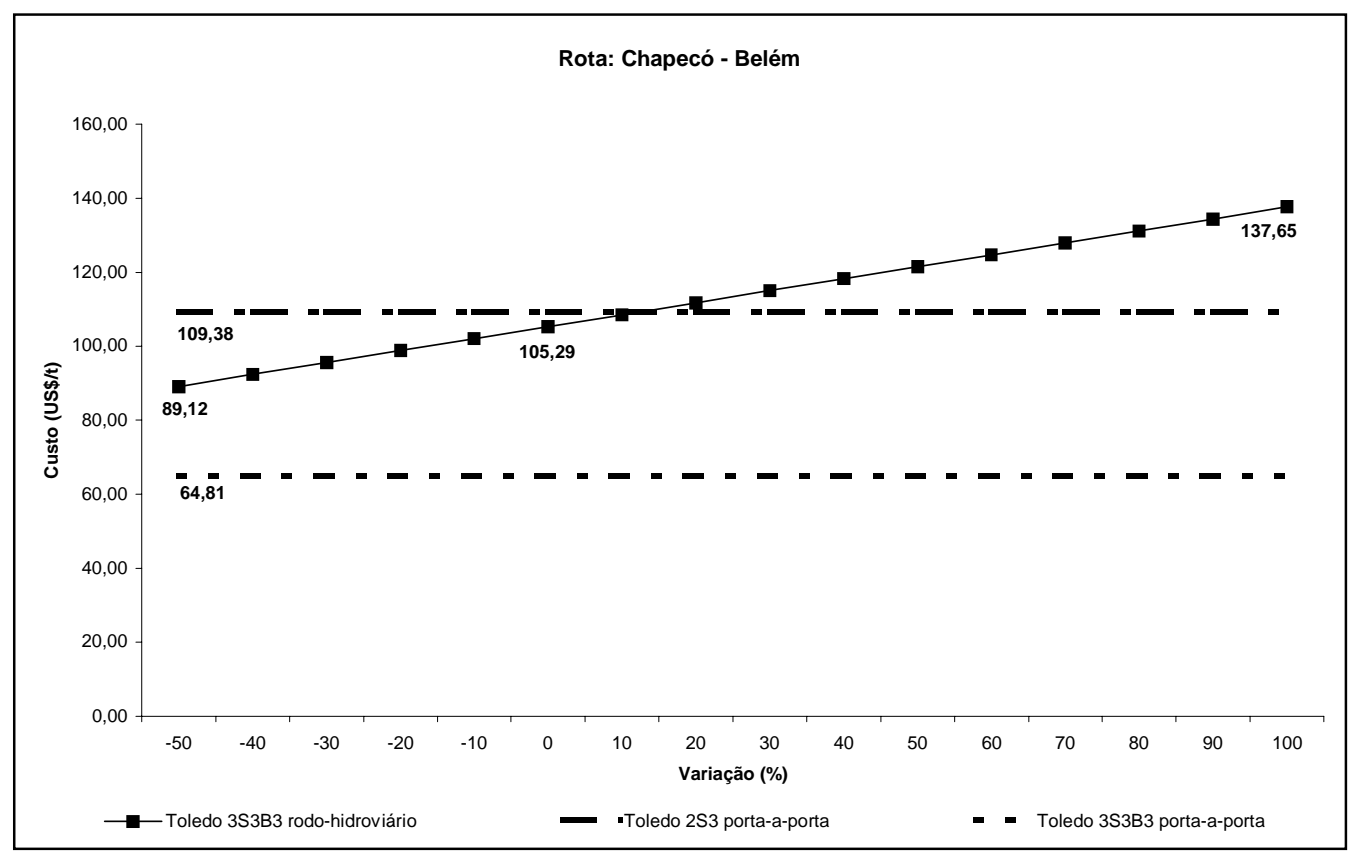

Figura 5.6: Variação dos custos portuários: Chapecó - Belém

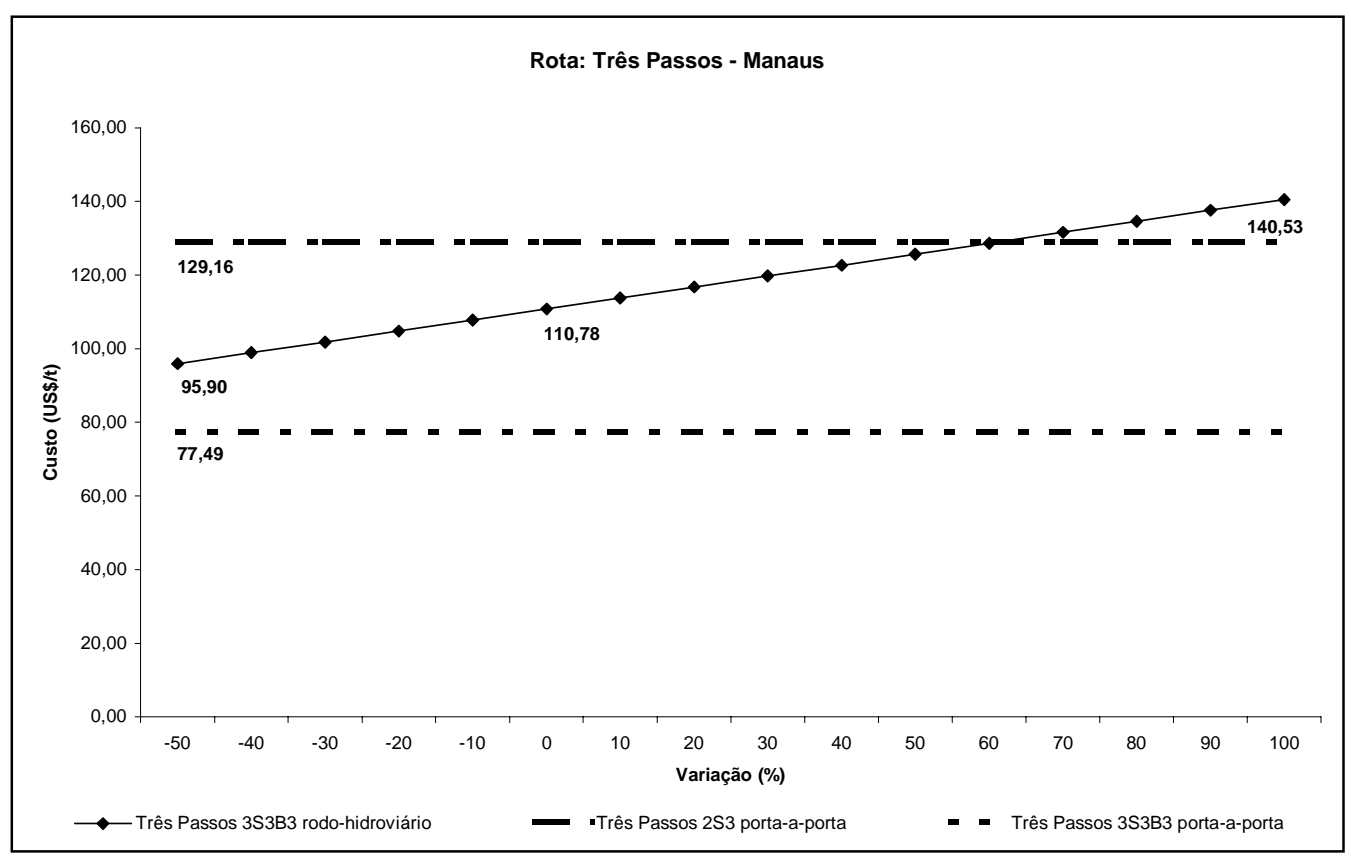

Figura 5.7: Variação dos custos portuários: Três Passos - Manaus

Nas rotas de Paranaguá - Belo Horizonte e Dois Vizinhos - Ipatinga, respectivamente conforme a Figura 5.10 e a Figura 5.11, verifica-se que mesmo uma redução de $50 \%$ no 
custo portuário não viabiliza essas rotas para o transporte rodo-hidroviário por cabotagem.

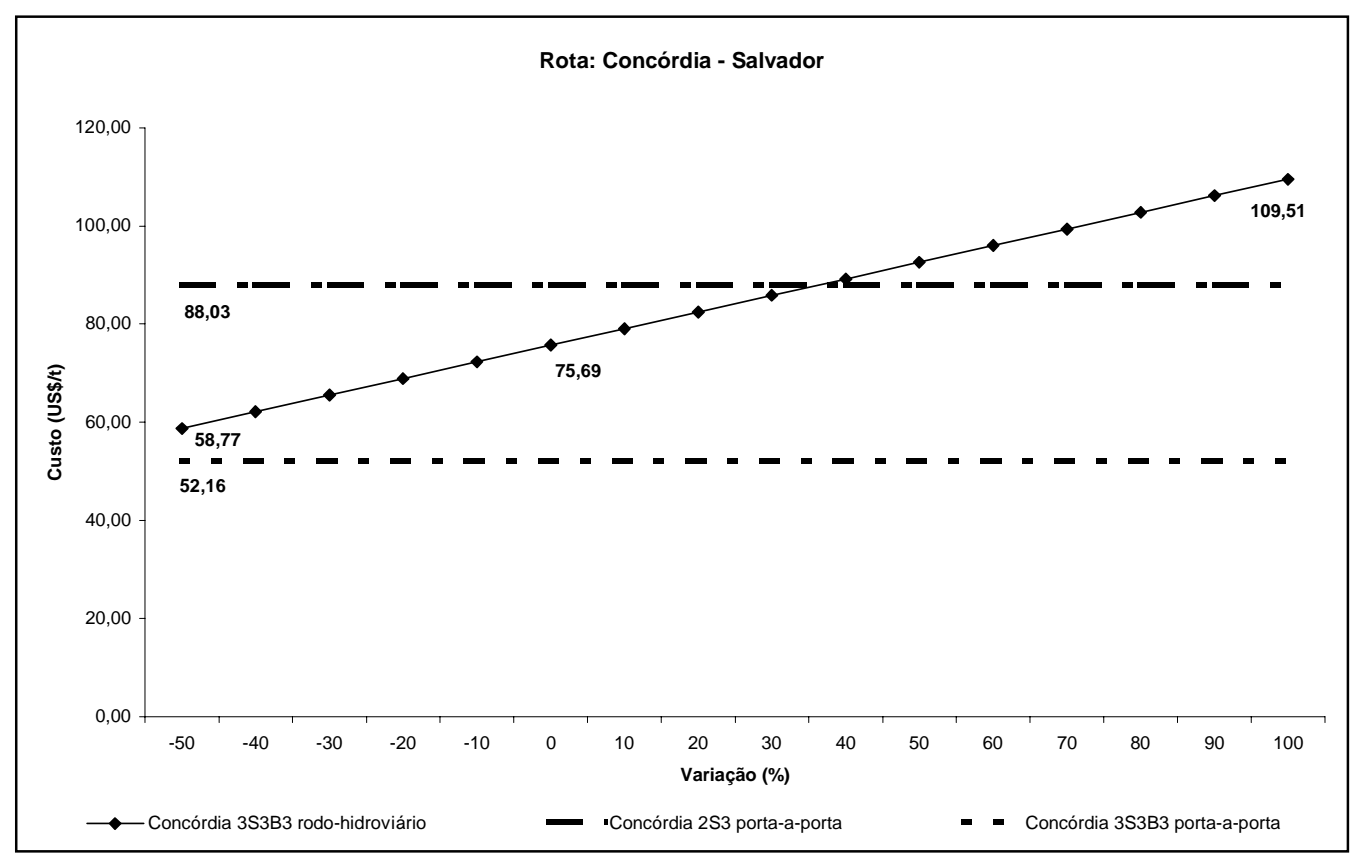

Figura 5.8: Variação dos custos portuários: Concórdia - Salvador

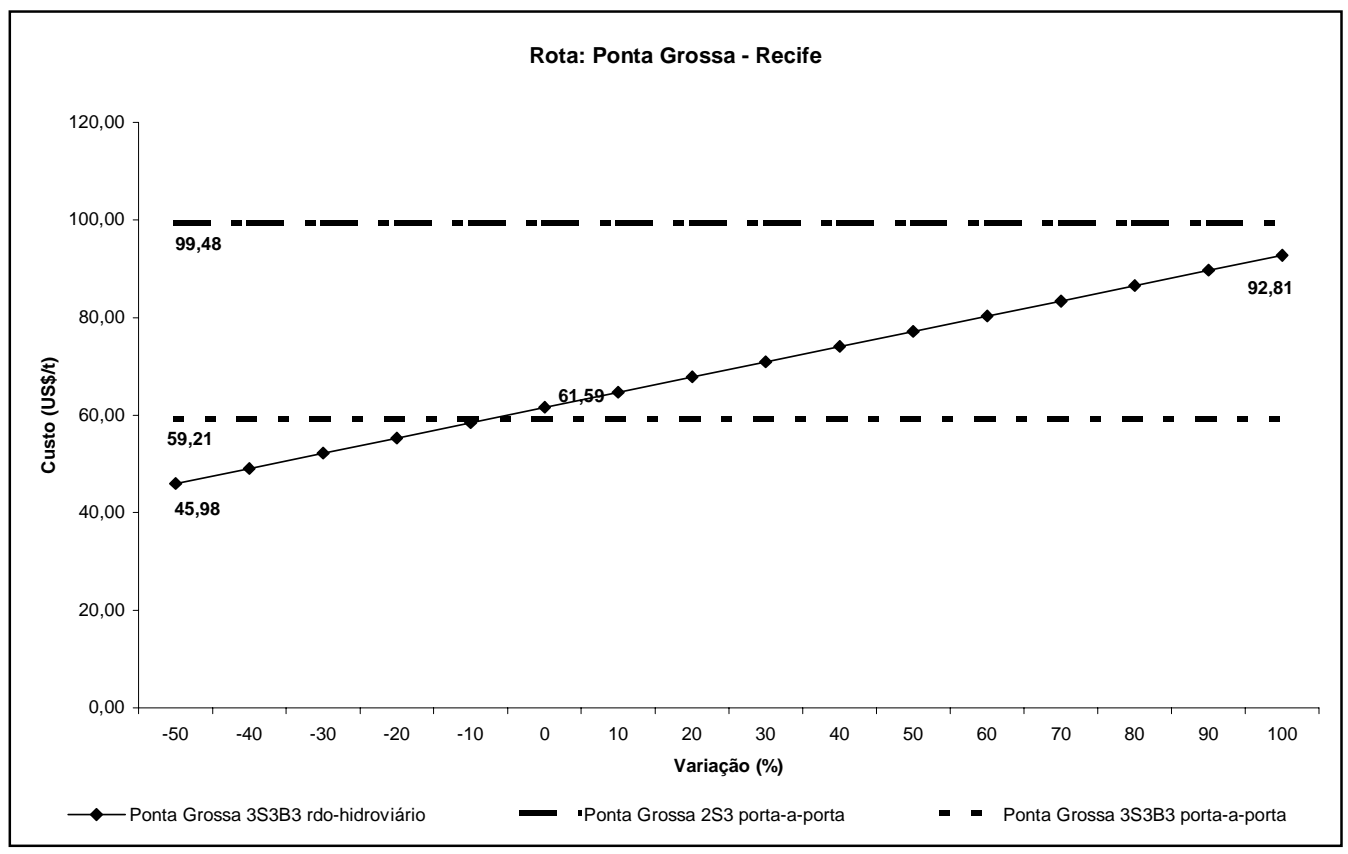

Figura 5.9: Variação dos custos portuários: Ponta Grossa - Recife

Nessa análise de sensibilidade dos custos portuários, observa-se plotados nos gráficos os valores dos custos por tonelada transportada para o veículo 3S3B3 porta-a-porta. Nota- 
se que somente na rota Ponta Grossa - Recife a redução de aproximadamente $10 \%$ dos custos portuários torna a cabotagem economicamente viável, comparado-se ao transporte porta-a-porta com o veículo 3S3B3. Nas demais rotas apresentadas na análise de sensibilidade, o transporte rodoviário com o bitrem frigorífico torna-se economicamente mais viável que a cabotagem.

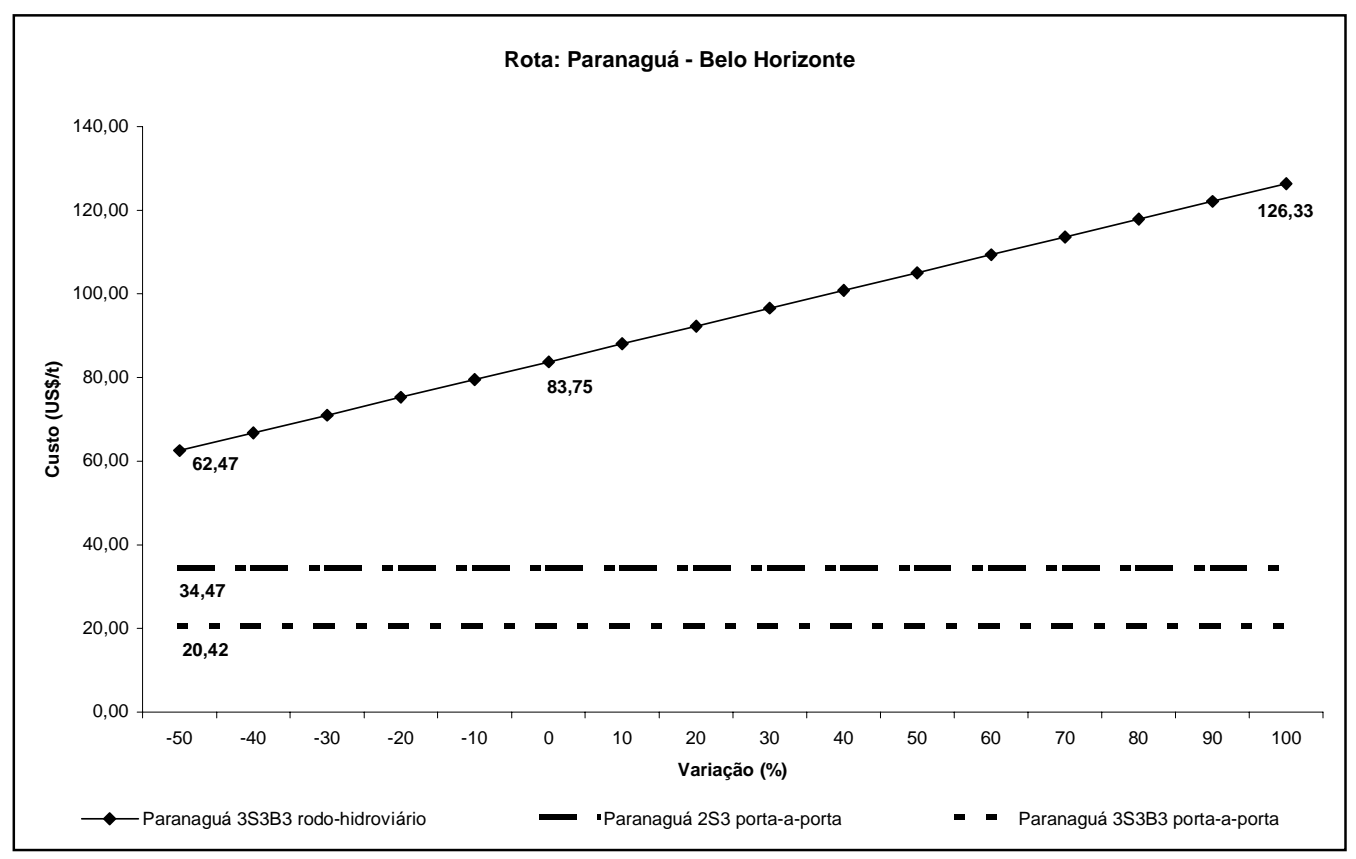

Figura 5.10: Variação dos custos portuários: Paranaguá - Belo Horizonte

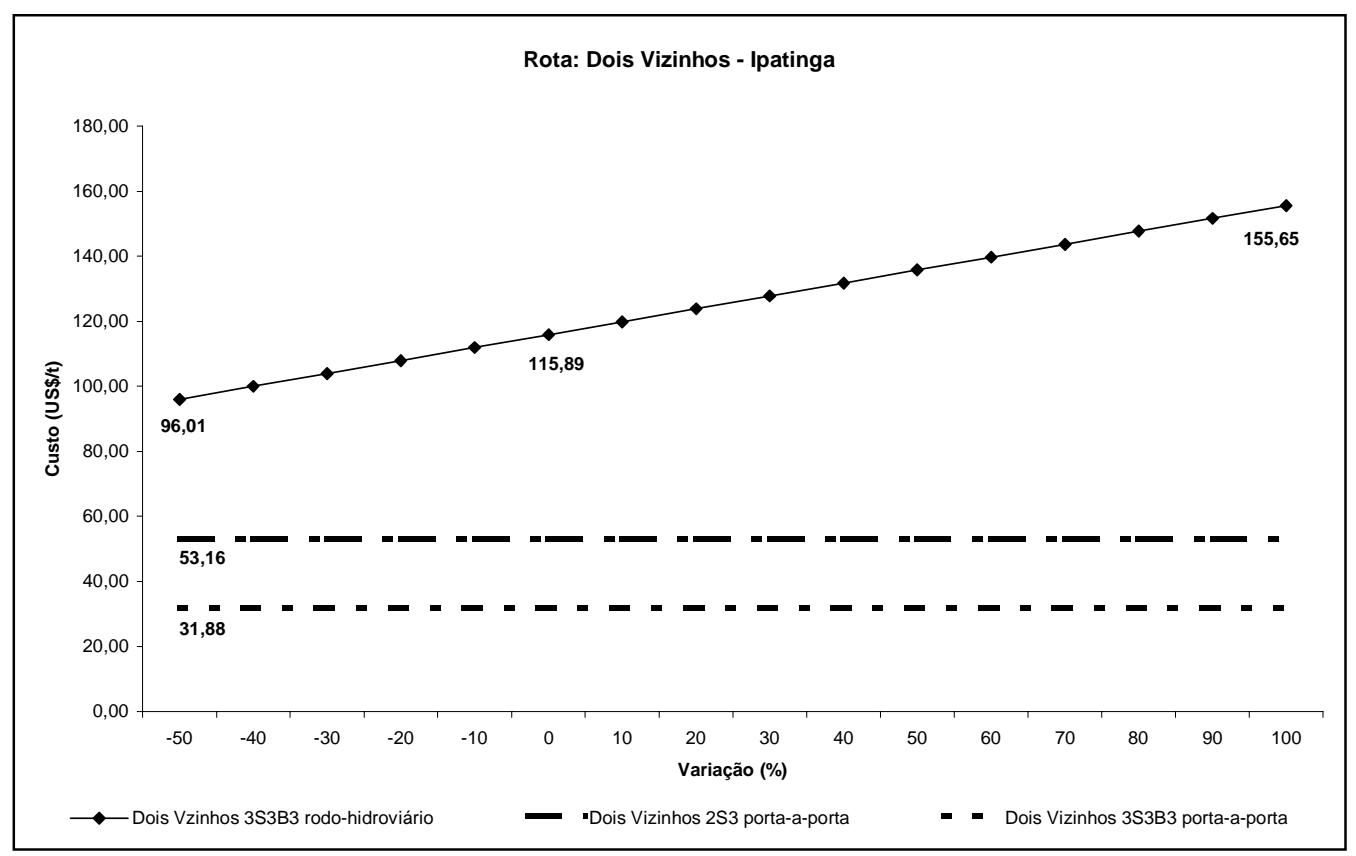

Figura 5.11: Variação dos custos portuários: Dois Vizinhos - Ipatinga 


\section{CONCLUSÕES E RECOMENDAÇÕES}

\subsection{Conclusões}

A principal conclusão dessa investigação é que existem potenciais ganhos econômicos da alternativa de transporte intermodal rodo-marítimo, associado a CVC 3S3B3 bitrem com implemento porta-contêineres no acesso aos portos e no trajeto porto centro de distribuição em relação à tecnologia de transporte utilizada atualmente, de transporte rodoviário porta-a-porta com a $\mathrm{CVC} 2 \mathrm{~S} 3$ - semi-reboque com implemento rodoviário baú frigorífico e capacidade de carga de 26 paletes padrão PBR. Essa viabilidade foi observada nas rotas de longo curso de navegação, caracterizadas por distâncias rodoviárias entre as fábricas e centros de distribuição superiores a $1.700 \mathrm{~km}$ e distâncias rodoviárias, entre os portos de desembarque e o destino final, inferiores a $600 \mathrm{~km}$. Assim, conforme a distribuição geográfica das plantas industriais, os centros de distribuição beneficiados pelo transporte intermodal rodo-marítimo foram Salvador, Recife, Natal, Fortaleza, Belém e Manaus.

Os resultados numéricos mostram que o transporte intermodal rodo-marítimo de contêineres apresentou significativa economia, particularmente nas rotas com origem das cargas próximas aos portos (Duque de Caxias, Paranaguá e São Paulo). Nestes casos ocorreram ganhos no custo por tonelada transportada de até $100 \%$. As demais rotas apresentaram ganhos variáveis entre 1,2 a $65 \%$ no custo por tonelada transportada.

Nas rotas mais curtas com utilização dos portos de Paranaguá, Itajaí e São Francisco do Sul e destino nos portos de Santos, Rio de Janeiro e Vitória a alternativa rodohidroviária tem desempenho econômico inferior ao transporte rodoviário porta-a-porta com a tecnologia atual. No caso específico do Porto de Vitória, as elevadas tarifas de 
transbordo de contêineres contribuem para a dificuldade de inserção desse nó nas opções viáveis.

A introdução da CVC 3S3B3 bitrem com implemento baú frigorífico e capacidade de carga de 40 paletes padrão PBR no transporte porta-a-porta entretanto, oferece aos transportadores uma alternativa que, na grande maioria das rotas estudadas, é mais competitiva que a integração modal rodo-hidroviária.

A análise de sensibilidade de algumas rotas a variações nos custos de transbordo nos portos mostram que, para os portos com tarifas mais econômicas e distâncias de viagem marítima da mesma ordem de grandeza da distância rodoviária, como por exemplo Recife, pequenas reduções nas tarifas dos portos de origem e/ou do destino viabilizam a integração rodo-hidroviária mesmo em competição com a alternativa tecnológica da CVC do tipo 3S3B3.

Para centros de distribuição próximos a portos de destino com tarifa mais elevada de transbordo e/ou custos relativos do transporte marítimo com escalas intermediárias e distâncias de viagem superiores às rotas rodoviárias mais diretas, como Fortaleza, Manaus e Belém, reduções drásticas nas tarifas portuárias ou nos custos do transporte hidroviário são necessárias para viabilizar a integração modal.

O custo do tempo na escolha do modo de transporte também é um fator importante de decisão, pois o fluxo da comercialização, da produção e da entrega de bens manufaturados, e da venda ao consumidor final ocorre em um espaço curto de tempo, dentro do mês. Neste contexto a integração modal rodo-hidroviária tem desempenho inferior às alternativas de transporte rodoviário porta-a-porta.

\subsection{Recomendações}

Como complemento a esta investigação sugere-se investigar o impacto no custo do transporte intermodal rodo-hidroviário se, ao invés de embarcações LO/LO fossem 
utilizadas embarcações RO/RO e a CVC 3S3B3 bitrem com capacidade para 40 paletes PBR.

Outro complemento para esta pesquisa seria a criação de um modelo de alocação dos recursos estudados nos cenários que incorporasse, além do custo por tonelada transportada, os tempos de viagem. Do ponto de vista do nível de serviço, o custo do tempo de viagem é uma variável muito importante, pois impacta diretamente no nível de estoques de uma indústria e no custo de capital contábil entre a compra do produto pelo varejo e a revenda ao consumidor final.

Sugere-se também, a utilização das bases geográficas geradas nesta pesquisa, na investigação dos custos de investimento em infra-estrutura em transportes, visando analisar os aspectos táticos e estratégicos do transporte intermodal no Brasil.

Através da melhoria das informações sugere-se também a utilização da base de dados geográfica desta pesquisa em estudos referentes a problemas estratégicos de transporte no Brasil tais como, o impacto da melhoria e expansão da rede ferroviária em grandes corredores de transporte, o impacto de novas instalações logísticas, os fluxos de cargas entre as principais regiões de geração e atração de tráfego no país e cenários alternativos de política tarifária de transportes. 


\section{REFERÊNCIAS BIBLIOGRÁFICAS}

ABCR (2001). Valores de pedágios e localização de praças. Associação Brasileira de Concessionárias de Rodovias. Disponível em: 〈http://www.abcr.org.br〉. Acesso em: 10 novembro.

ABCS (2001a). Consumo per capita brasileiro de suínos por região. Associação brasileira de criadores de suínos. Disponível em: 〈http://www.abcs.org.br〉. Acesso em: 17 agosto.

ABCS (2001b). Associação brasileira de criadores de suínos. Disponível em: <http://www.abcs.org.br>. Acesso em: 17 agosto.

ABEF (2001). Consumo per capita brasileiro de frango. Associação brasileira de produtores e exportadores de frango. Disponível em: 〈http://www.abef.com.br〉. Acesso em: 17 agosto.

ABRIL (2000). Mapa rodoviário brasileiro. São Paulo: Editora Abril. Escalas $1: 2.000 .000$ e $1: 7.000 .000$.

AGROINDÚSTRIA (1999). Relatório de balanço anual. São Paulo. /relatório interno não publicado/.

ALLEN, W.B.; LIU, D.; S. SINGERS (1993). Accessibility measures of U.S. Metropolitan Areas. Transportation Research. Part B, Methodological, 27B(6), p.43949.

ANDERSON, R.A., SWEENEY, D.J., WILLIANS, T.A. (2002). Estatística aplicada à administração e economia. São Paulo: Pioneira.

BALLOU, R. (1992). Business Logistics Management. 3rd ed. Prentice Hall.

BACEN (2001). A economia brasileira. Boletim do Banco Central do Brasil. Disponível em: <http://www.bacen.gov.br/htms/Banual2001/rel2001cap1p.pdf>. Acesso em: 16 out 2002

BERTSEKAS, D.P.; TSENG, P. (1988). The relax codes for linear minimum cost network flow problems. Annals of Operations Research, v.13, p.125-90. 
BERTSEKAS, D.P.; TSENG, P. (1994). Relax-IV: A faster version of the RELAX Code for solving minimum cost flow problems, Research supported NSF under Grant CCR-9103804 and Grant CCR-9311621.

BLISKA, F. M. M. (1999) Impactos de alterações nas exportações brasileiras de carnes sobre a economia brasileira. 217p. Dissertação (Mestrado) - Escola Superior de Agronomia Luiz de Queiroz, Universidade de São Paulo, Piracicaba. 1999.

BOTTER, R.C.; ROQUE, J.R. (1987). Uma avaliação agregada do potencial e da competitividade do sistema de cabotagem brasileiro. In: COPIANVAL - PAN AMERICAN INSTITUTE OF NAVAL ENGINNERING, 10., 1987. Anais.

BOTTER, R.C.; ONO, R.T.; FERNANDES, M.G. (2000). Estudo de viabilidade do transporte marítimo de contêineres por cabotagem na costa brasileira. In: CONGRESSO NACIONAL DE TRANSPORTES MARÍTIMOS, CONSTRUÇÃO NAVAL E OFFSHORE, 18., 2000, Rio de Janeiro. Anais.

BRASIL (1999a). Lei $n^{\circ} .9 .503$, de 23 de setembro de 1997. Institui o código de trânsito brasileiro. Lex: Nova Coletânea de Legislação de Trânsito, Porto Alegre, $16^{\circ}$ Edição, p.9-90.

BRASIL (1999b). Resolução n. 12 de 06 de fevereiro de 1998. Estabelece os limites de peso e dimensões para veículos que transitem por vias terrestres. Conselho Nacional de Trânsito. Lex: Nova Coletânea de Legislação de Trânsito, Porto Alegre, $16^{\circ}$ Edição, p.437-38.

BRASIL (1999c). Resolução n. 68 de 23 de setembro de 1998. Requisitos de segurança necessários à circulação de combinação de veículos de carga - CVC, a que se refere os arts. 97, 99 e 314 do Código de Trânsito Brasileiro - CTB e os $\S 3^{\circ}$ e $4^{\circ}$ dos arts. $1^{\circ}$ e $2^{\circ}$, respectivamente, da resolução 12/98 - CONTRAN. Conselho Nacional de Trânsito. Lex: Nova Coletânea de Legislação de Trânsito, Porto Alegre, $16^{\circ}$ Edição, p.500-3.

BRASIL (2001a). Lei n. 8.630 de fevereiro de 1993. Dispõe sobre o regime jurídico da exploração dos portos organizados e das instalações portuárias e dá outras providências. Disponível em: <http://www.ligaportos.hpg.ig.com.br/Portos/Leis/LEI8630.htm> Acesso em 29 jul.

BRASIL (2001b). Portaria n. 13, de 6 de abril de 1999. Altera as normas da autoridade marítima para operação de embarcações estrangeiras em águas sob jurisdição nacional. Disponível em: 〈http://www.geipot.gov.br/download/1999/Port13.doc〉. Acesso em 30 ago.

BRASIL (2001c). Lei n. 8.611 de 19 de fevereiro de 1998. Dispõe sobre o transporte multimodal de cargas e dá outras providências. Disponível em: <http://www.geipot.gov.br/ >. Acesso em 29 jul.

CALIPER (1996a). TransCAD Transportation GIS Software. User's Guide Version 3.0 for Windows. Caliper Corporation, Newton, EUA. 
CALIPER (1996b). TransCAD Transportation GIS Software. Routing and Logistics with TransCAD 3.0. Caliper Corporation, Newton, EUA.

CAMELLO, P. (2002). Informações de custos operacionais relativos a cabotagem. Mensagem enviada por <pcamello@rio.alianca.com.br>. Mensagem recebida por <rjrorato@sc.usp.br>em 21 fev.

CARDOSO, P. M.; WIDMER, J. A. (1993). Construção de uma planilha de custos operacionais para veículos rodoviários de carga. In: XII CONGRESSO DE INICIAÇÃO CIENTÍFICA E TECNOLÓGICA EM ENGENHARIA, 12., 1993, São Carlos. Resumos. São Carlos: USP.

CECCHET, A.A. (2001). Informações sobre custos operacionais e valores de aquisição para cavalos mecânico Volvo. Mensagem enviada por <angelo@dicave.com.br>. Mensagem recebida por <rjrorato@sc.usp.br> em $10 \mathrm{fev}$.

COSTA, J.I.A. (1979). Comparação econômica entre transportes ferroviário e rodoviário - aplicação para escoamento regional de carga agrícola. 338p. Dissertação (Mestrado) - Instituto Militar de Engenharia , Rio de Janeiro. 1979.

CULINANE, K.; KHANNA, M. (2000). Economies of scale in large containerships: optimal size and geographical implications. Journal of Transportation Geography. V.8, p.181-195.

CUNHA, W.C. (2000). Cabotagem no Brasil: análise de custos operacionais. 263p. Dissertação (Mestrado) - Instituto Militar de Engenharia, Rio de Janeiro. 2000.

DAER-RS (2001). Mapa rodoviário do Estado do Rio Grande do Sul. Departamento Autônomo de Estradas e Rodagens do Estado do Rio Grande do Sul.<planviario.dwg >.

DAVIDSON, K.B. (1995). Accessibility and isolation in transport network evaluation. Paper presented in $7^{\text {th }}$ World Conference on Transport Research. Book of Abstracts, The University of New South Wales, pp.10-18.

DEMARCHI, S.H. (1995). Influência dos veículos pesados na capacidade de interseções rodoviárias. 213p. Dissertação (Mestrado) - Escola de Engenharia de São Carlos, Universidade de São Paulo, São Carlos. 1995

DER-SC (2001) Download de mapas no formato GIF. Disponível em: <http://www.sc.gov.br/der/>. Acesso em: 21 fev. Atualização de endereço: $<$ http://reder7.der.sc.gov.br/der-site/servicos/mapas/index.jsp> em 03 abril 2003.

DER-SP (2001a). Análise das conseqüências do tráfego de CVCs (Combinações de Veículos de Carga) sobre as obras de arte especiais da rede viária do DER-SP. Relatório técnico, contrato DER11.118-0.

DER-SP (2001b). Mapa rodoviário do Estado de São Paulo. Departamento de Estradas e Rodagens do Estado de São Paulo <mapa.dwg>. 
DEWITT, W.; CLINGER, J. (2000). Intermodal freight transportation. Committee on international freight transport. TRB. Disponível em: <http://www.trb.org>. Acesso em: 03 mar. 2001.

DINIZ, U. L. (2000). Alocação e dimensionamento de frotas de veículos para apoio a maquinário agrícola de usinas sucroalcooleiras. 109p. Dissertação (Mestrado) - Escola de Engenharia de São Carlos, Universidade de São Paulo, São Carlos. 2000.

DREWRY (1999). Drewry Shipping Consultants. Container market outlook: high risk \& high stakes: where is my payback? October, London.

EYRES, D.J. (1988). Ship construction, $3^{\mathrm{a}}$ edição. Butter Worth-Heinemann. Great Britain, 1988.

FABBRI, G.T.P.; FERNANDES JR., J.L.; WIDMER, J.A.; SÓRIA, M.H.A. (1990). Análise de composições rodoviárias quanto a fatores de destruição de pavimentos. In: REUNIÃO ANUAL DE PAVIMENTAÇÃO DA ABPV, 24., 1990, Belém, PA. p.14769.

FERNANDES JR., J.L. (1994). Investigação dos efeitos das solicitações do tráfego sobre o desempenho de pavimentos. 313p. Tese (Doutorado) - Escola de Engenharia de São Carlos, Universidade de São Paulo, São Carlos. 1994.

FERNANDES, D.L.G. (1997). Desempenho de veículos pesados na frenagem considerando os requisitos da regulamentação ECE-R13. In: CONGRESSO BRASILEIRO DE ENGENHARIA MECÂNICA, 14., 1997, Bauru. Anais.

FERNANDES, D.L.G. (2000). Análise de veículos rodoviários articulados pesados na frenagem através da técnica dos mapas de desempenho. 194p. Tese (Doutorado) Escola de Engenharia de São Carlos, Universidade de São Paulo, São Carlos. 2000.

FERNANDES, D.L.G.; CANALE, A.C.; ADAS, C.A. (1995a). Estudo do desempenho na frenagem de veículos pesados usando a técnica do balanceamento estático ou passeio do centro de gravidade. In: CONGRESSO BRASILEIRO DE ENGENHARIA MECÂNICA, 13., 1995, Belo Horizonte. Anais.

FERNANDES, D.L.G.; CANALE, A.C.; ADAS, C.A.; FONSECA, B. J. (1995b). Descrição de um sistema computacional para o estudo do desempenho na frenagem de veículos pesados. In: CONGRESSO BRASILEIRO DE ENGENHARIA MECÂNICA, 13., 1995, Belo Horizonte. Anais.

FGV (2000). Fundação Getúlio Vargas. As maiores empresas do agribusiness do Brasil. Disponível em: <http://www.fgv.br>. Acesso em: 10 ago. 2001.

FHA (1995). Comprehensive Truck Size and Weight Study. Federal Highway Administration. Disponível em: <http://www.bts.gov/ntl/DOCS/cts.html>. Acesso em: 11 Jun 2001. 
FONSECA, M.M. (1989). Arte naval. v.1, ed. 5. Rio de Janeiro: Serviço de documentação geral da Marinha.

GEIPOT (2000). Acompanhamento dos preços e desempenho operacional dos serviços portuários. Ministério dos Transportes. Disponível em: <http://www.geipot.gov.br/estudos_realizados/servicosportuarios/relatorio_final.doc>. Acesso em: 15 dez. 2001.

GIROTTO, A.F.; CHIUCHETTA, O.; CANEVER, M.D.; SANTOS FILHO, J.I. (2001). Custo de produção na avicultura de corte. Revista Brasileira de Agropecuária, fevereiro, n. 13, p.20-3.

GOMES, P.A.B. (2001). Informações sobre custos operacionais e valores de aquisição para implementos rodoviários Recrusul. Mensagem enviada por <paulogomes@recrusul.com.br>. Mensagem recebida por<rjrorato@sc.usp.br> em 12 nov.

GUIMARÃES, I.C.O. (1999). Geração de base geográfica multimodal de transportes em sistemas de informações geográficos. Dissertação (Mestrado) - Instituto Militar de Engenharia, Rio de Janeiro. 1999

HITCHCOCK, F.L. (1941). Distribution of a product from several sources to numerous localities. Journal of Math. Physics, v.20.

IBGE (2000). Censo populacional 2000, sinopse preliminar. Instituto Brasileiro de Geografia e Estatística. Disponível em: 〈http://www.ibge.gov.br>. Acesso em: 16 ago.2001.

IBGE (2002). Levantamento sistemático da produção agrícola e abate de animais, produção de leite, couro e ovos. Instituto Brasileiro de Geografia e Estatística. Disponível em: <http://www.ibge.gov.br>. Acesso em: 11 out.

KAWAMOTO, E. (1999). Análise de sistemas de transporte, $2^{a}$ edição, São Carlos.

KOMAROVA, A.D.H. (2000). Transporte multimodal de cargas: análise de alternativas. 165p. Dissertação (Mestrado) - Instituto Militar de Engenharia, Rio de Janeiro. 2000.

LEWIS, S. (1990). Use of geographical information systems in transportation modeling. ITE Journal, p.34-8, mar.

LINS, M.P.E.; FERREIRA Fº V.J.M. (2001). Sistemas de informações geográficas e modelagem em pesquisa operacional. Disponível em: $<$ http://members.tripod.com/ producao/edicao1/rprogis.html>. Acesso em: 01 ago.

MACHADO NETO, E.F. (1995). Influência dos veículos pesados na capacidade de rodovias de pista simples. 136p. Dissertação (Mestrado) - Escola de Engenharia de São Carlos, Universidade de São Paulo, São Carlos. 1995. 
MASELLA, M.M.B. (1979). Estudo de custos de transportes rodo-hidroviário: caso do corredor Ijuí/Rio Grande. 100p. Dissertação (Mestrado) - Instituto Militar de Engenharia, Rio de Janeiro. 1979.

MCCANN, P. (2001). A proof of the relationship between optimal vehicle size, haulage lenght and the structure of distance-transport costs. Transportation Research Part A. n.35. p.671-93.

MENEGAT, C. (2000). Análise de fretes de longa distância. Transferência de planilhas eletrônicas. Mensagem enviada por<cezar.menegatti@sadia.com.br>. Mensagem recebida por<rjrorato@sc.usp.br> em 12 fev.

MENEGAT, C. (2001a). Informações sobre custos de seguro e valor de carga. Mensagem enviada por <cezar.menegatti@sadia.com.br>. Mensagem recebida por <rjrorato@sc.usp.br>em 23 jul.

MENEGAT, C. (2001b). Detalhamento da unitização em paletes PBR. Mensagem enviada por <cezar.menegatti@sadia.com.br>. Mensagem recebida por <rjrorato@sc.usp.br>em 12 fev.

MESQUITA, A.H.M. (1980). Estudo intermodal do transporte de carga em um corredor - aplicação no macro-eixo Rio/São Paulo. 148p. Dissertação (Mestrado) Instituto Militar de Engenharia, Rio de Janeiro. 1980.

MORLOK, E.K. (1978). Introduction to Transportation Engineering and Planning. McGraw-Hill. Tokyo, 1978.

NIX, F. P.; CLAYTON, A. M.; BILLING, J. R. (1990). Truck weight and dimension regulations and containers. In: THE RTAC ANNUAL CONFERENCE, 1990, St. John's, Newfoundland.

NOVAES, A.G. (1976). Economia e tecnologia do transporte marítimo. Almeida Neves Editores. Rio de Janeiro, 1976.

NOVAES, A.G. (1978). Métodos de otimização: aplicação aos transportes. Ed. Edgard Blüncher. São Paulo, 1978.

ONO, R.T. (2001). Estudo de viabilidade do transporte marítimo de contêineres por cabotagem na costa brasileira. 132p. Dissertação (Mestrado) - Escola Politécnica, Universidade de São Paulo, São Paulo. 2001.

OYOLA, J.I.S. (1988). Uma nova abordagem na determinação de tarifa no transporte rodoviário de cargas. 165p. Dissertação (Mestrado) - Universidade Federal de Santa Catarina, Florianópolis. 1988.

PELIZARO, C. (2000). Avaliação de desempenho do algoritmo de um programa comercial para roterização de veículos. 153p. Dissertação (Mestrado) - Escola de Engenharia de São Carlos, Universidade de São Paulo, São Carlos. 2000. 
PET-COPPE (2001). Programa em Engenharia de Transportes, Projeto GIS geographic information system, COPPE, Universidade Federal do Rio de Janeiro. Disponível em: <http://www.gis.pet.coppe.ufrj.br/>. Acesso em: 20 fev.

PINTO, K.C.R. (1996). Contribuição a análise de decisão sobre os sistemas de distribuição física do suco de laranja brasileiro de exportação. 189p. Tese (Doutorado) - Escola de Engenharia de São Carlos, Universidade de São Paulo, São Carlos. 1996.

QUEIROZ, C.A.V. (1986). Metodologia para o cálculo de custos do transporte rodoviário de cargas e implicações tarifárias. 500p. Dissertação (Mestrado) - Instituto Militar de Engenharia, Rio de Janeiro. 1980.

RAIA JR., A.A.; SILVA, A.N.R. (1998). Um método expedito para verificação da consistência de redes para uso em um SIG-T.In: CONGRESSO NACIONAL DE PESQUISA E ENSINO EM TRANSPORTES, 12., 1998, Fortaleza. Anais.. v.2. pp. 107.

REIS, N. G. (1996). Viabilidade de operação do duplo semi-reboque de cinco eixos no Brasil. V. 1 e V. 2. 319p. Dissertação (Mestrado) - Escola de Engenharia de São Carlos, Universidade de São Paulo, São Carlos. 1996.

ROSE, A. (2001). Uma avaliação comparativa de alguns sistemas de informação geográfica aplicados aos transportes. 139p. Dissertação (Mestrado) - Escola de Engenharia de São Carlos, Universidade de São Paulo, São Carlos. 2001.

RUSSO, M.R.A. (1995). Impacto de manobras de veículos combinados sobre a geometria horizontal de interseções rodoviárias. 131p. Tese (Doutorado) - Escola de Engenharia de São Carlos, Universidade de São Paulo, São Carlos. 1995.

SANTOS, P.F. (1981). Transportes de produtos químicos no macro-eixo nordestecentro-sul: um modelo de programação linear para a alocação modal. 398p. Dissertação (Mestrado) - Instituto Militar de Engenharia, Rio de Janeiro. 1981.

SARKIS, L.F.P.G. (2000). Resíduos de serviços de saúde em cidades de médio porte: caracterização de sistemas de coleta e aplicação de um sistema de informação geográfica na roteirização de veículos de coleta e transporte. 215p. Dissertação (Mestrado) - Escola de Engenharia de São Carlos, Universidade de São Paulo, São Carlos. 2000.

SEIBLITZ, M.B.N.L. (1986). Faixas econômicas de utilização dos sistemas conteinerizados e convencional. 264p. Dissertação (Mestrado) - Instituto Militar de Engenharia, Rio de Janeiro. 1986.

SILVA, A.N.R. (1998a). Sistemas de informações geográficas para planejamento de transportes. 112p. Tese (Livre-docência) - Escola de Engenharia de São Carlos, Universidade de São Paulo, São Carlos. 1998. 
SILVA, A.N.R. (1998b). Ferramentas específicas de um sistema de informações geográficas para transportes.83p., ilustrado, São Carlos.

SIQUEIRA, T. (2000). Cargas ao mar. Portos e Navios, maio, 472, p.8-13.

SOUTHWORTH, F.; PETERSON, B.E. (2000). Intermodal and international freight network modeling. Transportation Research Part C. P.147-66.

STERN, A.M. (2001). Orçamento comercial para frete frigorífico. Mensagem enviada por<andre@coopercarga.com.br>. Mensagem recebida por <rjrorato@sc.usp.br> em 19 mar.

TIAGO, R.P. (2002). Estudo de pontos promissores para instalação de terminais intermodais rodo-ferroviários de contêineres no Estado de São Paulo. 103p. Dissertação (Mestrado) - Escola de Engenharia de São Carlos, Universidade de São Paulo, São Carlos. 2002.

TOLOFARI, S.R. (1951) Open registry shipping: a comparative study of costs and freight rates. Gordon and Breach Science Publishers. New York, 1951.

TRANSPORTES (2001). Evolução da frota mercante brasileira na cabotagem. Disponível em: <http://www.transportes.gov.br>. Acesso em: 15 junho.

VALENTE, A.M.; PASSAGLIA, E.; NOVAES, A.G. (1997). Gerenciamento de transporte e frotas. Pioneira. São Paulo, 1997.

VIEIRA, J.C.F. (1986). Metodologia para o cálculo de custos do transporte rodoviário de cargas e implicações tarifárias. 500p. Dissertação (Mestrado) - Instituto Militar de Engenharia, Rio de Janeiro. 1986.

VIVIANI, E. (1998). A utilização de um sistema de informação geográfica como auxílio à gerência de manutenção de estradas rurais não-pavimentadas. 292p. Tese (Doutorado) - Escola de Engenharia de São Carlos, Universidade de São Paulo, São Carlos. 1998.

VIVIANI, E; SÓRIA, M.H.A; SILVA, A.N.R. (1994). Gerenciamento de vias não pavimentadas e a utilização de sistemas de informação geográfica. In: CONGRESSO BRASILEIRO DE CADASTRO TÉCNICO MULTIFINALITÁRIO, 1., 1994, Florianópolis. Anais. p.118-26.

WIDMER, J.A. (2002a). Análise teórica da eficiência de frenagem de algumas configurações de veículos unitários e combinações de veículos rodoviários de carga brasileiros. In: Congresso SAE BRASIL 2002, 11., 2002, São Paulo.

WIDMER, J.A. (2002b). Compatibilidade de tráfego de bitrens de $25 \mathrm{~m}$ com a infraestutura viária brasileira. In: COLLOQUIUM DE IMPLEMENTOS RODOVIÁRIOS E MOSTRA DE ENGENHARIA, 1., 2002, Caxias do Sul. Anais. p7-12. 